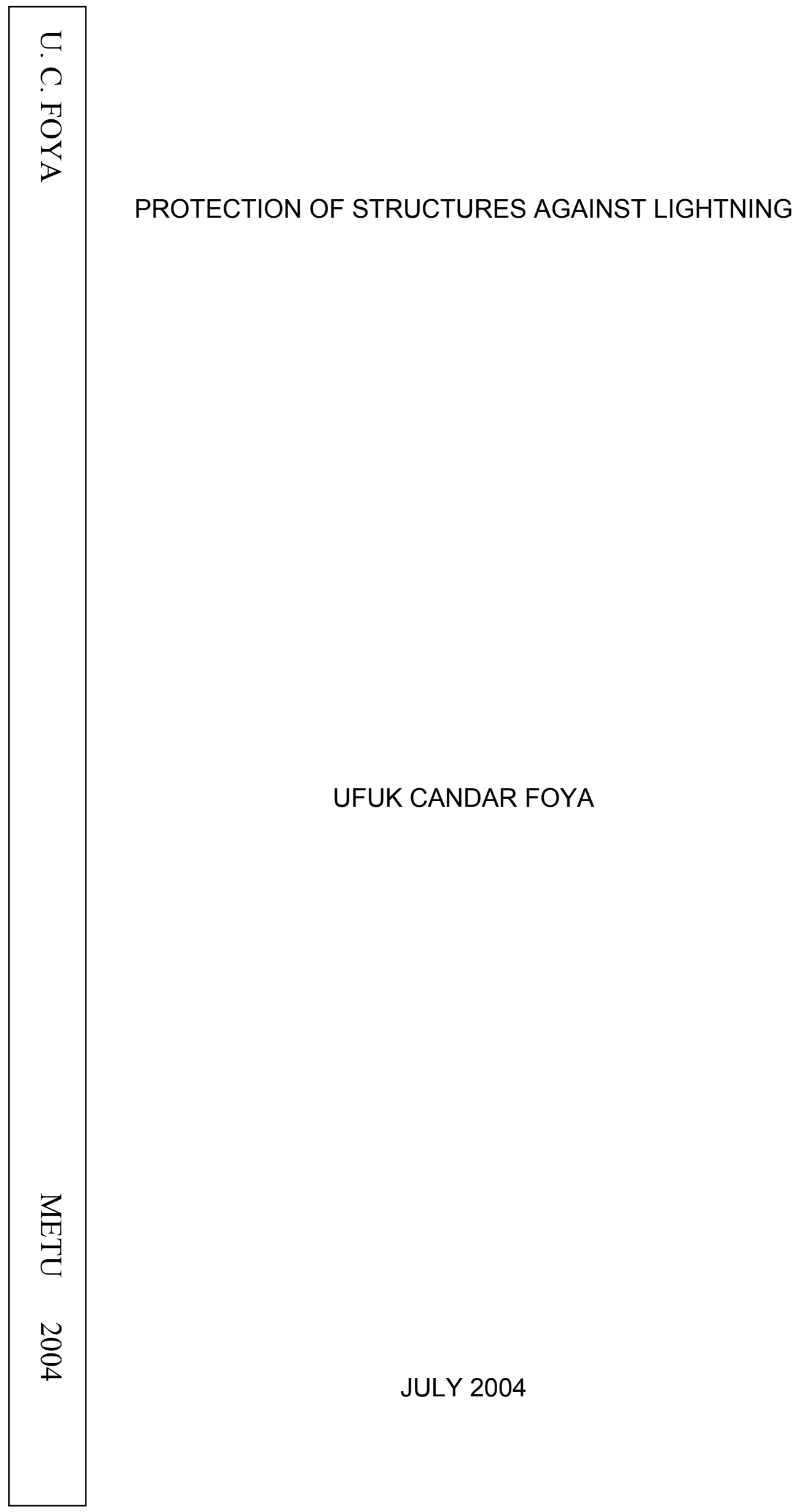


PROTECTION OF STRUCTURES AGAINST LIGHTNING

A THESIS SUBMITTED TO

THE GRADUATE SCHOOL OF NATURAL AND APPLIED SCIENCES OF MIDDLE EAST TECHNICAL UNIVERSITY

BY

UFUK CANDAR FOYA

IN PARTIAL FULFILLMENT OF THE REQUIREMENTS FOR

THE DEGREE OF MASTER OF SCIENCE

IN

ELECTRICAL ENGINEERING

JULY 2004 
Approval of the Graduate School of Natural And Applied Sciences

Prof. Dr. Canan Özgen

Director

I certify that this thesis satisfies all the requirements as a thesis for the degree of Master of Science.

Prof. Dr. Mübeccel Demirekler Head of Department

This is to certify that we have read this thesis and that in our opinion it is fully adequate, in scope and quality, as a thesis for the degree of Master of Science.

Prof. Dr. Nevzat Özay

Supervisor

Examining Committee Members (first name belongs to the chairperson of the jury and the second name belongs to supervisor)

Prof. Dr. Mirzahan Hızal

(ODTÜ, EE)

Prof. Dr. Nevzat Özay

(ODTÜ, EE)

Prof. Dr. Ahmet Rumeli

(ODTÜ, EE)

Prof. Dr. Osman Sevaioğlu

(ODTÜ, EE)

Yük. Müh. Ersin Zihnioğlu

(TEIAŞ) 
I hereby declare that all information in this document has been obtained and presented in accordance with academic rules and ethical conduct. I also declare that, as required by these rules and conduct, I have fully cited and referenced all material and results that are not original to this work.

Name, Last name: Ufuk Candar, Foya

Signature 


\title{
ABSTRACT \\ PROTECTION OF STRUCTURES AGAINST LIGHTNING
}

\author{
Foya, Ufuk Candar
}

M.Sc., Department of Electrical and Electronics Engineering

Supervisor: Prof. Dr. Nevzat Özay

July 2004, 131 pages

This thesis analyses the lightning protection concept. After a brief introduction to lightning, lightning discharge process and the consequences of a lightning stroke, the worldwide standards for the protection of structures against lightning are analysed and compared in the scope of requirement for the lightning protection.

The lightning protection systems since Franklin are traced and the protection methods are re-arranged in the basis of rolling sphere method. After discussing the changing philosophy in lightning protection, cage method is examined and applications of cage method are done according to different protection levels.

The thesis seeks to find an answer to the question such that which the safest method for the protection of structures against lightning according to new requirements would be.

Keywords: Lightning, Lightning Protection, Standards, Rolling Sphere Method,

Cage Method 


\title{
Öz
}

\section{BINALARIN YILDIRIMA KARŞI KORUNMASI}

\author{
Foya, Ufuk Candar
}

Yüksek Lisans, Elektrik-Elektronik Mühendisliği Bölümü

Tez Yöneticisi: Prof. Dr. Nevzat Özay

\author{
Temmuz 2004, 131 sayfa
}

$\mathrm{Bu}$ çalışma, yıldırımdan korunma konusunu incelemiştir. Yıldırım ve yıldırımın oluşum süreçleri ile etkilerine kısaca değinildikten sonra binaların yıldırıma karşı korunması ile ilgili ulusal ve uluslar arası standartlar, koruma seviyesinin belirlenmesi yönünden incelenerek, karşılaştırılmıştır.

Franklin'den bugüne yıldırımdan korunma sistemleri incelenmiş ve koruma metodları yuvarlanan küre modeli temelinde tekrar düzenlenmiştir. Yıldııımdan korunmanın değişen felsefesi tartışıldıktan sonra kafes yöntemi incelenerek, farklı koruma seviyeleri için kafes yöntemine dair uygulamalar yapılmıştır.

Bu çalışmada, günümüzün değişen intiyaçlarına göre binaların yıldırıma karşı en güvenilir korunma sistemi nasıl olmalıdır sorusu yanıtlanmaya çalışılmıştır.

Anahtar Kelimeler: Yıldırım, Yıldırımdan Korunma, Standartlar, Yuvarlanan Küre Modeli, Kafes Yöntemi 
To my Family and Dr. Atilla Soyelçin 


\section{ACKNOWLEDGMENTS}

The author wish to express his deepest gratitude to his supervisor, Prof. Dr. Nevzat Özay, for his guidance, advice, criticism, encouragement and insight throughout the research.

The author also would like to thank some other faculty members, Prof. Dr. Arif Ertaş, Prof. Dr. Ahmet Rumeli, Prof. Dr. Mirzahan Hızal, Prof. Dr. Muammer Ermiş, Prof. Dr. Nezih Güven, Prof. Dr. Osman Sevaioğlu and Prof. Dr. Mübeccel Demirekler for their kind contributions.

The author thanks Mustafa Kemal Köseoğlu, Ertan Saygınar and Tuncay Atman for their assistance. The documental supports of Ersin Zihnioğlu and Çetin Tekin are gratefully acknowledged.

The "E Building" friendships and solidarity between Power Engineering students are sincerely unforgettable, especially Gökçen Baş, Ersoy Mustafa, Melih Güneri, Mustafa Özkan and Evren Elmas.

The technical supports of Başar Tunçel and Görkem Pabuççuoğlu during typesetting of the thesis text and Emre Kaan Memiş for his helps in 3-D modelling and drawings are gratefully appreciated.

The author especially thanks Mete Sofuoğlu, Oğuz Mut, Engin Çomakçı, Özgür Kasar, Emrah Sarıiz, Egemen Değer Kavak, Kıvanç Yaluğ, Itır Soğancılar and Zeynep Şanlıer for their full motivational support and Emre Baturay Altınok, Fevzi Özlüer and Mehmet Horuş for all their office support.

The author also faithfully thanks Martin A. Uman for his kind interest when sharing his ideas.

The author respects Merve Ural for her kind tolerance, while studying and his parents and Ömür Foya for their self-sacrificing supports for his whole life. 
TABLE OF CONTENTS

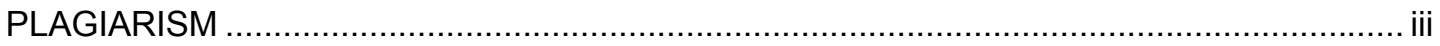

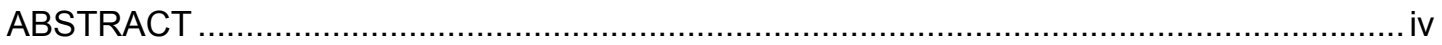

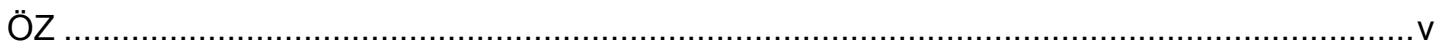

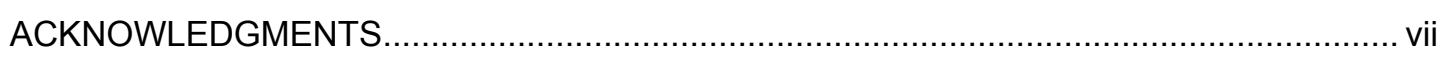

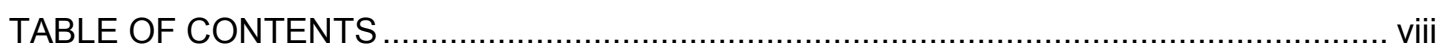

CHAPTER

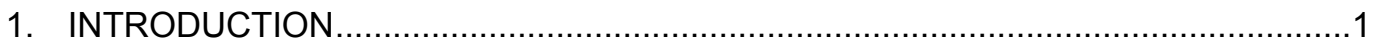

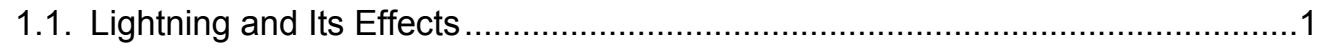

1.2. Need for Protection and Changing Requirements for Protection Systems..........4

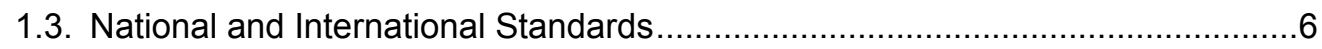

1.4. Scopes and the Purpose of This Thesis ………........................................

2. REVIEW OF DIFFERENT STANDARDS FOR PROTECTION REQUIREMENTS.....9

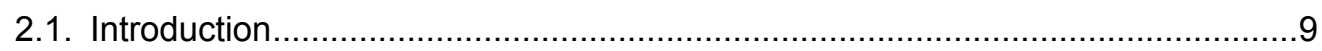

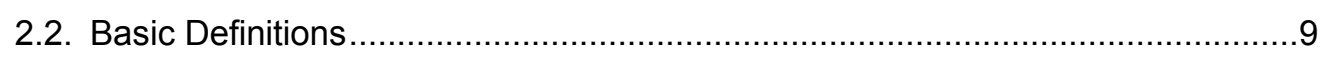

2.3. Spanish Standard (UNE 21-186: 1996) …............................................10

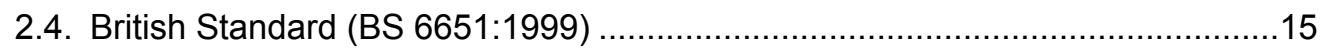

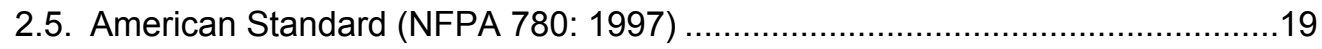

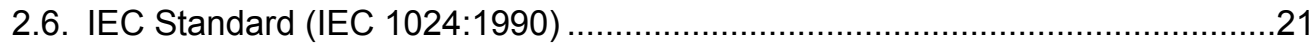

viii 
2.7. Turkish Draft.

2.8. Interpretations and Comparison of Reviewed Standards

2.9. Derivations and Modification of BS Algorithm

2.10 Examples for the Comparison of Reviewed Standards 30

2.11 Modifications Offered to Eliminate Conflicts among the Standards 37

3. LIGHTNING PROTECTION 41

3.1. Introduction .41

3.2. Rolling Sphere Method. .41

3.2.1. Derivation of Shielding Angles .46

3.2.2. Application of Shielding Angles 49

3.3. Early Streamer Emission (ESE) Air Terminals. .51

3.3.1. Radioactive type Lightning Arresters. .51

3.3.2. Active type ESE Air Terminals .52

3.3.3. Comparison of ESE type Lightning Arresters with Franklin Rods .56

3.3.4. Application of Franklin Rods in Lightning Protection .58

3.4. Introduction to Cage Method 60

4. APPLICATION OF THE CAGE METHOD .66

4.1. Introduction. 66

4.2. Basis of Cage Method 67

4.2.1. Air Termination System .67

4.2.2. Down Conductors .69 
4.2.3. Grounding System ...................................................................

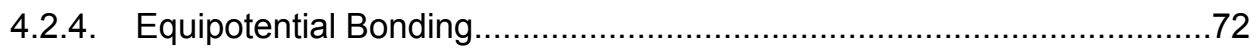

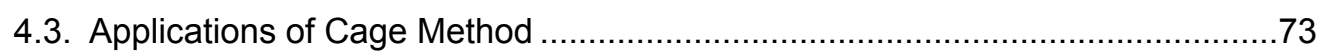

4.4. Comparison of the Standards using Cage Method Application ........................75

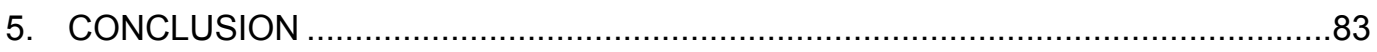

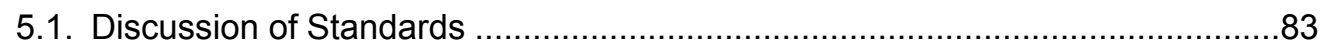

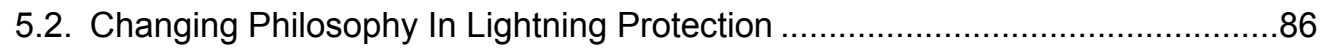

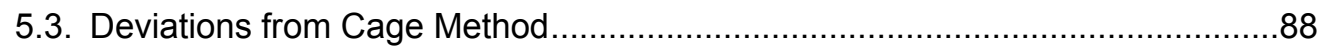

REFERENCES

APPENDICES

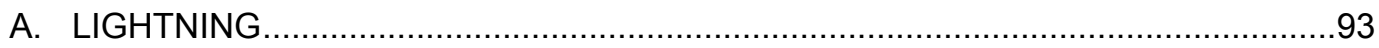

B. WEIGHTING FACTORS OF SPANISH STANDARD (UNE 21-186:1996).............105

C. WEIGHTING FACTORS OF BRITISH STANDARD (BS 6651:1999) …...............107

D. WEIGHTING FACTORS OF AMERICAN STANDARD (NFPA 780:1993) .............109

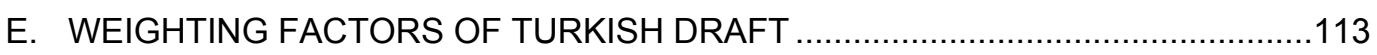

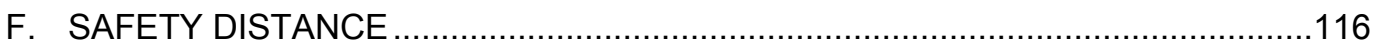

G. MATERIALS AND SIZES TO BE USED FOR A LPS ....................................125

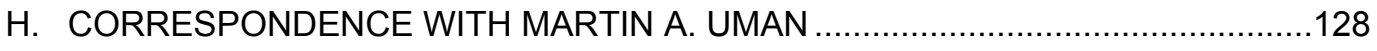




\section{LIST OF TABLES}

Table 2.1 Relationship between thunderstorm days per year (Nk) and lightning flashes per square $\mathrm{km}$ per year $(\mathrm{Ng})$

Table 2.2 Determination of environmental coefficient C1 ......................................12

Table 2.3 Required protection levels according to the computed effectiveness $E$

Table 2.4 Relationship between thunderstorm days per year and lightning flashes per square

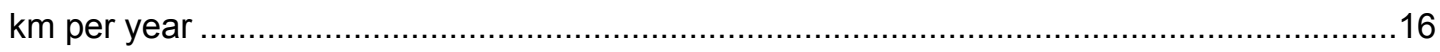

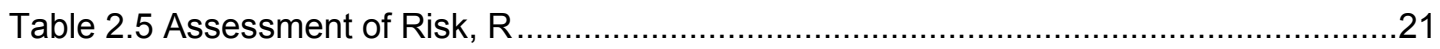

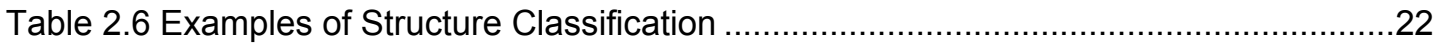

Table 2.7 Required protection levels according to the computed effectiveness $\mathrm{E}$................24

Table 2.8 Determination of environmental coefficient Ce ........................................25

Table 2.9 Required protection levels according to the computed effectiveness $\mathrm{E}$...............27

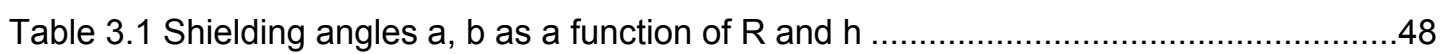

Table 3.2 Positioning of simple rod according to protection level..................................49

Table 3.3 Manufacturer sheet for Active Lightning Arrester With Piezoelectric Crystal .........56

Table 3.4 Manufacturer sheet for Active Lightning Arrester Having Atmospheric Field Effect56

Table 4.1 Placement of Interception Devices and DC according to Protection Levels .........73

Table 4.2 Comparison of Materials used in accordance with different protection levels ........82

Table 5.1 Required Ac values according to the computed effectiveness E........................84

Table 5.2 Required Ac values for $\mathrm{Nc}=2.4^{*} 10^{-3}$ corresponding to the average case...............85

Table A.1 Cumulative frequency of Peak Current (kA) (min 2 kA) ....................................100

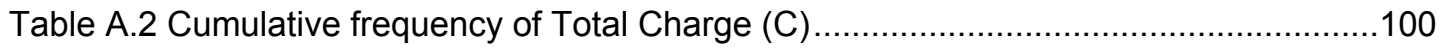

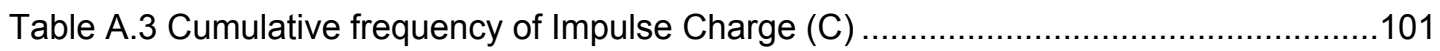

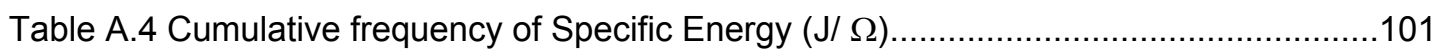

Table A.5 Cumulative frequency of Time intervals between Lightning Strokes (ms) ..........101

Table A.6 Cumulative frequency of Total Flash Duration $(\mu \mathrm{s})$...................................101

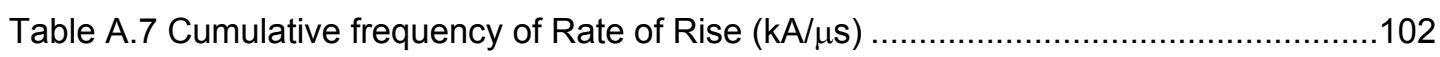

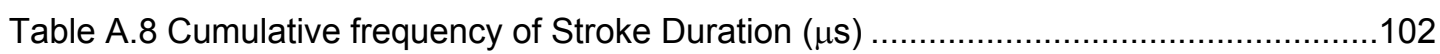

Table A.9 Cumulative frequency of Front Time Duration $(\mu \mathrm{s})$..................................103

Table B.1 Weighting factor C2 (structural coefficient) ............................................105

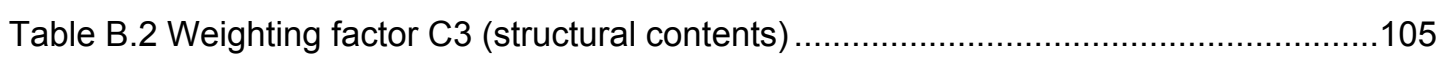

Table B.3 Weighting factor C4 (structure occupancy) .......................................105

Table B.4 Weighting factor C5 (lightning consequences) ....................................106 


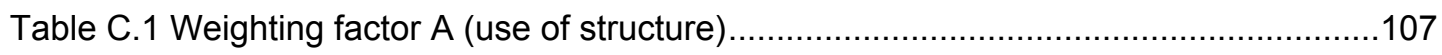

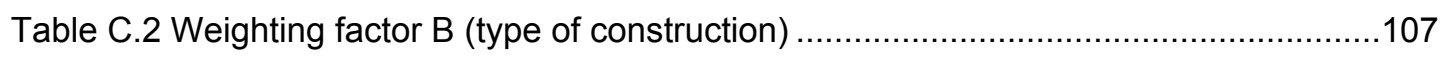

Table C.3 Weighting factor $\mathrm{C}$ (contents or consequential effects) ...............................108

Table C.4 Weighting factor $\mathrm{D}$ (degree of isolation) .................................................108

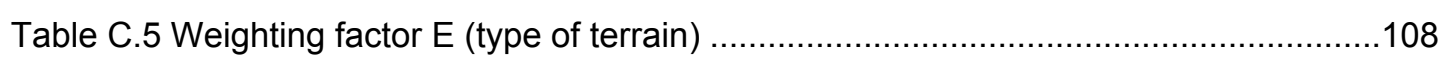

Table D.1 Index A (type of structure) ............................................................. 109

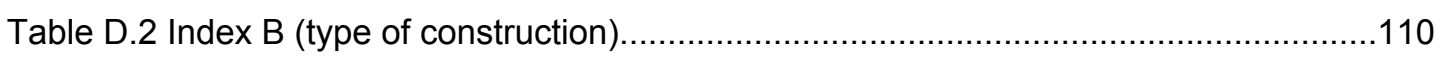

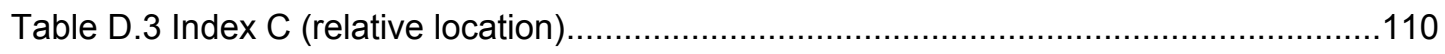

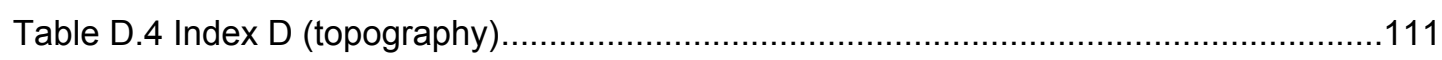

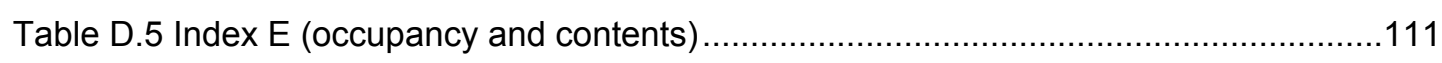

Table D.6 Index F (lightning frequency isoceraunic level) .....................................112

Table E.1 Weighting factor A1 (type of walls) ....................................................113

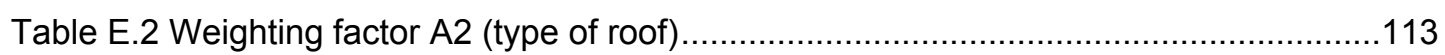

Table E.3 Weighting factor A3 (type of roof coating) ............................................113

Table E.4 Weighting factor A4 (constructions on the roof such as smoke hole etc.) ..........114

Table E.5 Weighting factor B1 (occupancy) ..................................................... 114

Table E.6 Weighting factor B2 (type of materials inside) .......................................114

Table E.7 Weighting factor B3 (worth of equipment inside) .......................................114

Table E.8 Weighting factor B4 (hazard minimizing precautions) ................................115

Table E.9 Weighting factor C1 (consequences on environment due to materials inside) ....115

Table E.10 Weighting factor C2 (loss of service continuity in structure due to materials

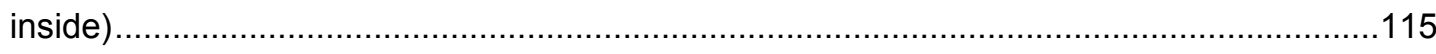

Table E.11 Weighting factor C3 (other hazards) .................................................115

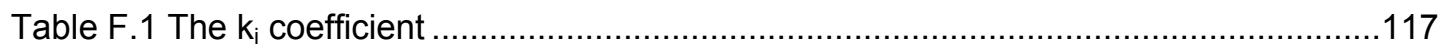

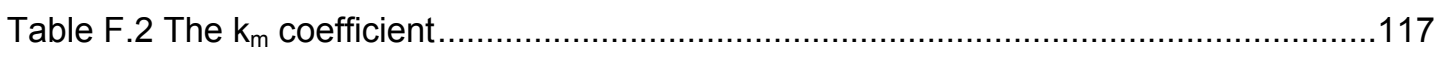

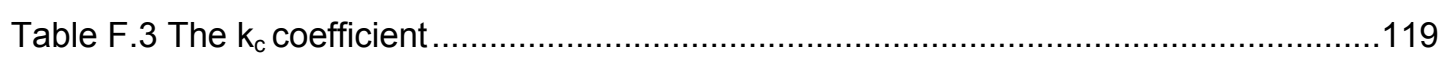

Table G.1 According to the self-resistance, $\rho$ of soil, the Equivalent Earthing Resistance $Z$

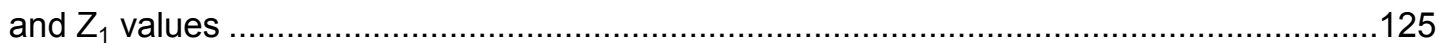

Table G.2 Minimum cross-sections of the materials to be used in LPS ...........................126

Table G.3 Minimum thickness of the metal sheets and metal pipes used in the ATS.........127

Table G.4 Minimum cross-sections of the bonding conductors ..................................127

Table H.1 Cumulative Probability of Strike to facility ................................................129

Table H.2 Placing Interception Device and Down Conductors according to Protection Levels. 


\section{LIST OF FIGURES}

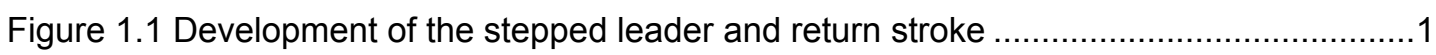

Figure 1.2 Isoceraunic Map showing Thunderstorm Days per Year in Turkey........................2

Figure 2.1 Plan of Collection Area, Ac according to Spanish Standard ...............................12

Figure 2.2 Plan of Collection Area, Ac according to British Standard ..................................16

Figure 2.3 Comparison of Collection Areas given in Spanish and British Standards .............31

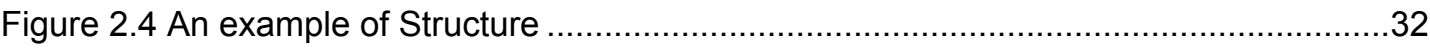

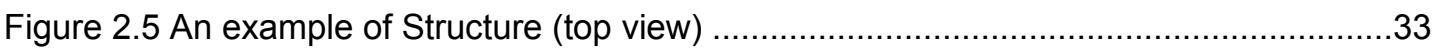

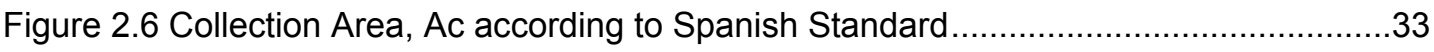

Figure 2.7 Collection Area, Ac according to British Standard................................................

Figure 2.8 Flow Diagram for Protection Requirement according to Different Standards .......39

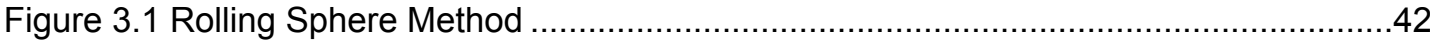

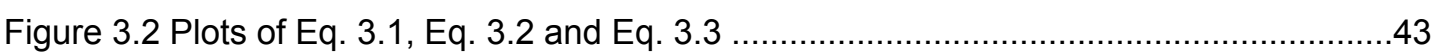

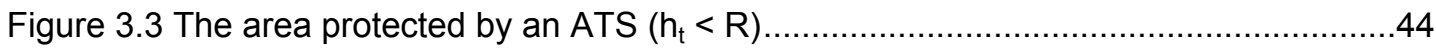

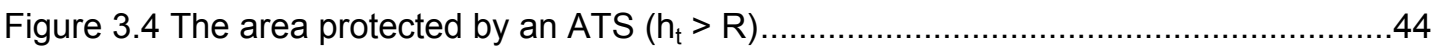

Figure 3.5 The protected area with two vertical conductors $\left(h_{t}<R\right) \ldots \ldots \ldots \ldots \ldots \ldots \ldots \ldots \ldots \ldots . . .45$

Figure 3.6 Sample for Derivation of Shielding Angles of Franklin Rod................................46

Figure 3.7 Figure used for Conservative Calculation......................................................4

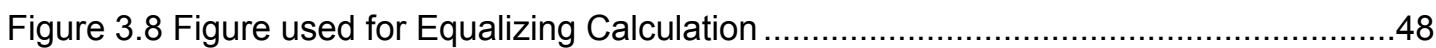

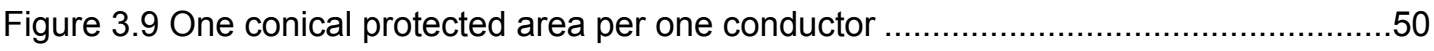

Figure 3.10 Protected area for horizontal conductor between A-A tips ..............................50

Figure 3.11 LPS design using protection angle method with different heights ......................51

Figure 3.12 Protection Radius of Franklin Rod (simple rod) ..............................................53

Figure 3.13 Protection Radius of an ESE Lightning Conductor ..........................................54

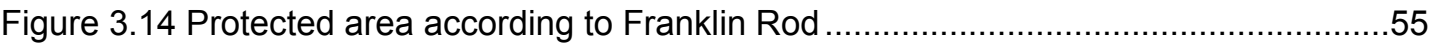

Figure 3.15 Protected area according to ESE type lightning arrester .................................55

Figure 3.16 Vertical Conductors mounted on the Roof (non-isolated type)..........................58

Figure 3.17 Vertical Conductors apart from the Structure (isolated type) .............................59

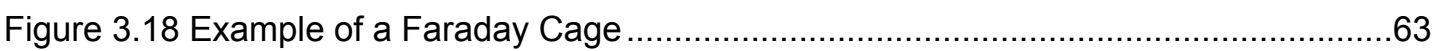

Figure 3.19 Faraday Cage with Bonded Metallic Penetration ...........................................63

Figure 3.20 Faraday Cage with Unbonded Metallic Penetration .........................................64

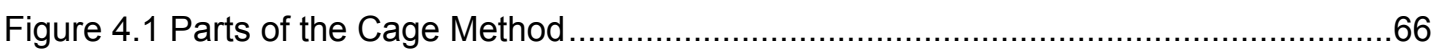

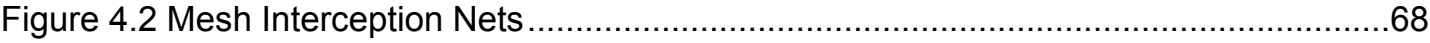


Figure 4.3 Equipotential bonding of down conductors for a $60 \mathrm{~m}$ high building ..... 70

Figure 4.4 Elemental Faraday Cage ................................................................... 74

Figure 4.5 Complex shaped structure with rolling ball application..................................74

Figure 4.6 Application of Rolling Sphere for two Structures ..........................................75

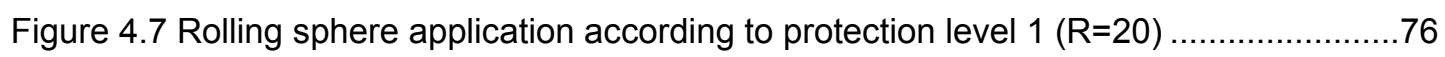

Figure 4.8 Cage method application according to protection level 1 ..............................77

Figure 4.9 Rolling sphere application according to protection level $2(\mathrm{R}=30 \mathrm{~m}) \ldots \ldots \ldots \ldots \ldots . . .78$

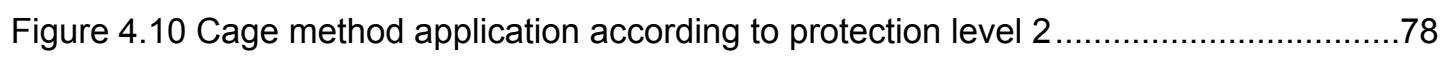

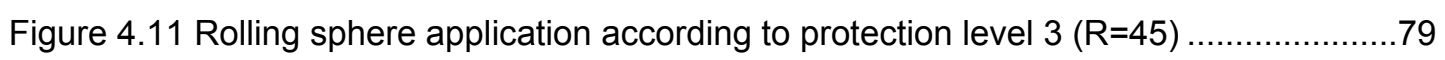

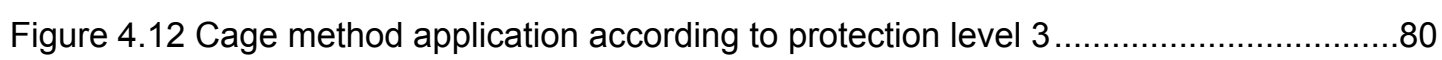

Figure 4.13 Rolling sphere application according to protection level $4(R=60) \ldots \ldots \ldots \ldots \ldots \ldots . . . . . . .11$

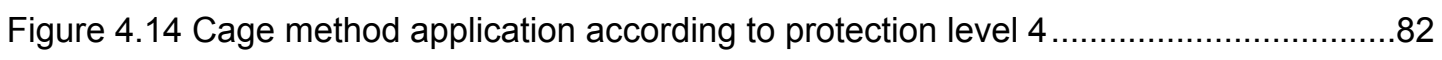

Figure 5.1 Combinations of Methods to Establish the Safest LPS . ................................87

Figure A.1.a Thundercloud charge distribution and categorization of the four types of

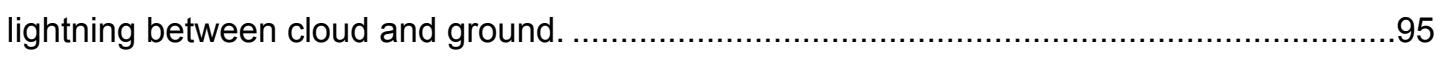

Figure A.1.b Thundercloud charge distribution and categorization of the four types of

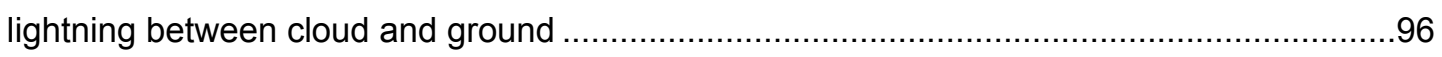

Figure A.2 Various processes that make up a negative CG lightning discharge.................97

Figure A.3 Discharge process of multiple stroke flash from left to right ...........................98

Figure F.1 Safety distance, d when applying DC's and VC's .................................116

Figure F.2 The coefficient kc=1 in a one-dimensional configuration .............................118

Figure F.3 The coefficient $\mathrm{k}_{\mathrm{c}}=0.66$ in a two-dimensional configuration .........................118

Figure F.4 The coefficient $k_{c}=0.44$ in a three-dimensional configuration............................118

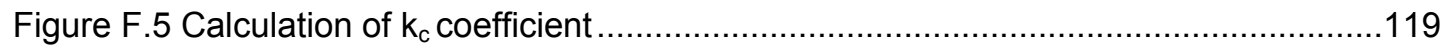

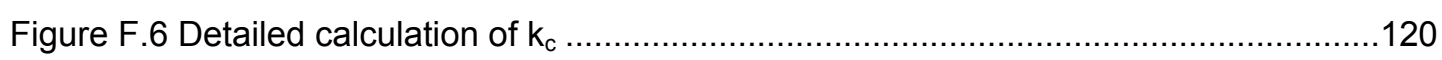

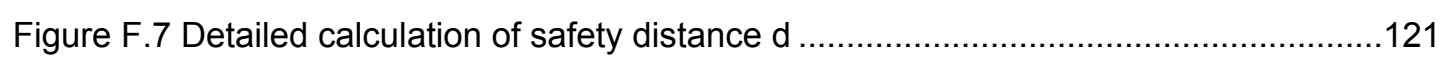

Figure F.8 Safety distance between protection system and the structures ......................122

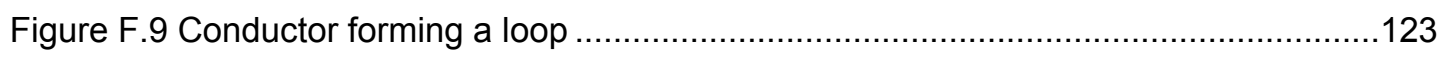

Figure F.10 Routes for down conductors in a building with centilevered upper floors .........123 


\section{CHAPTER 1}

\section{INTRODUCTION}

\subsection{Lightning and Its Effects}

Mankind comes across several natural events like flood, avalanche, earthquake, landslide etc. that can be prevented. Only precautions are taken against these events the reasons of which are known using technological and scientific knowledge and their applications. It has been the case that these natural events become natural disasters and the nature does not excuse or forgive, if any precaution is not taken.

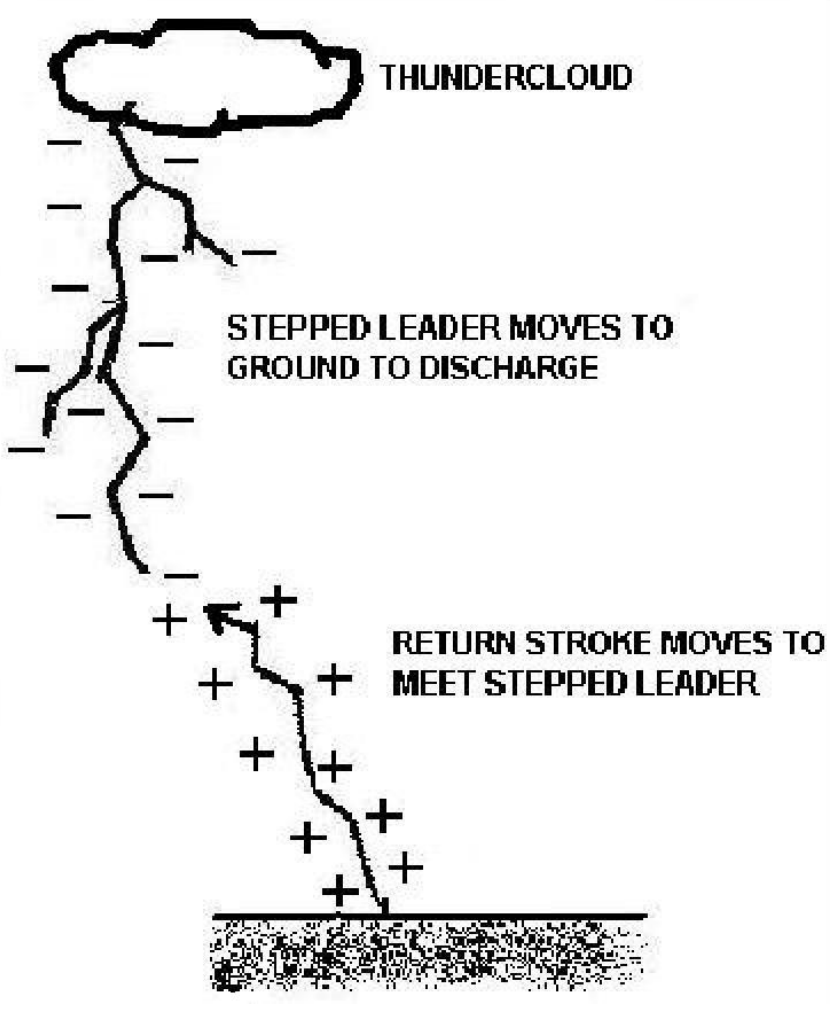

Figure 1.1 Development of the stepped leader and return stroke 
Basically, lightning is one of the natural events, being a flow of electrical current between the earth and storm clouds, occurs as varying charges of positive and negative polarity build up in the atmosphere during a storm.

In a discharge, it should be understood that a channel, like a conductor wire is formed between cloud and ground. Through this channel, charge is transferred to ground. 90 percent of the cloud to ground discharges worldwide are initiated by downward-moving negatively charged leaders. While negative charges are moving downwards (stepped leader), positive charges are induced on Earth. When the negative charges arrives near to the Earth where high electrical fields are developed, a bright, visible channel (return stroke) is formed from the ground up and the discharge occurs as given in Figure 1.1. Both negative and positive charges neutralize each other. A detailed study of the lightning phenomenon is given in Appendix A.

Due to different climatic conditions, the lightning current characteristics changes. Up to 200 kA of current has been observed. For details of the lightning characteristics, Appendix A should be seen. In addition, the lightning stroke frequency differs geographically. A ceraunic level is the thunderstorm days per year. According to the observations, isoceraunic maps are prepared and local ceraunic levels are obtained from these maps. The isoceraunic map of Turkey is given in Figure 1.2.

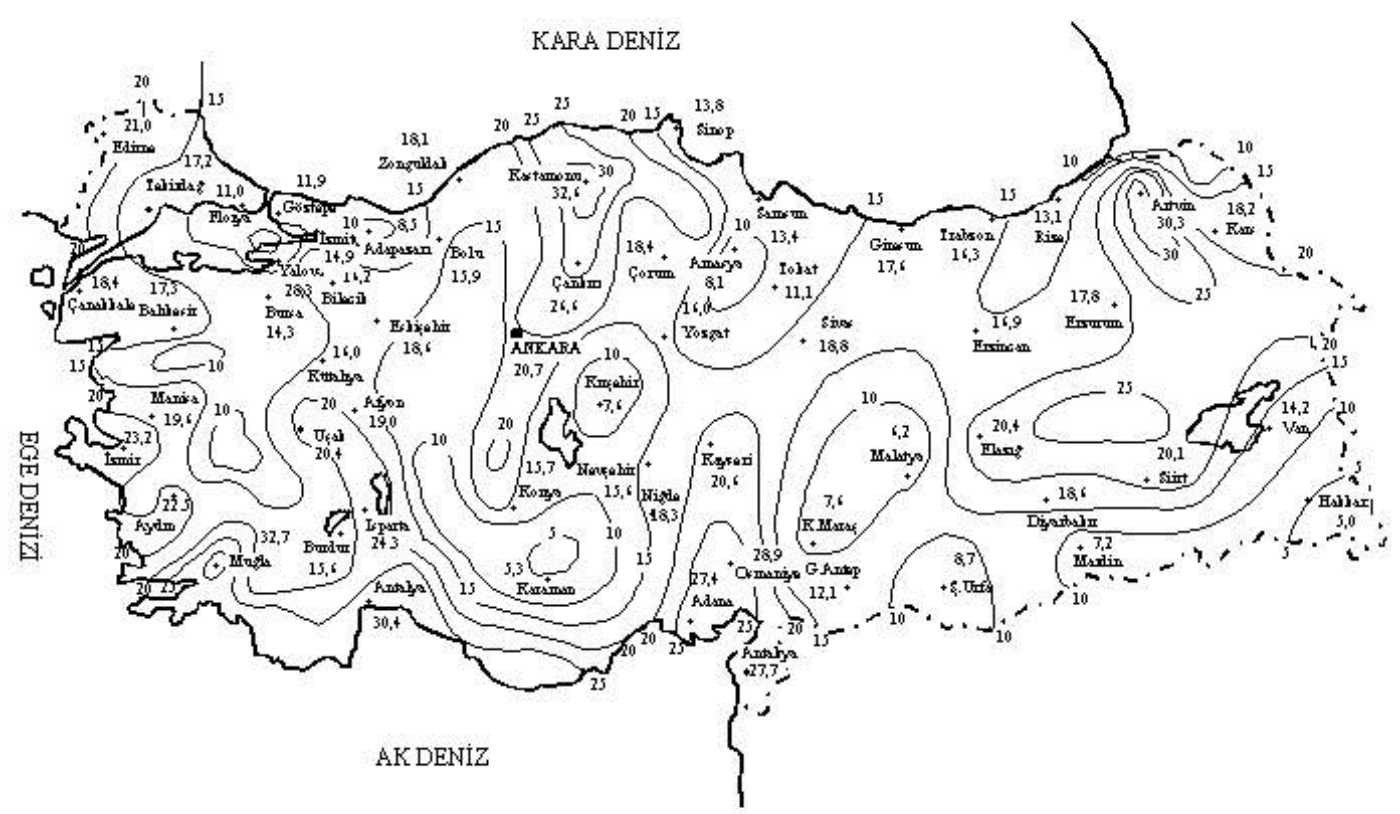

Figure 1.2 Isoceraunic Map showing Thunderstorm Days per Year in Turkey 
Since Benjamin Franklin, the first physicist to examine and investigate the lightning phenomenon, many scientists have been still observing and investigating lightning event to find out the right and the most effective protection method throughout the world. R.H. Golde and Martin A. Uman are the two important scientists who have analysed and written about the basics of lightning theories. ${ }^{1}$ Especially, M.A. Uman has a great and respectful background on lightning physics. Their books and papers are the main sources containing many observations, experiments, investigations, and measurements. Besides the results of their works, the newest standards and codes for the lightning protection should be studied to understand the lightning concept and protection.

Lightning can be destructive to buildings and to numerous systems critical to daily life and it can be lethal to people. ${ }^{2}$ Therefore, mankind must take precautions to minimize and/or to prevent its dangerous results, such as electrodynamics, pressure and sound, electrochemical, thermal and electro-magnetic interference effects. Some of the observation on the effects of lightning strokes is quoted below:

"The energy releases by a lightning strike can be of the order of $10^{10}$ Joules, more than the energy in 1000 gallons of gasoline or more than the energy of some bombs. Fortunately, only a small portion of this energy couples to the building to produce damage." ${ }^{3}$

The $\mathrm{BOLT}^{4}$ listed the damaging effects of lightning as following: fire, fracture and spalling, voltage surges, high electric fields and arcing, explosions. ${ }^{5}$ The effects of lightning damage structures, electronic systems, and people.

"The USA electric power industry reports $30 \%$ of all outages to be lightning related. ${ }^{6}$ Insurance companies here categorize some $5 \%$ of all paid claims as resulting from lightning. ${ }^{7,8}$

"The US Department of Energy has recorded 346 known lightning events to its facilities during the 1990-2000 period. ${ }^{9}$ In total, lightning is responsible for about $\$ 4-5$ billion annual losses in the USA. ${ }^{10,11}$

"Half of the forest fires are lightning caused, costing about $\$ 100$ million annually. Over 100 thousand PCs (nearly $\$ 100$ million) annually are destroyed or damaged by lightning." ${ }^{12}$

"On the military side, DDESB ${ }^{13}$ reports 88 identifiable lightning-induced explosions in its records, with costs and deaths not calculated. DDESB was formed because of the Picatinny Arsenal incident (July 1926), which killed 14 people and cost $\$ 70$ million. More recently 
(June 2001) in Buryatia, Russia the munitions losses exceeded 20 million rubles. Here, fires burned for two days and were contained only after heavy rains. Three thousand people were evacuated, seventeen people were killed.." ${ }^{14}$

In modern protection techniques, the electromagnetic effects of lightning have to be taken into account. For example, according to Württembergische Versicherung AG, Stuttgart in Germany, the ratio of surges and lightning discharges is $27,4 \%$ if the causes of damage to electronic equipment are examined. ${ }^{15}$

\subsection{Need for Protection and Changing Requirements for Protection Systems}

The statistics show how dangerous a lightning is and it must be prevented. The effects and consequences of a lightning stroke force protection requirement against lightning; thus, the protection phenomenon becomes very important.

The precautions must have scientific and technical base. The technologies being used are developed using the theoretical models and scientific information. Mostly, the scientific information is obtained from the observations of lightning. To develop a protection system against lightning, the historical background (such as what a lightning is, how it is formed, the nature and characteristics of lightning etc.) about lightning should be known.

As safety is the main objective, all the protection designs and applications, therefore equipments and systems to be installed must be selected properly considering the changing requirements not to give rise to lightning hazards.

Drawing down an electrical discharge has been the main objective of a lightning protection system (LPS) what Franklin thought nearly 250 years ago. Since Franklin, several methods have been developed and according to new needs, the methods have been modified or totally changed due to the changes in the philosophy of lightning protection.

Benjamin Franklin thought catching the lightning by a simple conductor and drawing the lightning current to the ground. His method is composed of a simple conductor and a grounding system. His original thought is quoted below:

"There is something however in the experiments of points, sending off or drawing on the electrical fire, which has not been fully explained, and which I intend to supply in my next ... from what I have observed on experiments, I am of opinion that houses, ships, and even towers and churches may be eventually secured from the strokes of lightning by their means; 
for if instead of the round balls of wood or metal which are commonly placed on the tops of weathercocks, vanes, or spindles of churches, spires, or masts, there should be a rod of iron eight or ten feet in length, sharpened gradually to a point like a needle, and gilt to prevent rusting, or divided into a number of points, which would be better, the electrical fire would, I think, be drawn out of a cloud silently, before it could come near enough to strike."16

At the 1876 meeting of the British Association, James Clark Maxwell suggested that a lightning conductor attracted to a building a greater number of discharges than in its absence and that therefore fewer discharges would occur in the region surrounding the conductor. $\mathrm{He}$ advocated utilizing the principle of the Faraday cage in place of the usual lightning conductor [Franklin Rod]. However, this was ignored until lately and the developments were concentrated to increase the effectiveness of the simple rods.

Since Franklin, very little development was done until the beginning of $20^{\text {th }}$ century until some researches done on the radioactive elements. In 1914, the Hungarian physicist L. Szillard raised the question of whether the attractive effect of a normal lightning rod could be increased by the addition of a radioactive source. This radioactive type of lightning arresters was the first development in Early Streamer Emission (ESE) type air terminals.

Apart from radioactive types, active type of ESE air terminals with piezoelectric crystal and atmospheric field effect were developed.

Radioactive and active type of ESE air terminals are claimed to trigger earlier ionisation than simple lighting rods. Data sheets were prepared based on the experiments under laboratory conditions. According to worldwide discussions, the functions of the ESE type of air terminals have not been proven under natural conditions. The radioactive types were prohibited while the active types are thought to be the same as simple rods. Thus, Franklin's method is still in use to intercept lightning flashes that otherwise would strike the building. This is the same philosophy since Franklin for over 250 years. However, it is not sufficient for new requirements.

New problem arises when the lightning stroke is caught by the air terminals. The electromagnetic interference (EMI) is one of the major consequences of a lightning current. The lightning current flowing through a down conductor produces high electric field. This electric field affects the electronics, which is the basis of modern life and industry in the beginning of 21 st century. The changing philosophy in lightning protection is to minimize the consequences of a lightning stroke in addition to drawing the current from air terminals to ground safely. 
Due to the wide-range usage of electronic devices, not only external protection also internal protection is needed to protect these devices from the EMI of the lightning current flowing through the external LPS's. The severe flashes can damage the internal electrical and electronic systems in structures.

The EMI of a lightning discharge must be minimized. This cannot be done using a simple rod. A mesh must be formed to reduce the high inductance of the current path. The mesh is formed by increasing the number of down conductors. Therefore, the current flow on each conductor is decreased. High-induced voltage due to the di/dt characteristics of lightning current is prevented when the current is decreased.

This method which was inspired from Faraday's known theory and introduced before ESE type lightning arresters is accepted as a modern method that corresponds to new requirements for protection against lightning and it is put in the worldwide standards for application.

\subsection{National and International Standards}

The worldwide standards are prepared to instruct the application of techniques. In lightning protection, IEC (International Electrotechnical Commission) states the basics of national standards and the details are left to national committees.

The lightning is a non-linear phenomenon. There is no possibility to develop a model in laboratory and apply this model to structures everywhere, which can result in a unique standard. However, the national standards are not the same due to the changing requirements of regions. Lightning characteristics are different from that in laboratory and also in different regions. For lightning protection technique, different models are developed and standards show these models and application criteria.

The aim is to protect the structure or region and the protected area obtained may vary different with different standards. There are also conflicts between the standards in calculation of the protection requirement. According to the statements of IEC, national standards assign different priorities and in calculation of the protection requirement, these priorities correspond to different weighting factors. Priorities determine the protection requirement and the level of protection. In application, these changing priorities produce conflicts. 
In the standards, there are three methods of establishing the required protected area. The important design criterion according to protection levels determined by the use of the procedures in standards are: 1) shielding angle with a number of normally vertical and horizontal conductors; 2) mesh width with a mesh of lightning conductors and 3) rolling sphere with rolling an imaginary sphere of radius $R$ equal to lightning initiation distance over lightning conductors. The shielding angle method is for the Franklin type of protection when using simple Franklin rods while determination the mesh width corresponds to the cage method. In rolling sphere method, a sphere is rolling over the structure without touching the area to be protected.

These three different methods should be interrelated to result in the same protection level. This is done by J. Wiesinger by equalizing the protective area by angle to the protective area by rolling sphere. The results of his work are used to increase the effect of the cage method for better protection against lightning.

Due to the newest philosophy of lightning protection, the EMI problems can be reduced by the application of cage method. Thus, cage method is the modern method although it is an old theory. The other methods should be thought to increase the effect of cage method. Moreover, the rolling sphere method should be used in the application of cage method while installing conductors on the structure and the shielding angle method should be used to increase the protected region of the cage method.

\subsection{Scopes and the Purpose of This Thesis}

This thesis analyses the lightning and the lightning protection concept. The history of the lightning protection methods is traced. The national and international standards about lightning protection will be discussed and compared. This thesis will seek to find an answer to the question to the safest method for a LPS.

In Chapter 2, typical worldwide standards, such as IEC, Spanish, British, American and the Turkish Draft for lightning protection are analysed and compared with the scope of protection requirement. On examples, the risk analysis is done using the weighting factors assigned in the standards. The differences and conflicts in the results are discussed. To eliminate the conflicts, modifications in procedures and equations are made so that a unique protection requirement could be found.

Chapter 3 is about the lightning protection. From Franklin to today, the methods used in the protection against lightning are studied. Instead of historical order, the methods developed 
are re-arranged on theoretical basis, which would be helpful to understand the development in lightning protection and relations between developed methods. Recent discussions on existing protection techniques are given and the answer for the changing requirements in lightning protection is sought.

In Chapter 4, the application of the modern method in lightning protection is studied. The changing philosophy in lightning protection forces the use of cage method in modern life. The basis and modelling of cage method is given in this chapter. At the end of the chapter, a sample structure is applied rolling sphere method for the LPS design analysis by using rolling spheres with different radius and then cage method is applied according to the different protection levels corresponding to the rolling sphere radius.

Finally; in Chapter 5, the results obtained with different standards are interpreted and concluding remarks on the contents of this thesis such as the basis of all the protection methods, tendency in protection system application, wrong applications, cage method with deviations are presented. 


\section{CHAPTER 2}

\section{REVIEW OF DIFFERENT STANDARDS FOR PROTECTION REQUIREMENTS}

\subsection{Introduction}

Although lightning theory introduced in Chapter 1 and given in full in Appendix $A$ is very well established, it is still incapable of explaining very clearly many of the fundamental concepts related to lightning strokes. As a result, these have to be interpreted. These interpretations are best illustrated by the national standards of different countries.

The first step in the design of a LPS is the determination of the protection requirement, then calculation of protection level against the dangerous effects of lightning discharges. The standards reviewed have been chosen such that they could reflect different points of view for the protection. These are Spanish Standard (UNE 21-186:1996) which is same as French Standard (NF C 17-102:1995), British (BS 6651:1999), American (NFPA 780:1997) and IEC (IEC 1024:1993) which similar to German Standards. Finally, the Turkish draft is analysed and found to be a combination of these

\subsection{Basic Definitions}

The following definitions appear in all standards:

- Ceraunic Level, Nk: is the thunderstorm days per year and differs geographically. Local ceraunic levels can be obtained from isoceraunic maps prepared according to the observation statistics. Figure 1.2 should be seen for the isoceraunic map of Turkey. $T_{d}$ is used in IEC 1024-1-1 while $N_{k}$ stands for ceraunic level in UNE 21-186: 1996.

- The Lightning Flash Density, $\mathbf{N g}$ : is the number of flashes to ground per square $\mathrm{km}$ per year. It is obtained from a calculation of observations over a period of many years. $\mathrm{Ng}$ can be determined by the use of the local ceraunic level $\mathrm{Nk}$, which is obtained either through empirical formula or by means of a table. 
- Collection Area of a Structure, Ac: is the area of the plan of the structure plus the area assumed to be shielded by the structure concerned, depending on the height. The collection area can be thought as a risk area under lightning. The Spanish Standard and Turkish draft uses Ae while Ac stands for collection area in British Standard.

- Expected frequency of direct lightning to a structure, $\mathrm{Nd}$ : is the yearly average frequency $\mathrm{Nd}$ of direct lightning to a structure and is directly proportional to $\mathrm{Ng}$ and Ac. BS 6651 uses $p$ instead of Nd. On the other hand, American Standard defines risk index, $\mathrm{R}$.

- Tolerable Frequency, Nc: is the tolerable frequency of lightning to the structure. To determine the need of protection, the expected frequency, $\mathrm{Nd}$ is compared with the tolerable frequency, Nc.

- Weighting Factor: is an interpretation used for the risk analysis of a structure to be protected. These factors are selected according to type, usage and surrounding of the structure concerned. The risk factor and importance of the structure also sets weighting factors. It is referred also coefficient or index.

- Effectiveness, E: is the probability calculated to find out the degree of a lightning protection level using the ratio $\mathrm{Nc} / \mathrm{Nd}$.

- Protection Level: is the degree of a LPS determined by the effectiveness that is calculated using 1-Nc/Nd. Protection level selected determines the corresponding lightning system design.

After these basic definitions, the standards can be studied. There are different calculations and weighting factors in different standards. These differences, at the end, affect the protection system to be used.

\subsection{Spanish Standard (UNE 21-186: 1996)}

The analysis will continue with Spanish Standard whose title is "Protection of structures and of open areas against lightning using early streamer emission air terminal" and the parts related to this thesis study is given in Appendix B. 
Calculation of the expected frequency $\mathrm{Nd}$ of direct lightning to a structure is formulated as follows:

$\mathrm{Nd}=\mathrm{Ng}^{*} 1.1^{*} \mathrm{Ac} \mathrm{C}^{*} 1^{*} 10^{-6} /$ year

where

$\mathrm{Ng}$ is the flash density,

Ac is the collection area, defined below

1.1 is the safety coefficient related to the strike evaluation,

$\mathrm{C} 1$ is the environmental coefficient given in Table 2.2.

The lightning flash density, $\mathrm{Ng}$ is formulated as follows:

$\mathrm{Ng}=0.02 * \mathrm{Nk}^{1.67}$

which is a curve fitted to the values given in Table 2.1.

Table 2.1 Relationship between thunderstorm days per year (Nk) and lightning flashes per square $\mathrm{km}$ per year $(\mathrm{Ng})$

\begin{tabular}{|c|c|c|c|c|c|c|c|c|c|}
\hline $\mathrm{N}_{\mathrm{k}}$ & 5 & 10 & 15 & 20 & 25 & 30 & 35 & 40 & 45 \\
\hline $\mathrm{Ng}$ & 0.3 & 0.9 & 1.8 & 3.0 & 4.3 & 5.8 & 7.6 & 9.5 & 11.5 \\
\hline
\end{tabular}

The source of the table above is not given in the standard. However, the data might have been obtained from observations.

The Collection Area of a Structure, Ac is also called the equivalent collection area of the isolated structure in square meters. In its definition, the ground area and the structure thoughts to be having the same yearly direct lightning flash probability. It is the area between the lines obtained by the intersection of the ground surface and 1:3 slope line passing through the top of the structure and revolving around the structure as shown in Figure 2.1. 
In Figure 2.1, the shaded area plus black area is the collection area. The black part is the top view of the structure. For rectangular structure with length $L$, width $W$ and height $H$, the collection area $\mathrm{Ac}$ is then equal to:

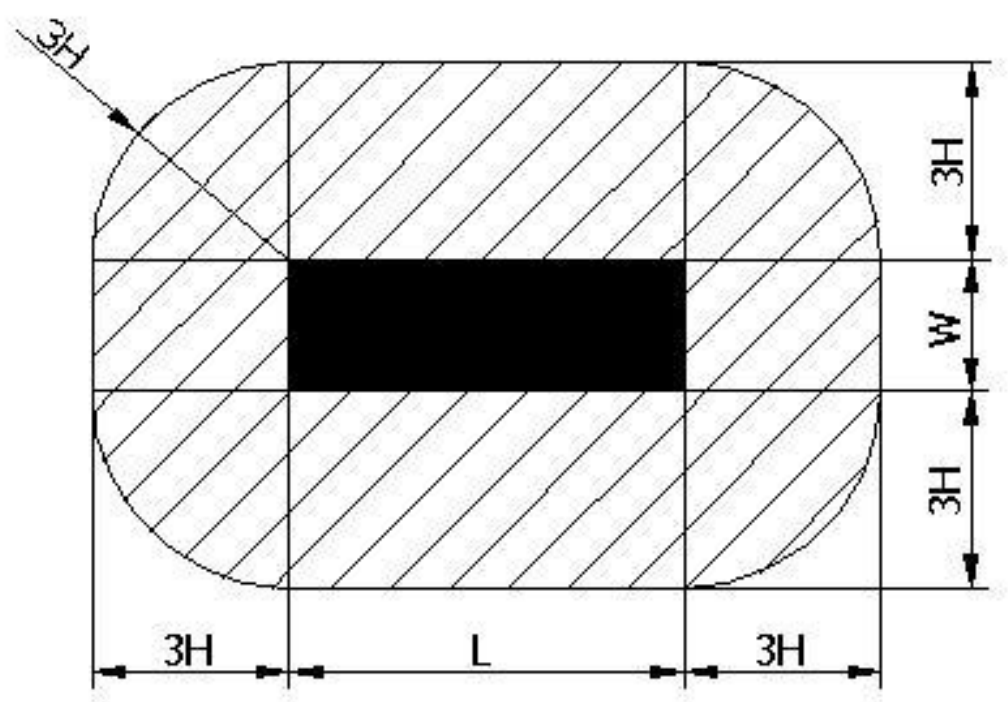

Figure 2.1 Plan of Collection Area, Ac

Table 2.2 Determination of environmental coefficient C1

\begin{tabular}{|l|c|}
\hline Relative Structure Location & C1 \\
\hline $\begin{array}{l}\text { Structure located within a space containing structures or trees of the same } \\
\text { height or taller }\end{array}$ & 0.50 \\
\hline Structure surrounded by smaller structures & 0.75 \\
\hline Isolated structure: no other structures within a distance of 3H & 1.00 \\
\hline Isolated structure on a hilltop or a headland & 2.00 \\
\hline
\end{tabular}

The standard states that the topography of the site and the objects located within the distance $3 \mathrm{H}$ from the structure significantly affect the collection area. This weighting factor is 
taken into account by applying environmental coefficient $\mathrm{C} 1$. If Table 2.2 is examined, it could be thought that the isolated structures are taken as a reference and assigned as 1 for environmental coefficient. Others are determined according to this reference.

The standard notes that when the collection areas of several structures are overlapped, the corresponding common collection area is considered as a single collection area.

The value of tolerable frequency, $\mathrm{Nc}$ is assessed through the analysis of the damage risk, taking account of suitable weighting factors such as type of construction, structure contents, structure occupancy, lightning stroke consequences. Four determining factors, given by coefficients $\mathrm{C} 2$ to $\mathrm{C} 5$ are to be assessed using tables given in Appendix $\mathrm{B}$ of this thesis.

If the weighting factors are examined, $\mathrm{C} 2$ shows that metal roof-metal structure has the least risk factor, 0.5 , while flammable type of structure with flammable roof has the maximum risk and assigned coefficient is 3 . Metal or steel structures are non-flammable, electrically conductive, and therefore more susceptible to ionisation. This type of roofs naturally will attract more lightning strokes to be terminated on them. However, the risk factor of 0.5 assumes that the roofs are grounded by down conductors.

Weighting factor, C3 is related with the structural contents. The non-flammable contents have no risk value while explosive contents have maximum weight. The explosion risk increases the risk factor. Content with no risk value is assigned 0.5 while the coefficient given to structures with explosive contents is 10 .

When the structure occupancy factor, $\mathrm{C} 4$ is analysed, evacuation difficulty increases the risk factor. The unoccupied structures do not cause panic. Therefore, these types of structures have the minimum risk factor of 0.5 . On the other hand, difficult evacuation or risk of panic causes high risk and it is assigned as 7 .

Lastly, the weighting factor C5 concerned with the lightning consequences are degreed. The highest risk factor is given to the case when there would be effects on the environment while the case of no consequences on the environment has the minimum risk. The risk factor is directly proportional to the consequences of lightning. The maximum factor given is 10 while the minimum value is 1 .

$\mathrm{C}=\mathrm{C} 2^{*} \mathrm{C} 3^{*} \mathrm{C} 4^{*} \mathrm{C} 5$ which gives us the overall weighting factor. Then $\mathrm{Nc}$ is expressed by the following formula: 
After calculation of the tolerable frequency, $\mathrm{Nc}$ and the probability of being struck, $\mathrm{Nd}$, the comparison between these two values will determine the protection requirement of the structure being analysed. If $\mathrm{Nd}<\mathrm{Nc}$ then no protection is needed or the protection is optional. Otherwise, if $\mathrm{Nd}$ is equal to or greater than $\mathrm{Nc}$, protection is required. The protection levels will be determined by the ratio between $\mathrm{Nc}$ and $\mathrm{Nd}$ (i.e., calculation of effectiveness). The effectiveness, $\mathrm{E}$ is calculated as follows after obtaining the values of $\mathrm{Nc}$ and $\mathrm{Nd}$.

$\mathrm{E}=1-\mathrm{Nc} / \mathrm{Nd}$

The Spanish Standard tabulates the relationship between the computed effectiveness, E and the required protection levels given in Table 2.3. It should be noted that the risk level decreases from protection level 1 to 3 . Effectiveness is directly proportional to the risk.

Table 2.3 Required protection levels according to the computed effectiveness $E$

\begin{tabular}{|c|c|}
\hline $\mathrm{E}=1-\mathrm{Nc} / \mathrm{Nd}$ & $\begin{array}{c}\text { Associated } \\
\text { protection level }\end{array}$ \\
\hline $\mathrm{E}>0,98$ & $\begin{array}{c}\text { I + additional } \\
\text { measures }\end{array}$ \\
\hline $0,95<\mathrm{E}<0,98$ & $\mathrm{I}$ \\
\hline $0,80<\mathrm{E}<0,95$ & II \\
\hline $0<\mathrm{E}<0,80$ & III \\
\hline
\end{tabular}

If the minimum risk factors are taken, $\mathrm{Nc}_{\max }$ is obtained as $24^{*} 10^{-3}$ from Eq. 2.4. If the maximum risk factors are taken, $\mathrm{Nc}_{\min }$ is obtained as $1.43^{*} 10^{-6}$. The ratio is 16,800 .

According to Eq. 2.1, by taking $\mathrm{C} 1$ as 0.5 , it should be assumed that calculated $\mathrm{Nd}$ is $24^{*} 10^{-3}$ and $\mathrm{Nc}$ is $24^{*} 10^{-3}$ which is equal to $\mathrm{Nc}_{\max }$. This is the safest case. $\mathrm{Nd}$ is equal to $\mathrm{Nc}$;

- Typical additional protective measures are: limitation of the step or touch voltage, restriction of fire propagation and reduction of the effects of voltage surges induced on sensitive equipment. 
therefore, protection is required. According to Eq. 2.5, E is obtained as zero that corresponds to protection level III that has the minimum risk value.

In the worst case, $\mathrm{Nc}$ is $1.43^{*} 10^{-6}$ which is $\mathrm{Nc}_{\text {min }}$. For the same collection area, taking $\mathrm{C} 1$ as 2 makes $\mathrm{Nd}$ four times larger and $\mathrm{Nd}$ is obtained as $96^{*} 10^{-3}$. Again, $\mathrm{Nd}>\mathrm{Nc}$ and protection is required. This time, $E$ is obtained as 0.999985 . If rounded, $E$ is found nearly 1 , which corresponds to protection level 1 and additional measures.

For average condition and importance of a structure, $\mathrm{Nc}$ is found as $5^{\star} 10^{-4}$ and $\mathrm{Nd}$ is $24^{*} 10^{-3}$, where $A c$ is taken the same. In this case the weighting factors are taken as following: $C 1=0.5 ; C 2=1.0 ; C 3=2.0 ; C 4=3.0$ and $C 5=1.0$. In this case, which can be applied to all common structures, $\mathrm{Nd}>\mathrm{Nc}$ and protection is required. The effectiveness, $\mathrm{E}$ is calculated as 0.979 , which corresponds to the limit between protection levels II and I.

\subsection{British Standard (BS 6651:1999)}

After Spanish Standard, the analysis will continue with the "Code of practice for the protection of structures against lightning" The relevant parts of the standard are given in Appendix C.

Formulation of Expected Frequency of Direct Lightning to a Structure, Nd is given below:

$\mathrm{Nd}=\mathrm{Ng}^{*} \mathrm{Ac}^{*} 10^{-6} /$ year

Where

$\mathrm{Ng}$ is the flash density,

$\mathrm{Ac}$ is the collection area given below.

It should be noted that there is no environmental coefficient and safety factor in Eq. 2.6. However, in weighting factors, there is a coefficient related with degree of isolation. This coefficient is similar to the environmental coefficient C1 in Spanish Standard.

The safety factor used in Eq. 2.1 has advantage while determination the requirement of protection. Increase in the expected risk by $10 \%$ makes the system safer.

There is not any formulation given in the standard for the determination of $\mathrm{Ng}$; instead, there is a table re-produced below. British Standard notes that the data for this table has been 
extracted from information in Conference Internationale des Grands Reseaux Electriques (CIGRE), Lightning Parameters for Engineering Application.

Table 2.4 Relationship between thunderstorm days per year and lightning flashes per square km per year (extracted from information in CIGRE, Lightning Parameters for Eng. Application)

\begin{tabular}{|c|c|c|c|c|c|c|c|c|c|}
\hline $\mathrm{N}_{\mathrm{k}}$ & 5 & 10 & 20 & 30 & 40 & 50 & 60 & 80 & 100 \\
\hline $\mathrm{Ng}$ (Mean) & 0.2 & 0.5 & 1.1 & 1.9 & 2.8 & 3.7 & 4.7 & 6.9 & 9.2 \\
\hline $\mathrm{Ng}$ (Limits) & $0.1-0.5$ & $0.15-1$ & $0.3-3$ & $0.6-5$ & $0.8-8$ & $1.2-10$ & $1.8-12$ & $3-17$ & $4-20$ \\
\hline
\end{tabular}

When the $\mathrm{Ng}$ limits are examined, the differences are thought to be high. The ratio of maximum limit to the minimum one reaches 10 . This difference is significant while determining the protection requirement. The maximum limits should be selected when there is a special sensitivity for the protection of a structure. Otherwise, the protection design should be done with mean values.

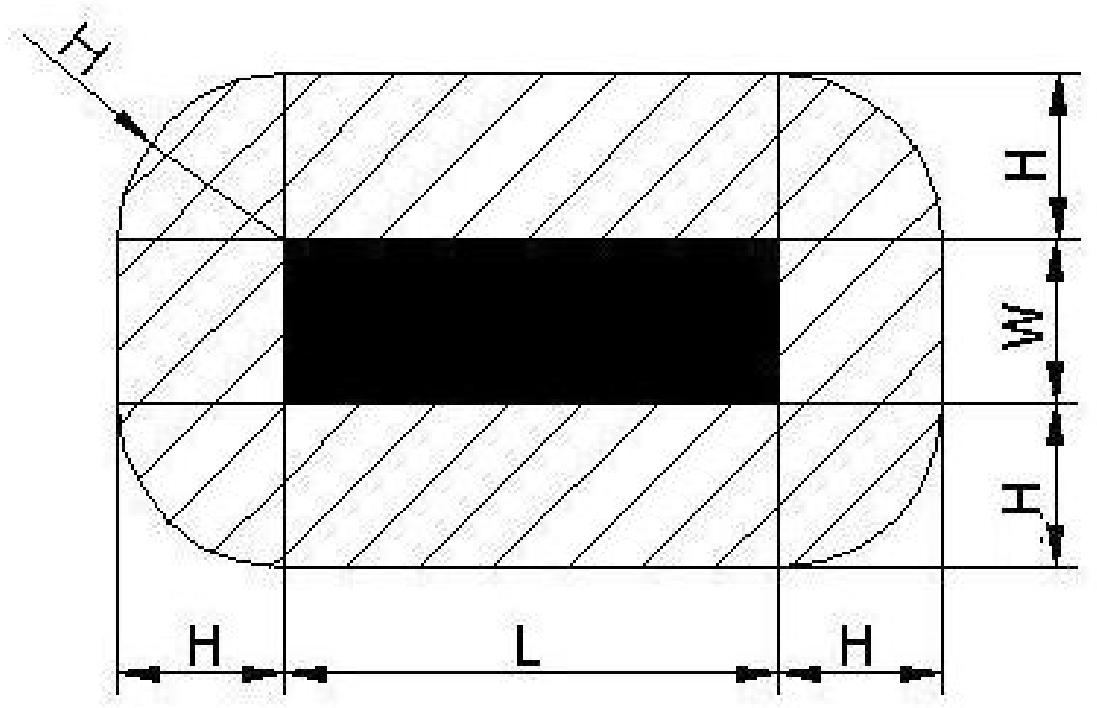

Figure 2.2 Plan of Collection Area, Ac 
The effective collection area, Ac of a structure is the area of the plan of the structure extended in all directions to take account of its height. The edge of the effective collection area is displaced from the edge of the structure at that point shown in Figure 2.2.

In Figure 2.2 below, the shaded area plus black area is the collection area as in the Spanish Standard. For the same simple rectangular structure with length $L$, width $W$ and height $H$, the collection area $\mathrm{Ac}$ is then equal to:

$A C=L W+2 H(L+W)+\pi H^{2}$

It should be noted that the difference between Eq. 2.7 and Eq. 2.3, which can be seen well in Figure 2.2. The four rounded corners formed by quarter circles of radius $\mathrm{H}$ instead of $3 \mathrm{H}$. If the collection areas are compared, the British Standard states smaller risk area to be protected. While calculation, taking the collection area larger effects the results by forcing more safety lightning protection to be used.

The weighting factors given in BS are used to determine the risk factor for structures. Similar to Spanish Standard, there are five coefficients (one more) that are A to E. The overall weighting factor is obtained as the product of these five coefficients (i.e., $A^{*} B^{*} C^{*} D^{*} E$ ). These are given in Appendix C.

Weighting factor $A$ is related with the use of structure. Houses and other buildings of comparable size are thought to have minimum risk factor equal to 0.3 , while schools, hospitals etc. have maximum risk factor, which is assigned as 1.7. The number of people in a place determines the risk factor. The crowded the structure, the higher will be for risk factor.

On the other hand, weighting factor B deals with the type of construction. Similar to Spanish Standard, metal structure of metal roof has minimum risk while any building with a thatched roof has the highest risk factor. The conductivity and non-flammable characteristics are assumed to decrease the risk factor. The weighting factor is between 0.1 and 2.0.

Factor $\mathrm{C}$ is determined according to the contents or consequential effects. Ordinary structures are thought to be least priority and 0.3 is assigned to these while schools, hospitals, etc. have the highest risk factor equal to 1.7. The consequences of lightning increase the risk factor. 
Factor $D$ is concerned with the degree of isolation of the structure similar to $C 1$ of Spanish Standard. Isolation increases the risk factor. 0.4 is assigned to structure located in a large area of structures or trees of the same or greater height while structure completely isolated or exceeding at least twice the height of surrounding structures or trees has weighting factor 2.0.

The last factor $E$ is related with the type of terrain. Flat levels are thought to be the safest geographic terrains of coefficient 0.3 while higher terrains as if mountains have the maximum risk factor as 7 . The risk factor increases with increasing altitude. If the isoceraunic map of Turkey is examined, altitude should be interpreted as relative altitude. For example, one of the highest terrains in Turkey is Hakkari. However, the ceraunic level of Hakkari is the minimum one in Turkey.

The weighting factor $D$ should be noted and compared with the environmental coefficient $C 1$ in Table 2.2. They are nearly the same and now both standards have five coefficients.

In BS, there is no calculation for the tolerable frequency, Nc as in the Spanish Standard. BS 6651 determines a risk factor directly in accordance with the following criterion. From the comparative probability of death for an individual per year of exposure data ${ }^{17}$, the accepted risk factor has been assumed as $10^{-5}$ per year, i.e. 1 in 100,000 per year.

This value should be compared with that of other accepted risk frequencies, which are 1 in 500,000 for natural disasters while it is 1 in 8,000 for traffic accidents. The poisoning event has the same risk of 1 in 100,000. The smoking (10 cigarettes per day) has a risk of 1 in 400 per year.

BS defines an overall risk factor, which is obtained as the product of $\mathrm{Nd}$ with the overall weighting factor. The comparison between the assumed risk factor, $\mathrm{Nc}$ and the overall risk factor determines the protection requirement of the structure concerned.

If the overall risk factor calculated is greater than the risk factor (assumed as $1 / 100,000$ ), protection is necessary. Otherwise, there is no need for any lightning protection. BS 6651 notes that risks less than $10^{-5}$ do not generally require protection; risks greater than $10^{-4}$ require protection; for risks between $10^{-5}$ and $10^{-4}$ protection is recommended.

There is no effectiveness term defined in BS 6651. Like the lack of effectiveness, there is no determination of any protection level. However, after some derivation (i.e., making the procedure of BS similar to that of Spanish Standard), both procedures in Spanish and British 
Standards could be unique and $E$ can be calculated, then according to $E$ value, the protection levels given in Spanish Standard can be used.

The maximum overall weighting factor is obtained as 19.7 , while the minimum one is 0.001 when rounded. The total ratio of maximum to minimum is 19,700 if the overall weighting factors are compared. In Spanish Standard, it is 67,200 if C1 is considered; otherwise, it is 16,800 that can be thought closer to that in British Standard.

As an illustration of the effects of weighting factors, if it is assumed that for the worst case it comes out to be 19.7 giving overall risk factor of $10^{-5}$. On the other hand, with the minimum weighting coefficients, it comes out to be 0.001 resulting in an overall risk factor of $5.08^{\star} 10^{-}$ ${ }^{10}$, which requires no protection for the same collection area.

For common structures, the overall weighting factor is obtained as nearly as 0.01 where $A=0.3 ; B=1.0 ; C=0.3 ; D=0.4$ and $E=0.3$. If the same collection area is considered then the overall risk factor becomes $5.08^{*} 10^{-9}$ that corresponds to no protection requirement. This is the average case, but the climatic conditions and structure plan would be determining factor here.

It should be noted that the ratio of overall risk factors for the safest case and the average case for common structures is 0.1 , which corresponds to the limit for protection requirement. If any case having more risk than the average case would correspond to protection requirement. For risks between $10^{-5}$ and $10^{-4}$, protection is recommended. The ratio is 10 . However, the ratio of maximum and minimum overall risk factor is 19,700 that is significantly high.

\subsection{American Standard (NFPA 780: 1997)}

This standard, "Standard for the Installation of lightning protection systems" has a different approach than the Spanish and British Standards. Instead of any collection area calculation or others, there are tables given and index values are assigned. The related parts of this standard are given in Appendix D.

The definition of the weighting factors, referred as indices, are given below:

The index value $A$ is related with the type of structure. Single-family residences have minimum index value which is 1 while structures of hazardous materials corresponds to 
highest risk value equals to 10 . The number of people to be affected from lightning and consequences determine the risk factor.

The index $B$ is concerned with the type of construction. Metal-electrically continuous structures and roofs have the minimum index value. Flammable like wooden type of construction has the highest value. The minimum value is 1 , while the maximum one is 5 . Electrically conductive and non-flammable structures are the least risky ones.

On the other hand, index $\mathrm{C}$ corresponds to the relative location. Relatively high structures in an area have high risk factors. The taller structures have the highest risk value, which is 10 , while the structures covering smaller ground areas, shorter ones have the minimum risk value, and it is assigned as 1 .

The index D deals with the topography. Similar to BS, flat terrains have minimum risk factor equal to 1 while higher terrains have higher risk factors. Terrains such as mountaintop are assigned as 5 . The risk factor increases with increasing altitude. Again, relative altitude should be thought while determination.

Index $E$ is related with the occupancy and contents of the structures. Unoccupied structures containing non-combustible materials are thought to be least risky while structures with high importance and containing explosives are the most risky. Explosion risk increases the risk factor. The maximum value assigned is 10 while the minimum one is 1 .

Finally, the index value $\mathrm{F}$ is determined according to the lightning frequency. Index values are assigned to the isoceraunic levels. The places of higher lightning frequencies are the more risky places. Index value 9 is assigned to isoceraunic level between $0-5$. On the other hand, regions of ceraunic level over 70 are given index value 1 .

There is risk index, $\mathrm{R}$ is defined in the American Standard and it is defined by the following formula:

\section{$R=(A+B+C+D+E) / F$}

The standard notes that the computed R-values for the eastern United States should be multiplied by a factor varying from 1.5 in the northeast to 0.5 in the southeast. This factor is due to the differences in storm characteristics in these regions. 
Table 2.5 Assessment of Risk, $R$

\begin{tabular}{|c|c|}
\hline R value & Risk value \\
\hline $0-2$ & Light \\
\hline $2-3$ & Light to Moderate \\
\hline $3-4$ & Moderate \\
\hline $4-7$ & Moderate to Severe \\
\hline Over 7 & Severe \\
\hline
\end{tabular}

Like the protection levels in previous standards, the risk values can be interpreted as protection levels. It should be remembered that, the risk value decreases from protection level 1 to 4 . In NFPA 780, the greater the $R$ value, the higher will be the risk. The R-value obtained from Eq. 2.8 corresponds the risk values given in Table 2.5. Light risk value can be thought as protection level 4 while severe risk value corresponds to protection level 1 plus additional measures.

The maximum R-value obtained according to Eq. 2.8 could be 40 while the minimum R-value is nearly 0.6 if rounded. In American Standard, for the safest case, there is also a risk value assigned although it is small indicated as light. Because of storm characteristics of the USA, it is understandable to require protection for every case and it is meaningful to obtain risk value of 40 due to the severe climatic conditions.

For average case, $R$ is found as 1.6 which corresponds to light risk value. In this case $A=1$; $B=3 ; C=1 ; D=1 ; E=2$ and $F=5$.

\subsection{IEC Standard (IEC 1024:1990)}

The IEC (International Electrotechnical Commission) is a worldwide organization for standardization comprising all national electrotechnical committees trying to harmonize the different national standards. The procedure for protection requirement is defined in detail within this standard. These are similar to the Spanish and Turkish Standards in calculation of collection area, expected lightning stroke frequency and determination of protection levels according to effectiveness. These are given in Spanish and Turkish Standards.

However, IEC does not define any tolerable risk frequency calculation. Instead, it states that the values of $\mathrm{Nc}$ are the responsibility of National Committees, where human, cultural and 
social losses are involved. The values of Nc may be established by the owner of the structure or by the designer of LPS, where losses are relevant to private property only.

This standard expresses that the values of Nc may be estimated through the analysis of the risk of damage taking into account appropriate factors such as:

- Type of construction,

- Presence of flammable and explosive substances,

- Measures provided to reduce the consequential effects of lightning,

- Number of people subject to damage,

- Type and importance of the public service concerned,

- Value of goods having suffered damage,

- Other factors.

The following table gives the classifications of the structures and the effects of lightning as given by this standard. It should be noted that the other national standards assign weighting factor coefficients to the structure classification and lightning effects given below.

Table 2.6 Examples of Structure Classification

\begin{tabular}{|c|c|c|}
\hline $\begin{array}{l}\text { Classification } \\
\text { of structures }\end{array}$ & Type of structure & Effects of lightning \\
\hline \multirow[b]{2}{*}{$\begin{array}{l}\text { Common } \\
\text { structures }\end{array}$} & Dwelling-house & $\begin{array}{l}\text { Puncture of electrical installations, } \\
\text { fire and material damage } \\
\text { Damage normally limited to objects } \\
\text { exposed to the point of strike or to } \\
\text { the lightning path }\end{array}$ \\
\hline & Farm & $\begin{array}{l}\text { - Primary risk of fire and hazardous } \\
\text { step voltages } \\
\text { - Secondary risk due to loss of } \\
\text { electric power, and life hazard to } \\
\text { livestock due to failure of electronic } \\
\text { control of ventilation and food } \\
\text { supply systems, etc. }\end{array}$ \\
\hline
\end{tabular}




\begin{tabular}{|c|c|c|}
\hline \multicolumn{3}{|c|}{ Table 2.6 (Continue) } \\
\hline $\begin{array}{l}\text { Classification } \\
\text { of structures }\end{array}$ & Type of structure & Effects of lightning \\
\hline \multirow{5}{*}{$\begin{array}{l}\text { Common } \\
\text { structures }\end{array}$} & $\begin{array}{l}\text { Theatre } \\
\text { Cinema } \\
\text { School } \\
\text { Department store } \\
\text { Sporting complex }\end{array}$ & $\begin{array}{l}\text { - Damage to the electrical } \\
\text { installations (e.g. electrical lighting) } \\
\text { likely to cause panic } \\
\text { - } \quad \text { Failure of fire alarms resulting in } \\
\text { delayed fire fighting measures }\end{array}$ \\
\hline & $\begin{array}{l}\text { Bank } \\
\text { Insurance company } \\
\text { Commercial company }\end{array}$ & $\begin{array}{l}\text { As above, plus problems resulting from } \\
\text { loss of communication, failure of } \\
\text { computers and loss of data }\end{array}$ \\
\hline & $\begin{array}{l}\text { Hospital } \\
\text { Nursing home } \\
\text { Prison }\end{array}$ & $\begin{array}{l}\text { As above, plus problems of people in } \\
\text { intensive care, and the difficulties of } \\
\text { rescuing immobile people }\end{array}$ \\
\hline & Industry & $\begin{array}{l}\text { Additional effects depending on the } \\
\text { contents of the factories, ranging from } \\
\text { minor to unacceptable damage and loss of } \\
\text { production }\end{array}$ \\
\hline & $\begin{array}{l}\text { Museums and } \\
\text { archaeological sites }\end{array}$ & Loss of irreplaceable cultural heritage \\
\hline $\begin{array}{l}\text { Structures } \\
\text { with confined } \\
\text { danger }\end{array}$ & $\begin{array}{l}\text { Telecommunications } \\
\text { Power plants } \\
\text { Industries with fire } \\
\text { hazards }\end{array}$ & $\begin{array}{l}\text { - Unacceptable loss of services to } \\
\text { the public } \\
\text { - Consequential hazards to the } \\
\text { immediate surroundings caused by } \\
\text { fire, etc. }\end{array}$ \\
\hline $\begin{array}{l}\text { Structures } \\
\text { dangerous } \\
\text { to their } \\
\text { surroundings }\end{array}$ & $\begin{array}{l}\text { Refinery } \\
\text { Service station } \\
\text { Firework factory } \\
\text { Munitions works }\end{array}$ & $\begin{array}{l}\text { Consequences of fire and explosion to the } \\
\text { plant and its surroundings. }\end{array}$ \\
\hline $\begin{array}{l}\text { Structures } \\
\text { dangerous to } \\
\text { the } \\
\text { environment }\end{array}$ & $\begin{array}{l}\text { Chemical plant } \\
\text { Nuclear plant } \\
\text { Biochemical } \\
\text { laboratories } \\
\text { and plants }\end{array}$ & $\begin{array}{l}\text { Fire and malfunction of the plant with } \\
\text { detrimental consequences to the local and } \\
\text { global environment }\end{array}$ \\
\hline \multicolumn{3}{|c|}{$\begin{array}{l}\text { NOTE } \\
\text { - Sensitive electronic equipment might be installed in all kinds of structures, } \\
\text { which can be easily damaged by over-voltages due to lightning }\end{array}$} \\
\hline
\end{tabular}


According to the local conditions, the weighting factors can be assigned from Table 2.6. IEC gives only this table and no value for $\mathrm{Nc}$ or weighting factor. The procedure is the same as in Spanish Code. Protection levels are determined according to the E value found using Table 2.7 , which is similar in all standards.

Table 2.7 Required protection levels according to the computed effectiveness $E$

\begin{tabular}{|c|c|}
\hline Protection level & E=1-Nc/Nd \\
\hline I & 0,98 \\
\hline II & 0.95 \\
\hline III & 0.90 \\
\hline IV & 0.80 \\
\hline
\end{tabular}

\subsection{Turkish Draft}

The Turkish Standards are mostly similar to IEC, although there are some differences. These are because of parts taken from the other national standards.

To highlight these differences, the same procedure as in other standards will be examined according to the Turkish draft. It must be noted that this procedure is nearly the same as that of Spanish Standard. The difference is the determination of tolerable frequency of strikes, Nc and there is no safety factor in determination of $\mathrm{Nd}$. The introduction of environmental coefficient in Eq. 2.9 is another difference, similar to that in Spanish Standard.

Calculation of the expected frequency $\mathrm{Nd}$ of direct lightning to a structure is formulated as follows:

$\mathrm{Nd}=\mathrm{Ng}^{*} \mathrm{Ac}^{*} \mathrm{Ce}^{*} 10^{-6} /$ year

Where

$\mathrm{Ng}$ is the flash density,

$A c$ is the collection area defined below

$\mathrm{Ce}$ is the environmental coefficient. 
The lightning flash density, $\mathrm{Ng}$ is formulated as follows:

$\mathrm{Ng}=0.04^{*} \mathrm{Nk}^{1.25}$

which is the same as that of IEC.

The Collection Area of a Structure, Ac is defined similar as in Spanish Standard and IEC shown in Figure 2.1.

$A c=L W+6 H(L+W)+9 \pi H^{2}$

(Eq. 2.11)

The standard states that the topography of the site and the objects located within the distance $3 \mathrm{H}$ from the structure significantly affect the collection area. This effect is taken into account by applying environmental coefficient Ce given in Table 2.8. It should be noted that the Spanish Standard assigns different values for the first two entries.

\section{Table 2.8 Determination of environmental coefficient $\mathrm{Ce}$}

\begin{tabular}{|l|c|}
\hline Relative Structure Location & Ce \\
\hline $\begin{array}{l}\text { Structure located within a space containing structures or trees of the same } \\
\text { height or taller }\end{array}$ & 0.25 \\
\hline Structure surrounded by smaller structures & 0.50 \\
\hline Isolated structure: no other structures within a distance of 3H & 1.00 \\
\hline Isolated structure on a hilltop or a headland & 2.00 \\
\hline
\end{tabular}

$\mathrm{Nc}$ is obtained using the equation below:

$\mathrm{Nc}=\mathrm{A}^{*} \mathrm{~B}^{*} \mathrm{C}$

where $\mathrm{A}, \mathrm{B}$ and $\mathrm{C}$ are weighting factors given in Appendix $\mathrm{E}$.

When the weighting factors are analysed, Coefficient $A$ is related with the type of structure and construction and has four sub-coefficients. $A$ is the product of these $\left(A=A 1^{*} A 2^{*} A 3^{*} A 4\right)$. 
A1 is related with the type of walls. The non-flammable such as metal or concrete type of walls have the smallest risk factor equal to 5.0 while flammable walls have the highest risk factor of 0.1 . Electrically conductive and non-flammable types of walls reduce the risk factor.

On the other hand, A2 is related with the type of roof. Steel roofs have smallest risk factor while wooden type of roofs are the most risky. Electrically conductive and non-flammable types of roofs reduce the risk factor. The maximum assigned coefficient is 4 while the minimum one is 0.1 .

A3 is concerned with the type of roof coating. When the material is highly pressed insulating, it has the highest risk factor assigned 0.05 while concrete material is the least risky which is 4.The metallic coatings decrease the risk.

A4 corresponds to the constructions on the roof. The sensitive devices increase the risk factor while the risk factor is minimum when there is nothing on the roof. If there is nothing on the roof, A4 is assigned as 1.0 while sensitive devices corresponds to 0.1 .

Coefficient $B$ is related with the structure occupancy and contents inside. It has four subcoefficients and $B$ is the product of these $\left(B=B 1^{*} B 2^{*} B 3^{*} B 4\right)$.

B1 is related with the occupancy. Panic risk increases the risk factor. Structures with no panic risk has occupancy factor 1.0 while structures with high panic risk are assigned as 0.01 .

B2 deals with the type of materials inside. The non-flammable materials have minimum risk factor equal to 1.0 while nuclear plants are the most risky structures and they have risk factor 0.01. The explosion risk increases the risk factor.

On the other hand, B3 concerns with the worth of equipment inside. The simple, worthless equipments have minimum risk factor of 1 while very valuable equipments have the highest risk factor of 0.01 . The risk factor is directly proportional to the value of the equipment inside.

Last factor B4 is about the hazard minimizing precautions. When there is no precaution, it is thought to be the highest risky structure, while structures having automatic fire extinguisher system have the minimum risk factor. The maximum risk coefficient assigned is 1 while the minimum one is 10 . The hazard minimizing equipment in the structure and its type determines the risk factor. 
Coefficient $\mathrm{C}$ is related with the consequences of lightning damages has three subcoefficients. $C$ is the product of these $\left(C=C 1{ }^{*} C 2{ }^{*} C 3\right)$.

$\mathrm{C} 1$ is related with the consequences on environment due to materials inside. Highly effective materials cause high risk factor while the materials with no consequence has the minimum risk factor. Coefficient for very high consequence on environment is 0.01 while no consequential effect is assigned as 1.0.

C2 concerns with the loss of service continuity in structure due to materials inside. Loss of service continuity causes high risk, which is assigned as 0.01 . On the other hand, no loss of service continuity has the minimum risk coefficient equal to 1.0 .

Lastly, C3 is related with other hazards. The degree of hazard is directly proportional to the risk factor. Very high hazard has the maximum risk factor of 0.01 while low hazard has coefficient of 1.0 .

\section{Table 2.9 Required protection levels according to the computed effectiveness $E$}

\begin{tabular}{|c|c|}
\hline Protection level & Effectiveness \\
\hline I + additional measures & $\mathrm{E}>0.98$ \\
\hline I & $0.95<\mathrm{E}<0.98$ \\
\hline II & $0.90<\mathrm{E}<0.95$ \\
\hline III & $0.80<\mathrm{E}<0.90$ \\
\hline IV & $0<\mathrm{E}<0.80$ \\
\hline No protection & $\mathrm{E}<0$ \\
\hline
\end{tabular}

The procedure for determination of the protection requirement is the same as given in Spanish Standard and IEC. According to the effectiveness calculated, the protection level is determined. The difference between Spanish Standard and Turkish draft is that there are four protection levels in Turkish draft as stated in IEC.

The maximum tolerable frequency, $\mathrm{Nc}$ is obtained as 800 while the minimum one is $5^{\star} 10^{-17}$. The total ratio of maximum to minimum is $1.6^{*} 10^{19}$. When compared to other standards, the range is significantly large. It is 16,800 in Spanish Standard. Although the procedures are the 
same as Spanish Standard, the difference between the ratios probably results in different protection requirements.

According to Eq. 2.9, by taking $\mathrm{Ce}$ as 0.25 , it should be assumed that calculated $\mathrm{Nd}$ is 800 and $\mathrm{Nc}$ is 800 , which is equal to $\mathrm{Nc}_{\max }$. This is the safest case. $\mathrm{Nd}$ is equal to $\mathrm{Nc}$; therefore, protection is required. According to Eq. 2.5, E is obtained as zero that corresponds to protection level IV that has the minimum risk value.

For the worst case, $\mathrm{Nc}$ is $5^{\star} 10^{-17}$ which is $\mathrm{Nc}_{\text {min. }}$. Taking $\mathrm{Ce}$ as 2 makes $\mathrm{Nd}$ eight times larger, for the same collection area. $\mathrm{Nd}$ is obtained as 6,400. Again, $\mathrm{Nd}>\mathrm{Nc}$ and protection is required. This time, $E$ is obtained as 0.999985 . If rounded, $E$ is found 1 , which corresponds to protection level 1 and additional measures.

In the average case, the weighting factors could be taken as following: $A 1=0.5 ; A 2=2.0$; $A 3=1.0 ; A 4=0.6 ;(A=0.6)$. $B 1=0.1 ; B 2=0.2 ; B 3=0.2 ; B 4=1.0 ;(B=0.004)$ and $C 1=1.0 ; C 2=1.0$, $C 3=1.0 ;(C=1.0)$. Therefore, the Nc value is obtained as $2.4^{*} 10^{-3}$ for common structures and it should be assumed that $\mathrm{Nd}$ is 800 . In this case, which can be applied to all common structures, $\mathrm{Nd}>\mathrm{Nc}$ and protection is required. The effectiveness, $\mathrm{E}$ is calculated as 1 , which corresponds to protection level 1 and additional measures.

\subsection{Interpretations and Comparison of Reviewed Standards}

To determine the requirement of lightning protection and to install the safest protection system against lightning is given by the procedures in every standard above. The safety degree of a LPS's is determined by the weighting factors. The comparison of these will be useful and they can be improved for the local conditions if the priorities and conditions of local areas are examined carefully.

In Spanish Standard, if the structural coefficient is examined, the flammable material structure increases the risk while metal structure with metal roof has minimum risk effect. The explosive contents increase the risk. If the occupancy is considered, the more the occupancy, the higher the risk is. If the lightning has environmental consequences, the risk is highest.

If the BS coefficients are examined, the highest risk coefficient is given to schools, hospitals, children's, and other homes. If this table is examined, the priority is given to human health. Factories etc. have average degree while the places of high occupancy have higher risk. 
Same to Spanish standard, when the type of construction is analysed, steel framed structure with metal roof has minimum degree while thatched roof has the highest risk.

If the contents or consequential effects are examined, the priority is again given to schools, hospitals and children, then historic buildings. The higher and the more isolated the building, the higher risk degree it has and the risk increases when the type of terrain goes from flat country to mountain country. In BS, public health and history, art etc. are the priorities to be protected.

In American Standard, the highest degree is given to buildings containing hazardous materials and health centres. Power generation and historic structures have the same index value. Similar to Spanish and British Standards, the flammable type of constructions have the highest risk while metallic structures are the safest ones. The priority is given to structures higher than their surroundings.

Similar to BS, the topography of structure is important. Risk increases from flat land to mountaintop in NFPA. If the occupancy and contents are examined, the highest risk value is given to explosives and historic contents. The public health has the priority to be protected.

Finally, if the Turkish draft is analysed, the electrically conductive structures are more safety. The risk factor increases from non-flammable type to nuclear plants. An additional risk factor is due to any precaution to decrease the damage: if there is no precaution, it is the highest risk factor. The consequential effect is directly proportional to the risk factor.

After the analysis of the standards above, if they are compared; British and American Standards give importance to public health, children and historic structures while in Spanish and Turkish, the priority is given to the environmental effects of lightning such as explosions. As metallic structures are electrically conductive and serve like a LPS's, these metallic structures are assigned with minimum risk factors in all standards.

\subsection{Derivations and Modification of BS Algorithm}

The following analysis is made to modify the British Standard so that $\mathrm{Nc}$ and $\mathrm{Nd}$ values can be obtained similar to the Spanish Standard.

Assuming $\mathbf{N d}>\mathbf{N c}$, when the inequality between $\mathrm{Nc}$ and $\mathrm{Nd}$ in Spanish Standard is written with all components in the open form, the following inequality is obtained: 
After transferring the denominator of $\mathrm{Nc}$ to the other side of the inequality, the following expression is obtained:

$\mathrm{Ng}^{*} \mathrm{Ac}^{*} 10^{-6 *} 1.1^{*} \mathrm{C} 1^{*} \mathrm{C} 2^{*} \mathrm{C} 3^{*} \mathrm{C} 4^{*} \mathrm{C} 5>3^{*} 10^{-3}$

(Ineq. 2.2)

According to the procedure from BS, assuming overall risk factor is greater than $p$, when this inequality between $p$ and overall risk factor is written in the open form, the inequality becomes:

$\mathrm{Ng}^{*} A C^{*} 10^{-6 *} A^{*} B^{*} C^{*} D^{*} E>10^{-5}$

(Ineq. 2.3)

It is clearly seen than, both inequalities Ineq. 2.2 and Ineq. 2.3 are similar except the safety factor 1.1. However, this does not change anything. The BS formulas can be modified to reach the inequality between $\mathrm{Nd}$ and $\mathrm{Nc}$ as in the Spanish Standard.

It should be remembered that the weighting factor $D$ in BS related with the degree of isolation is similar to the environmental coefficient $\mathrm{C} 1$ used for calculation of $\mathrm{Nd}$ in Spanish Standard. The safety factor of 1.1 should be added into Eq. 2.6 in BS. This makes BS safer. As a result, by transferring weighting factor $\mathrm{D}$ into Eq. 2.6, a new $\mathrm{Nc}$ and $\mathrm{Nd}$ such as $\mathrm{Nc}$ and $\mathrm{Nd}$ ' can be defined in BS and can be formulated as in the followings:

$N d^{\prime}=\mathrm{Ng}^{*} 1.1^{*} \mathrm{Ac} c^{*} \mathrm{D}^{*} 10^{-6} /$ year

$N c^{\prime}=10^{-5} / A^{*} B^{*} C^{*} E$

The above equations are similar to equations Eq. 2.1 and Eq. 2.4, respectively. After obtaining the new values of $\mathrm{Nc}^{\prime}$ and $\mathrm{Nd}$ ', the Eq. 2.5 can be used to find out the effectiveness in BS. Calculated effectiveness can be used to determine the protection level given in Table 2.5 .

\subsection{Examples for the Comparison of Reviewed Standards}

The examples given below would be useful to compare the standards. The effects of different interpretation of risk factors and collection areas in different standards are analysed in calculation of protection requirements. 


\section{Example-1 Collection Areas given in Spanish and British Standards}

As written in explaining and calculating the collection area, Ac of each standard, the comparison of the British and Spanish (Turkish) Standards was done. With an example, the comparison can be clarified.

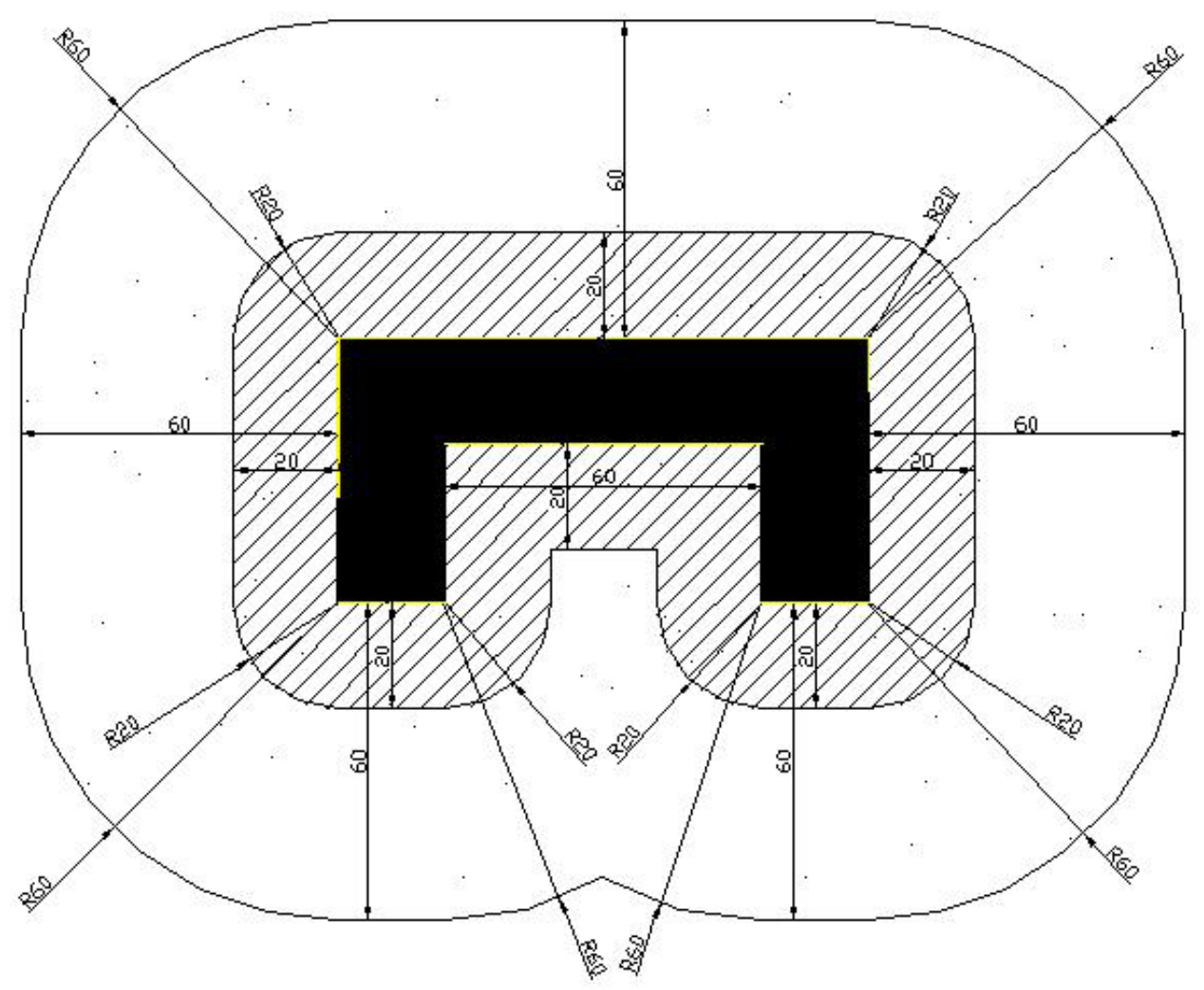

Figure 2.3 Comparison of Collection Areas given in Spanish and British Standards (Structure with $\mathrm{H}=20 \mathrm{~m}$, Black Plan)

In Figure 2.3, there is a plan of a building, shown with black colour. The height, $\mathrm{H}$ of the building is $20 \mathrm{~m}$. The black area plus the shaded area is the collection area according to British Standard, while the black area plus the shaded area plus the dotted area is the collection area according to Spanish Standard.

According to Eq. 2.3, the collection area is $A c=L W+6 H(L+W)+9 \pi H^{2}$ in Spanish Standard where it is $\mathbf{A c}=\mathbf{L W}+\mathbf{2} \mathbf{H}(\mathbf{L}+\mathbf{W})+\pi \mathbf{H}^{2}$ given in British Standard formulated in Eq. 2.7. The 
collection area can be thought as a risk area under lightning. The collection area increases the risk probability of lightning strike.

As in Figure 2.3, the collection area of Spanish Standard covers that of British Standard. As Spanish Standard takes larger area in analysis, it uses higher risk factor. As a result, the higher safety protection level is selected. Consequently, while calculating the risk factor and the requirement of protection, the procedure in Spanish Standard seems safer.

\section{Example-2 Comparison of Reviewed Standards for Protection Requirement (Case-1)}

For the given example of a structure, the protection requirements according to worldwide standards described above will be analysed and compared. The objective is to reach the same protection level with different standard procedures.

For the given structure in Figure 2.4, there are two parts. Dimensions are chosen as follows: $H_{A}=40 \mathrm{~m} ; L_{A}=15 \mathrm{~m} ; W_{A}=20 \mathrm{~m}$ and $H_{B}=20 \mathrm{~m} ; L_{B}=45 \mathrm{~m} ; W_{B}=20 \mathrm{~m}$. In Figure 2.5, the top view of the structure is given.

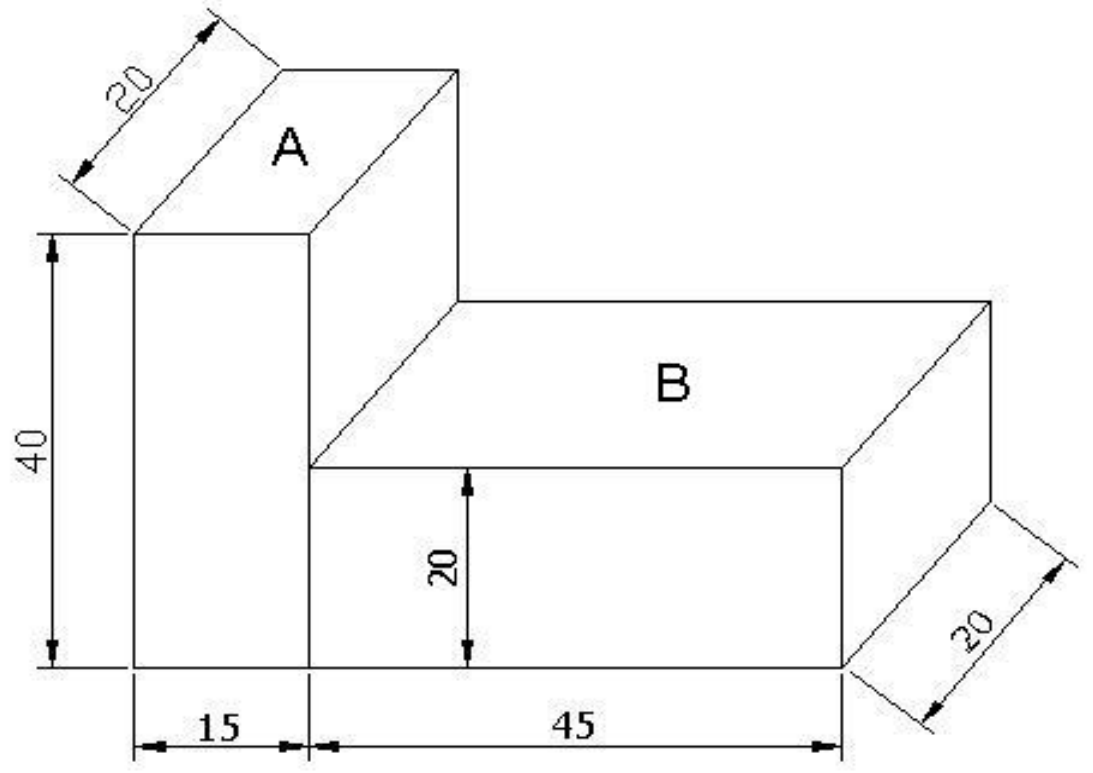

Figure 2.4 An example of Structure 


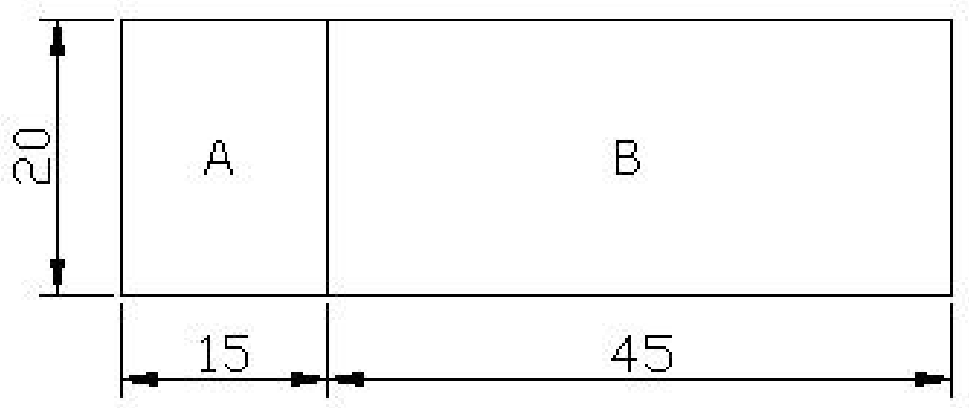

Figure 2.5 An example of Structure (top view)

The chosen structure is steel framed and the roof is metallic. There is nothing on the roof. It is surrounded by smaller structures on a flat type of terrain. This structure is used as a hospital and service continuity is important. There is no explosion risk but there are particularly flammable equipments inside. Fire protection system is available and the equipments used in the hospital are valuable. The assumed local isoceraunic level of the area is 50 .

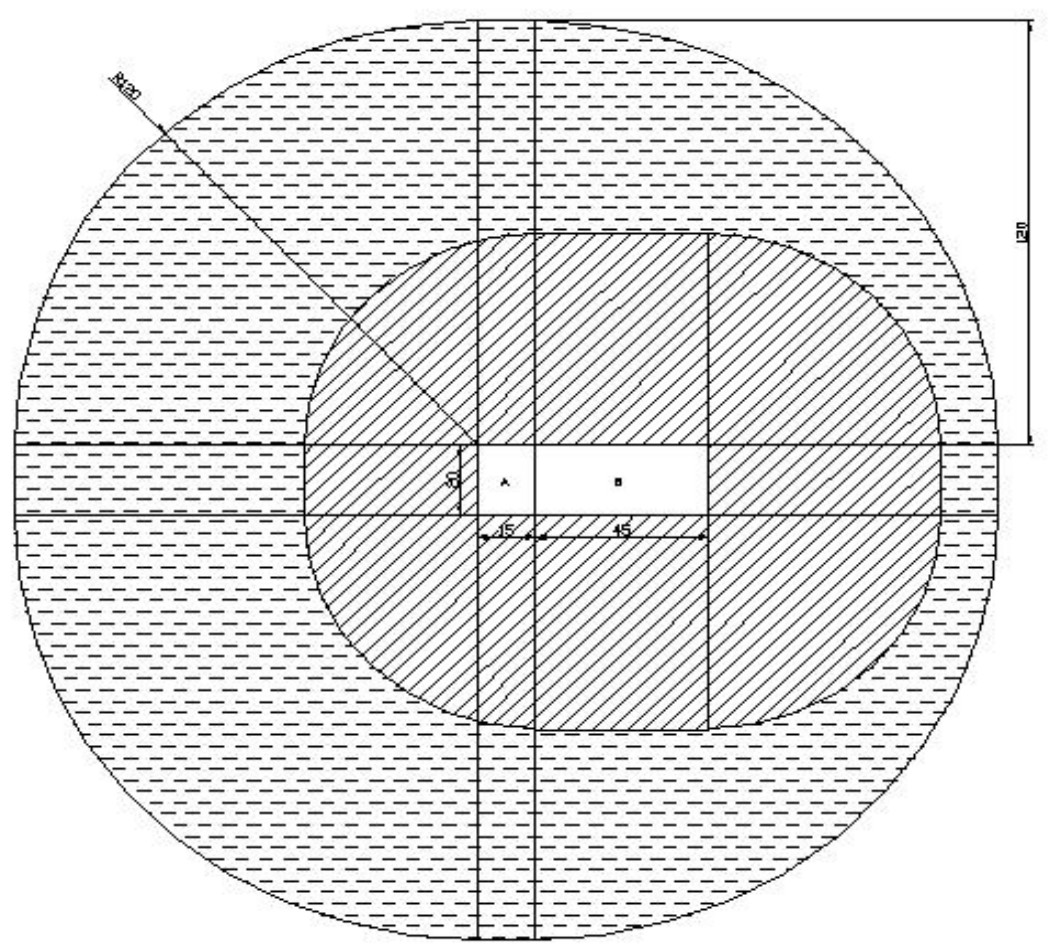

Figure 2.6 Collection Area, Ac according to Spanish Standard 
When the procedure in Spanish Standard is used, according to the structural data given, the coefficients are determined as following: $C 1=0.75 ; C 2=0.5 ; C 3=5.0 ; C 4=7.0 ; C 5=5.0$. According to Eq. 2.2, $\mathrm{Ng}$ is found as 13.75. The collection area is shown in Figure 2.6.

The outer dashed area is the collection area of part A while the inner area hatched with cross lines is the collection area of part $B$. The outer collection area covers the inner part. Therefore, $A c$ that will be taken is the outer area equal to $53,940 \mathrm{~m}^{2}$ where $H_{A}, L_{A}$ and $W_{A}$ values are used in Eq. 2.3. Nd is found to be nearly 0.61 and $\mathrm{Nc}$ is obtained as $3.43^{*} 10^{-5}$ from Eq. 2.1 and Eq. 2.4, respectively. In this case, $\mathrm{Nd}>\mathrm{Nc}$. Therefore protection is required. The effectiveness, $\mathrm{E}$ is calculated as nearly 1 from Eq. 2.5, which corresponds protection level 1 and additional measures according to Table 2.3.

On the other hand, for the same structure, the weighting factors determined according to British Standard are: $A=1.7 ; B=0.1 ; C=1.7 ; D=2.0 ; E=0.3$. According to Table 2.4, $\mathrm{Ng}$ is found as 3.7. The collection area is shown in Figure 2.7.

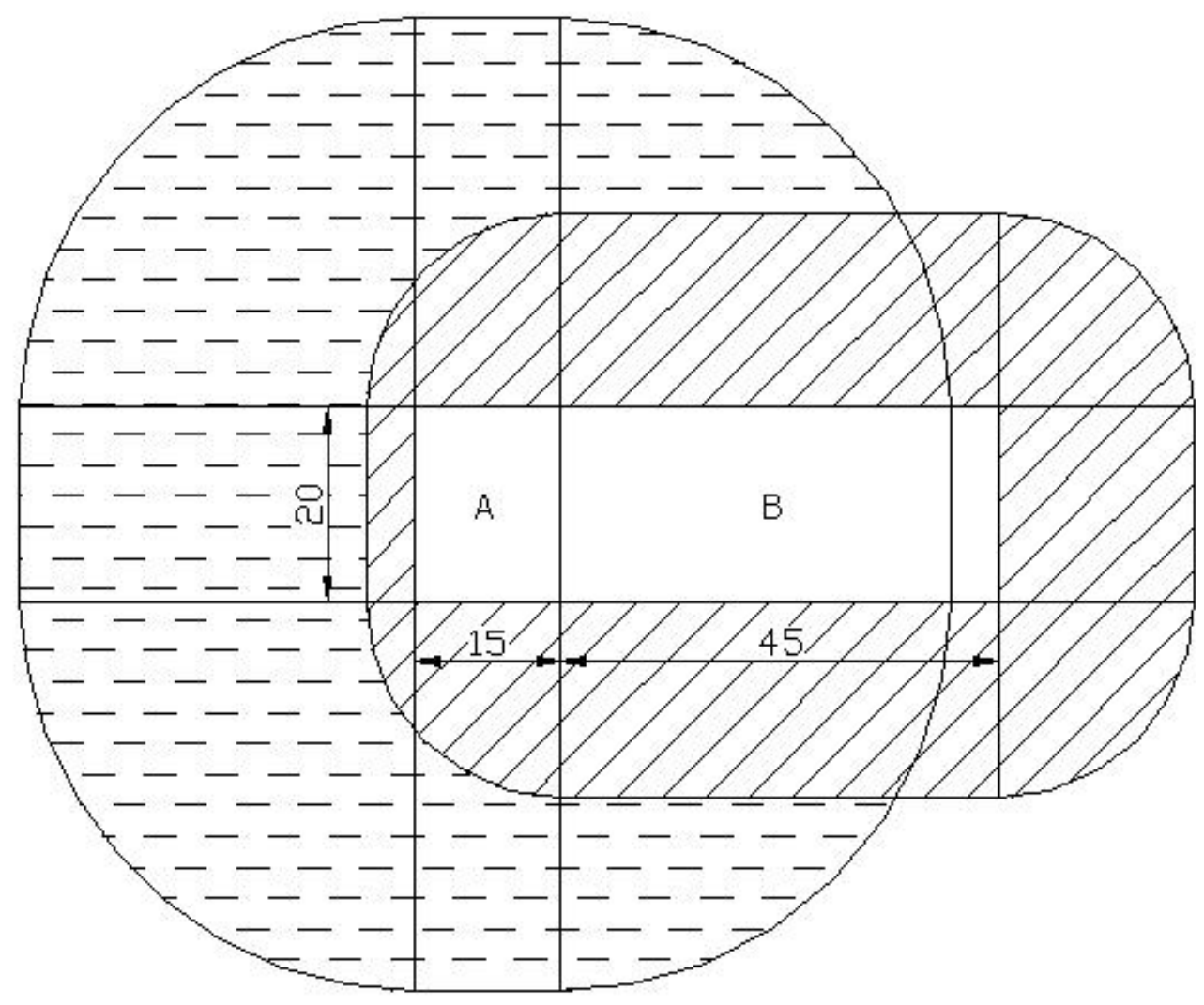

Figure 2.7 Collection Area, Ac according to British Standard 
The collection area is the area covered by the boundaries formed by the union of both collection areas. Therefore, Ac will be approximately $9,555 \mathrm{~m}^{2}$ when calculated. $\mathrm{Nd}$ is found nearly $3.5^{*} 10^{-2}$ from Eq. 2.6 and $p$ is $10^{-5}$. Overall risk factor is found $6.13^{*} 10^{-3}$ by multiplying $\mathrm{Nd}$ by weighting factors. In this case, the overall risk factor is greater than the acceptable risk, p. Therefore; protection is required.

To calculate the effectiveness, $\mathrm{E}$ and determine the protection requirement, Eq. 2.13 and Eq. 2.14 should be used. According to these derived equations, $\mathrm{Nd}^{\prime}=7.8^{*} 10^{-2}$ and $\mathrm{Nc}^{\prime}=1.2^{*} 10^{-4}$, respectively. ( $\mathrm{Nd}^{\prime}>\mathrm{Nc}^{\prime}$, therefore protection is required). Effectiveness, $\mathrm{E}$ is found nearly 1 , which corresponds protection level 1 and additional measures according to Table 2.3.

If American Standard is employed, the index values are determined as $A=10 ; B=1 ; C=5$; $D=1 ; E=9 ; F=4$. According to Eq. 2.8 , the risk index, $R$ is calculated as 6.5 that the case corresponds to risk value of Moderate to Severe.

Finally, according to Turkish draft, the coefficients are determined as following: $A 1=4.0$; $\mathrm{A} 2=4.0 ; \mathrm{A} 3=2.0 ; \mathrm{A} 4=1.0 ; \mathrm{B} 1=0.01 ; \mathrm{B} 2=0.2 ; \mathrm{B} 3=0.2 ; \mathrm{B} 4=2.0 ; \mathrm{C} 1=1.0 ; \mathrm{C} 2=0.01 ; \mathrm{C} 3=1.0$ and $\mathrm{Ce}=0.5$. According to Eq. $2.15, \mathrm{Ng}$ is found as 5.32 . The collection area is the same as the one shown in Figure 2.6 and $A c=53,940 \mathrm{~m}^{2}$. A is obtained as 48 ; $B$ is $8^{*} 10^{-4}$ while $C$ is equal to 0.01 .

$\mathrm{Nd}$ is found nearly 0.14 and $\mathrm{Nc}$ is obtained nearly $3.84^{*} 10^{-4}$ from Eq. 2.9 and Eq. 2.12, respectively. In this case, $\mathrm{Nd}>\mathrm{Nc}$. Therefore, protection is required. The effectiveness, $\mathrm{E}$ is calculated as nearly 1 from Eq. 2.5, which corresponds protection level 1 and additional measures according to Table 2.9.

As a result, except the American Standard, the Spanish, British and Turkish Standards determine the protection level 1 and additional measures while the American Standard's risk value is Moderate to Severe. The risk value, $R$ is nearly in the limit. However, the case is as risky as the one in other standards that could be assumed to correspond to protection level 1. It could be interpreted that the difference is due to the different approach.

\section{Example-3 Comparison of Reviewed Standards for Protection Requirement (Case-2)}

With the same structure dimensions, the case analysed is as follows: The structure is located within a space containing structures having similar heights on a flat terrain. The walls and the roof are made of metal and electrically continuous. It is normally occupied; however, there is no risk of panic. The structure is a factory building and small assembly. The service 
continuity is important. There are simple and worthless equipments inside and they are nonflammable. There is no precaution against fire in the structure. The local ceraunic level is 20.

In Spanish Standard, according to the structural data given, the coefficients are determined as following: $\mathrm{C} 1=0.5 ; \mathrm{C} 2=0.5 ; \mathrm{C} 3=0.5 ; \mathrm{C} 4=3.0 ; \mathrm{C} 5=5.0$. According to $\mathrm{Eq} .2 .2, \mathrm{Ng}$ is found as 3. The collection area is shown in Figure 2.6 and $A c=53,940 \mathrm{~m}^{2}$. $\mathrm{Nd}$ is found nearly 0.089 and $\mathrm{Nc}$ is obtained as $8^{*} 10^{-4}$ from Eq. 2.1 and Eq. 2.4 , respectively. In this case, $\mathrm{Nd}>\mathrm{Nc}$. Therefore protection is required. The effectiveness, E is calculated as 0.99 from Eq. 2.5, which corresponds protection level 1 and additional measures according to Table 2.3.

On the other hand, British Standard determines the weighting factors as following: $A=1.0$; $B=0.1 ; C=0.3 ; D=1.0 ; E=0.3$. According to Table 2.6, $\mathrm{Ng}$ is found as 1.1. The collection area is given in Figure 2.7 and $A c=9,555 \mathrm{~m}^{2}$. Nd is found nearly 0.01 from Eq. 2.6 and $p$ is $10^{-5}$. Overall risk factor is found $9.5^{\star} 10^{-5}$ by multiplying $\mathrm{Nd}$ by weighting factors. In this case, the overall risk factor is greater than the acceptable risk, $\mathrm{p}$. Therefore; protection is required.

To calculate the effectiveness, $E$ and determine the protection requirement, Eq. 2.13 and Eq. 2.14 should be used. According to these derived equations, $\mathrm{Nd}^{\prime}=1.2^{*} 10^{-2}$ and $\mathrm{Nc}^{\prime}=1.1^{*} 10^{-3}$, respectively. ( $\mathrm{Nd}^{\prime}>\mathrm{Nc}$ ', therefore protection is required). Effectiveness, $\mathrm{E}$ is found nearly 0.91 which corresponds protection level 2 according to Table 2.3 .

If protection requirement according to the American Standard is examined, the index values are determined as $A=5 ; B=1 ; C=10 ; D=1 ; E=4 ; F=7$. According to Eq. 2.8, the risk index, $R$ is calculated as 3 that the case corresponds to risk value of Moderate.

Finally, if Turkish draft is concerned, the coefficients are determined as following: $A 1=4.0$; $A 2=4.0 ; A 3=2.0 ; A 4=1.0 ; B 1=1.0 ; B 2=1.0 ; B 3=1.0 ; B 4=1.0 ; C 1=1.0 ; C 2=0.01 ; C 3=1.0$ and $\mathrm{Ce}=0.25$. According to Eq. $2.10, \mathrm{Ng}$ is found as 1.7. The collection area is shown in Figure 2.6 and $A c=53,940 \mathrm{~m}^{2}$. In this case, $A$ is $32, B$ is 1 and $C$ is 0.01 . Nd is found nearly $2.3^{*} 10^{-2}$ and $\mathrm{Nc}$ is obtained as 0.32 from Eq. 2.9 and Eq. 2.12, respectively. In this case, $\mathrm{Nd}<\mathrm{Nc}$. Therefore, there is no protection requirement.

To sum up, this time, the case is not as important as the hospital case. It is expectable for the hospital case resulting in the highest protection levels. However; in this case, the Spanish Standard determines protection level 1 and additional measures which shows the most risky case. Protection level 2 is obtained according to the British Standard. Moderate risk value determined from the American Standard could be interpreted as protection level 3 
when compared to IEC norms. According Turkish Standard, there is no need for any lightning protection.

This case surprisingly results in different protection levels according to different standards. Consequently, a problem arises now: Which result is correct? If the correct one is not applied, this case corresponds to two results: 1) unnecessary protection is applied and it is waste of money or 2) the required protection is not applied and it leaves the structure unsafe against lightning.

In engineering, money and safety are the two most important criteria to be considered. In this case, both are under risk and there is an engineering problem when any protection system is applied.

\subsection{Modifications Offered to Eliminate Conflicts among the Standards}

The conflicts in the results can be eliminated with some assumptions and modifications in acceptable risk frequencies. The weighting factors should be modified if necessary. This is done in the following example. The most meaningful "acceptable risk factor" assumption is in the British Standard if the reviewed standards are considered. This is taken as the basis of risk factor for other standards.

The characteristics of the structure considered in this case are the same as the above example. The ceraunic level chosen is 20 , which is the average figure in Turkey. The dimensions of the structure are $20 \mathrm{~m}^{*} 20 \mathrm{~m}^{*} 20 \mathrm{~m}$, which corresponds to a plan area of $400 \mathrm{~m}^{2}$ $\left(4 * 100 \mathrm{~m}^{2}\right)$ and 6 floors. From these assumptions, according to BS, the protection requirement of the defined structure is calculated as below:

$A=1.0 ; B=0.1 ; C=0.3 ; D=1.0 ; E=0.3$. According to Table 2.1, $\mathrm{Ng}$ is found as 1.1. The collection area obtained according to Eq. 2.7 is $3,257 \mathrm{~m}^{2}$ where $\mathrm{L}=20 \mathrm{~m}, \mathrm{~W}=20 \mathrm{~m}$ and $\mathrm{H}=20$ $\mathrm{m}$ for a simple rectangular prism shaped structure. From these data, $\mathrm{Nd}$ is found to be as $3.94^{*} 10^{-3}$ using Eq. 2.13. According to Eq. $2.14, \mathrm{Nc}$ is equal to $1.1^{*} 10^{-3}$.

$\mathrm{Nd}>\mathrm{Nc}$, therefore protection is required. $\mathrm{E}$ is obtained as 0.72 , which corresponds to protection level 4 according to IEC. For the common structures, protection level 4 should be an expected result due to no consequential effects on the environment, no explosion risks and simple, not valuable contents of this common structure. 
The modifications in other standards should be done with the assumption of $E=70$ corresponding to protection level 4 for the same structure analysis.

To begin with Spanish Standard, the coefficients are determined as following: $\mathrm{C} 1=0.5$; $\mathrm{C} 2=0.5 ; \mathrm{C} 3=0.5 ; \mathrm{C} 4=3.0 ; \mathrm{C} 5=5.0$. ( $\mathrm{C}$ is found to be 3.75). According to Eq. $2.2, \mathrm{Ng}$ is found as 3 . The collection area, $A c=16,510 \mathrm{~m}^{2}$.

$\mathrm{Nd}$ is found nearly 0.027 . When $\mathrm{E}$ is taken as 0.70 then $\mathrm{Nc}$ is obtained as $8.1^{*} 10^{-3}$ from Eq. 2.5. According to Nc value obtained and weighting factors, Eq. 2.4 should be modified as follows:

$\mathrm{Nc}=0.03 / \mathrm{C}$

On the other hand, the American Standard does not require any modification. The reason is that this standard has different determination methods for the protection requirement than others and the results. Besides this, the results of both British and American Standards are similar although they have different procedures.

Finally, the Turkish Standard should need a modification, too. For the same case, the coefficients for a common structure are: $A 1=4.0 ; A 2=4.0 ; A 3=2.0 ; A 4=1.0 ; B 1=1.0 ; B 2=1.0$; $B 3=1.0 ; B 4=1.0 ; C 1=1.0 ; C 2=0.01 ; C 3=1.0$ and $C e=0.25$. According to Eq. $2.10, \mathrm{Ng}$ is found as 1.7. The collection area, $A c=16,510 \mathrm{~m}^{2}$ as in Spanish Standard.

In this case, $A$ is $32, B$ is 1 and $C$ is 0.01 . Nd is found to be $7.7^{*} 10^{-3}$ if safety coefficient equal to 1.1 is added in Eq. 2.9. When $E$ is taken as 0.70 than $\mathrm{Nc}$ is obtained as $8.4^{*} 10^{-3}$ from Eq. 2.5. According to Nc value obtained and weighting factors determined, a coefficient equal to 7.25*10 $0^{-3}$ should be inserted in Eq. 2.12. As a result, Eq. 2.12 should be modified as follows:

$\mathrm{Nc}=7.25^{*} 10^{-3 *}\left(\mathrm{~A}^{*} \mathrm{~B}^{*} \mathrm{C}\right)$

After these modifications in the standards, Example-3 should be examined again. It should be remembered that in that case, different protection levels are obtained according to different standards reviewed.

According to Spanish Standard, $\mathrm{Nd}$ calculated is 0.089 . $\mathrm{Nc}$ is obtained as 0.008 . $\mathrm{Nd}>\mathrm{Nc}$, thus protection is required. The effectiveness becomes 0.91 , which corresponds to protection level 2. 


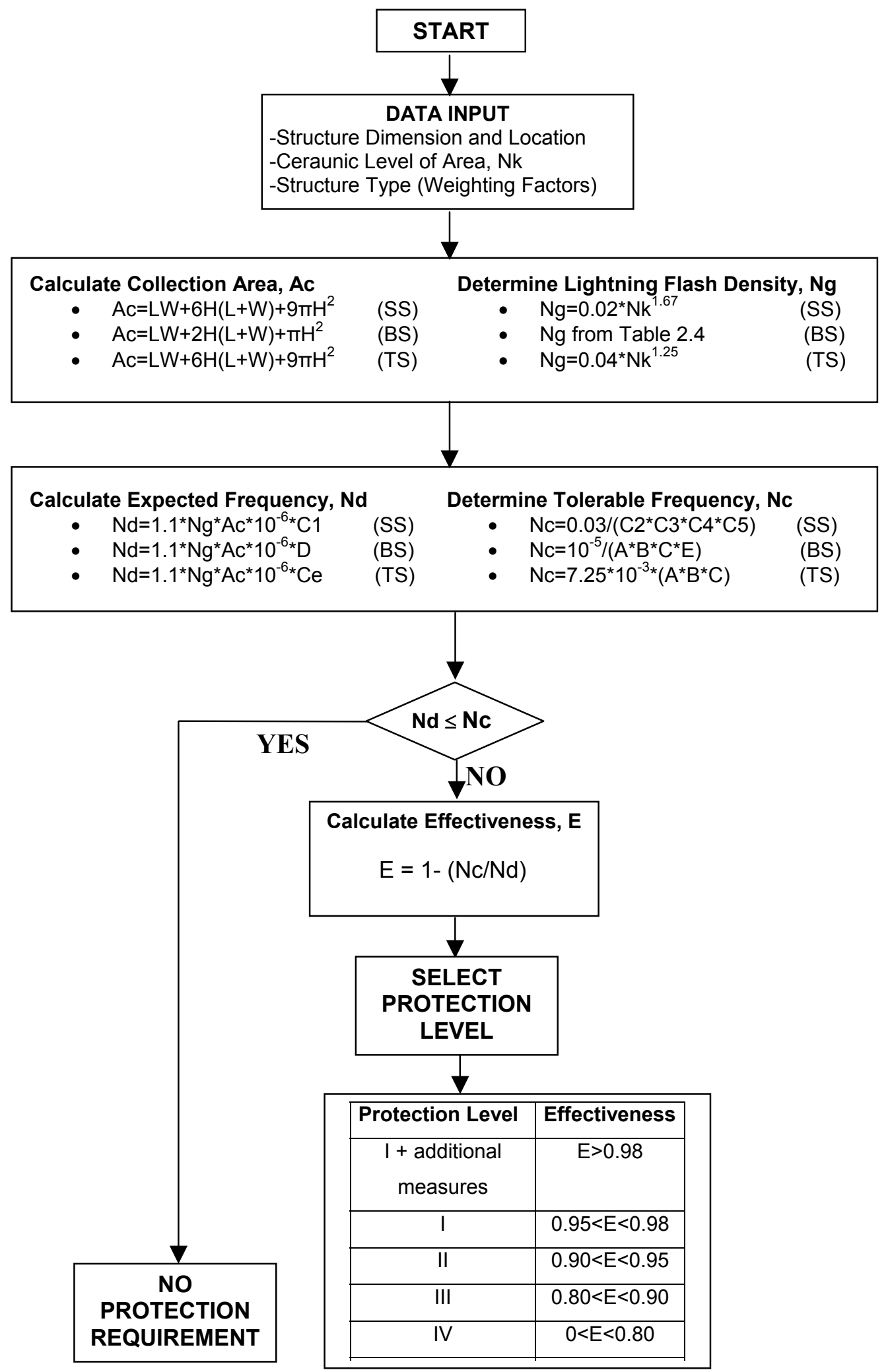

Figure 2.8 Flow Diagram for Protection Requirement according to Different Standards 
There is no change in calculation according to British Standard. BS states that protection 2 is required. In addition, the procedure has not changed in the American Standard. Therefore, it determines the risk as moderate, which corresponds to protection level 2.

Finally, when the protection requirement procedure given in Turkish Standard after modification is used; $\mathrm{Nc}$ is calculated as $2.11^{*} 10^{-3}$. $\mathrm{Nd}$ is $2.3^{*} 10^{-2} . \mathrm{Nd}>\mathrm{Nc}$; therefore protection is required. Effectiveness is equal to 0.91 that corresponds to protection level 2 .

In conclusion, after the modifications, the results of the procedures in the reviewed standards become the same and protection level 2 is determined. The results are the same if case 1 in example-2 is considered again. This time all the standards result in protection level 1 except the American Standard, additional measures are required. Besides these, some other cases are analysed and it is seen that these derived equations work to give the same protection levels.

In Figure 2.8, the flow diagram for protection requirement according to different reviewed standards is given. It should be noted that the American Standard is not considered in the diagram due to its different procedure. The last form of the modified and derived equations are put in the flow diagram to satisfy the uniqueness of the reviewed standards. 


\section{CHAPTER 3}

\section{LIGHTNING PROTECTION}

\subsection{Introduction}

In the latter part of the eighteenth century, Benjamin Franklin proposed the original concept of LPS's for buildings. His well-known idea was to position a metallic lightning rod (called an air terminal in modern parlance) above the building to intercept lightning flashes that otherwise would strike the building. ${ }^{18}$ The lightning rods were attached to down conductors, which were in then connected to ground rods driven into the soil near the building.

Franklin thought that his LPS achieved two functions: to divert the lightning flash from the building and conduct its energy harmlessly to ground, and to dissipate the electrical energy in the cloud and thus prevent damages arising from lightning flashes.

Originally, there was no indication of the shielding angle provided by these rods. These were developed later using rolling sphere concept. All other protection methods are based upon the rolling sphere method although these are not in historical order. The shielding angles are determined and mesh sizes are chosen according to the rolling sphere method.

\subsection{Rolling Sphere Method}

Observations show that a lightning stroke appears as if a fictitious sphere of radius $\mathrm{R}$ was centred on and moving rigidly with the downward leader head. ${ }^{19}$ Considering a simple rod of height $\mathrm{h}$ relative to the reference surface (building roof, ground etc.), there are 3 possibilities according to Figure 3.1 given below:

- if the sphere comes into contact with the vertical rod $(A)$ only, the vertical rod will be the strike point,

- if the sphere comes into contact with the reference surface and not with the vertical rod, the strike point will be on the ground at S only, 
- if the sphere is exposed to both the simple rod and the reference surface at the same time, there are two possible strike points: $A$ and $C$, but the lightning discharge will never strike the hatched area.

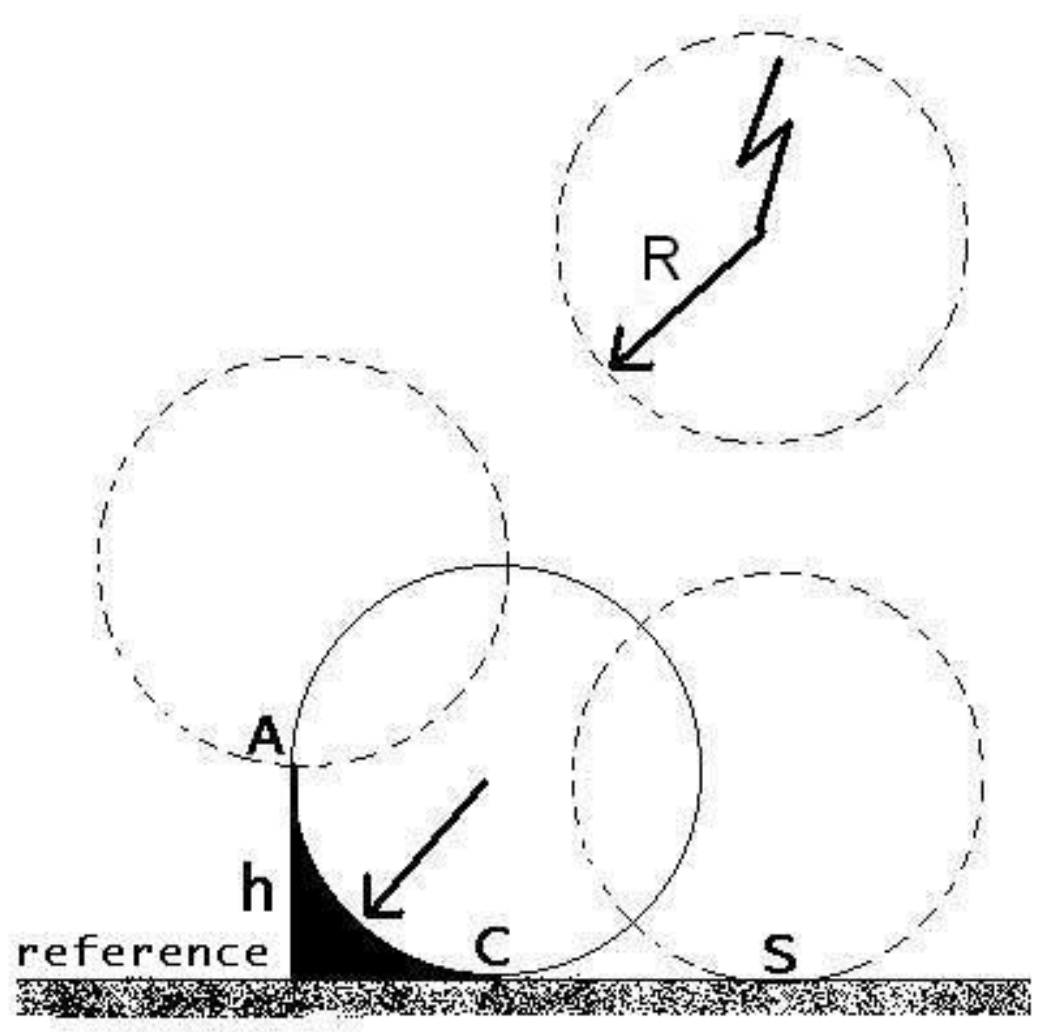

Figure 3.1 Rolling Sphere Method

In the late fifties and the beginning of the sixties, the discrepancies between the expected performance and the actual service performance stimulated a general interest in investigations of the effect of the ground wires on different power lines, and the influence of their geometry, heights, and the shielding failures experienced.

Based on these results, a lightning flash model was established ${ }^{20}$ in which the final flashover (striking distance R) between the leader and the protection system depended on the current in the following lightning stroke. The striking distance increases with the lightning current according to the formula:

$R=2^{*} I_{O}+30^{*}\left(1-e^{-10 / 6.8}\right)$ 
Or the more simple expression:

$\mathrm{R} \approx 9.4 * 10^{2 / 3}$

for $\mathrm{R}$ in meters and lo in $\mathrm{kA} .^{21}$

In the case of a simple rod, according to the electro-geometrical model, the striking point is determined by the ground object that is the first one to be located at a distance $\mathrm{R}$ from the downward leader even though this object is the flat ground itself. ${ }^{22}$ According to Spanish Standard, the striking distance is formulated as follows where $I$ is the peak current of the first stroke in kA's and R is used instead of D. It should be noted that Eq. 3.2 and Eq. 3.3 are nearly the same. The Spanish Standard could be thought to take the initiation distance formulation as rounded for easy calculation.

$R(m)=10 * 10^{2 / 3}$

In Figure 3.2, the equations Eq. 3.1 to Eq. 3.3 are plotted. It should be noted that there are no significant deviations.

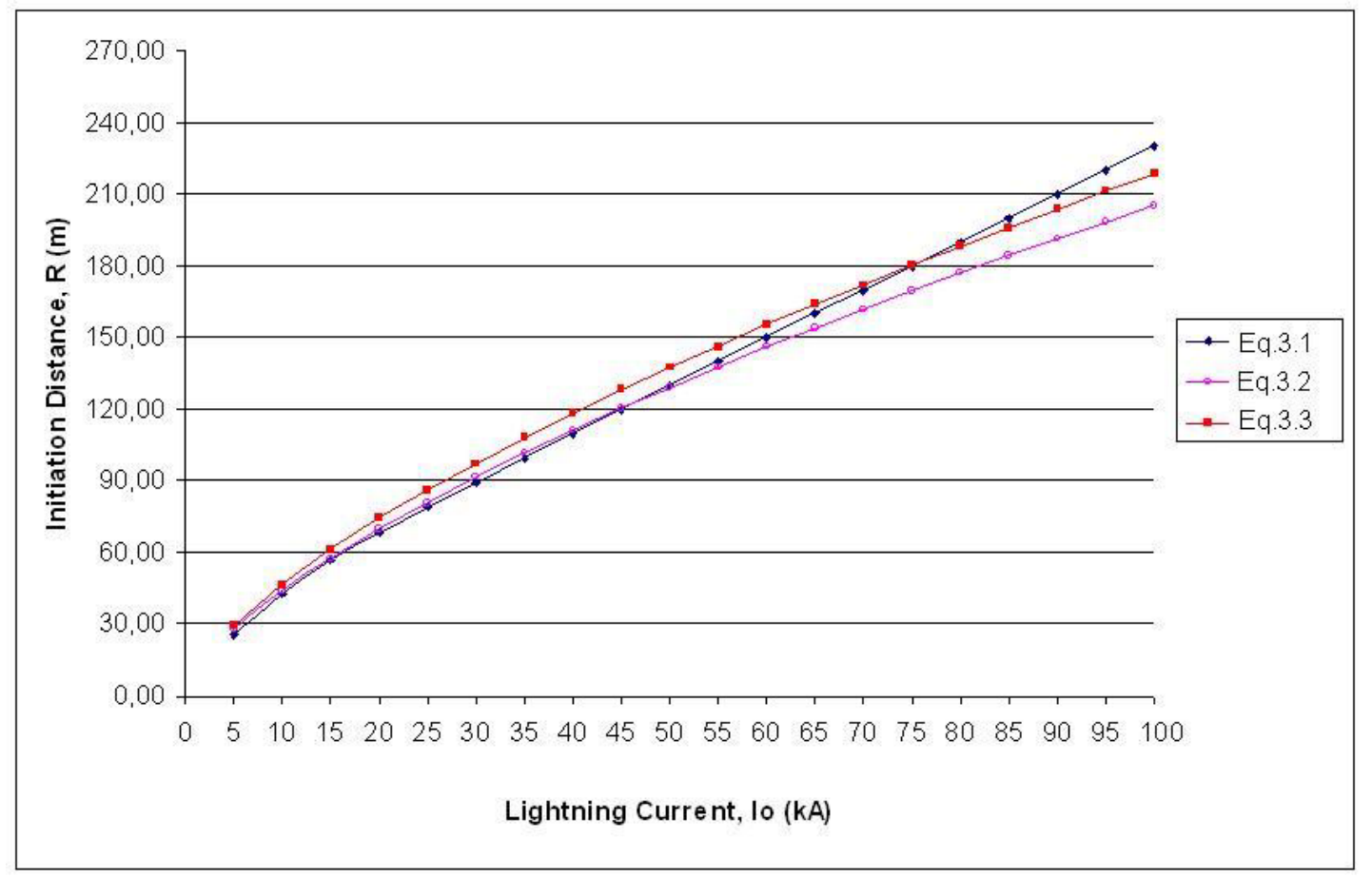

Figure 3.2 Plots of Eq. 3.1, Eq. 3.2 and Eq. 3.3 
The Figures 3.3 and 3.4 given below show the basic applications of the rolling ball method. In Figure 3.4, there is a similar shape with the one in Figure 3.3. However, this time, the reference plane is slope and $h_{t}>R$.

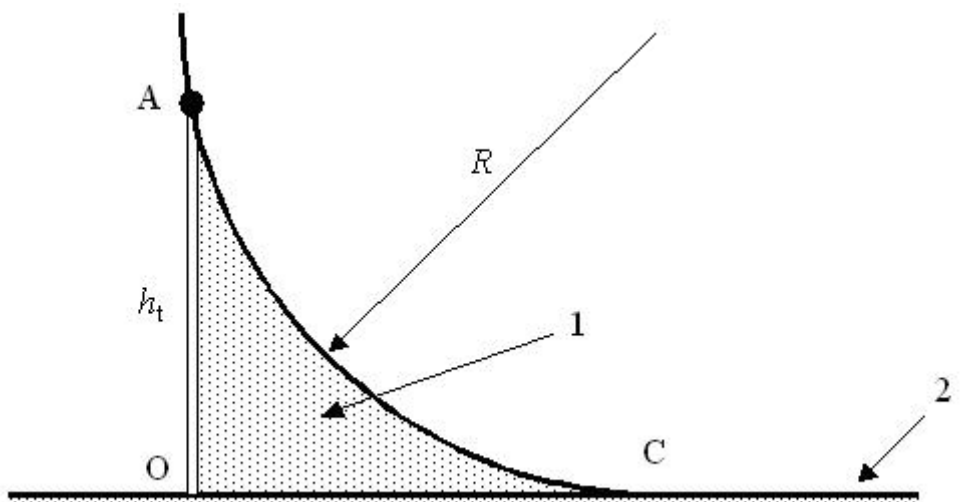

Figure 3.3 The area protected by an ATS $\left(h_{t}<R\right)$

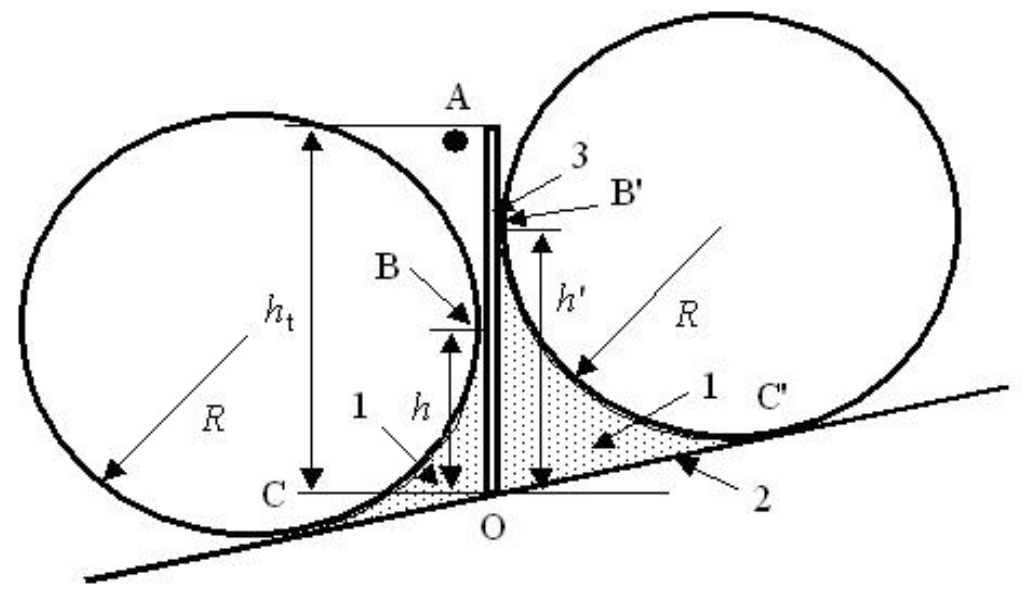

Figure 3.4 The area protected by an ATS $\left(h_{t}>R\right)$

where

1: protected area

2: reference plane, ground

3: air termination conductor 

$\mathrm{R}$ : radius of rolling ball
$\mathrm{h}, \mathrm{h}$ ': air termination conductor heights
$h_{t}$ : height of air termination conductor with respect to reference plane
A: a point on the air termination system (ATS)
$B, B$ ': touch points of rolling ball to the conductor
C, C': touch points of rolling ball to the ground

Apart from Figures 3.3 and 3.4, the following figure shows the application of rolling sphere method with two vertical conductors.

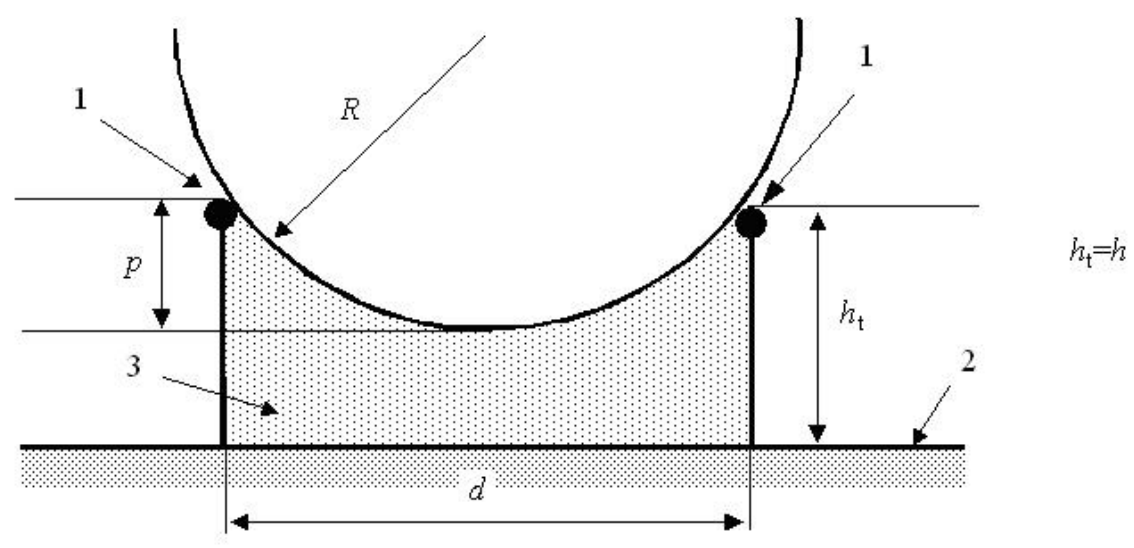

Figure 3.5 The protected area with two vertical conductors $\left(h_{t}<R\right)$

where

1: ATS with two conductors

2: reference plane, ground

3: protected area

$h_{t}$ : height of air termination conductor with respect to reference plane

$\mathrm{h}$ : air termination conductor height

$\mathrm{R}$ : radius of rolling ball

$\mathrm{d}$ : distance between two air termination conductors

$p$ : penetration depth of rolling ball $\left(p<h_{t}\right)$ obtained from Eq. 3.4 below:

$p=R-\left[R^{2}-(d / 2)^{2}\right]^{1 / 2}$ 


\subsubsection{Derivation of Shielding Angles}

As noted in introduction that Franklin did not think of any shielding angles of simple rods. The shielding angles are assigned later and a method is formed called "shielding angle method". However, if the concept is analysed in detail, the shielding angles are obtained from the application of rolling sphere method. Thus, there is no need to introduce a different method.

It should be noted in Figure 3.6 given below that according to shielding angle assigned, the protected area is shown with dots covered by shielding angle $\alpha$ around the Franklin rod with height of $h$. On the other hand, the rolling sphere method determines an additional hatched area as shown in Figure 3.6. The shielding angles are obtained from equalization of the protected areas to satisfy such a unique protected area. J. Wiesinger introduced such a derivation ${ }^{23}$ equalizing the protected areas.

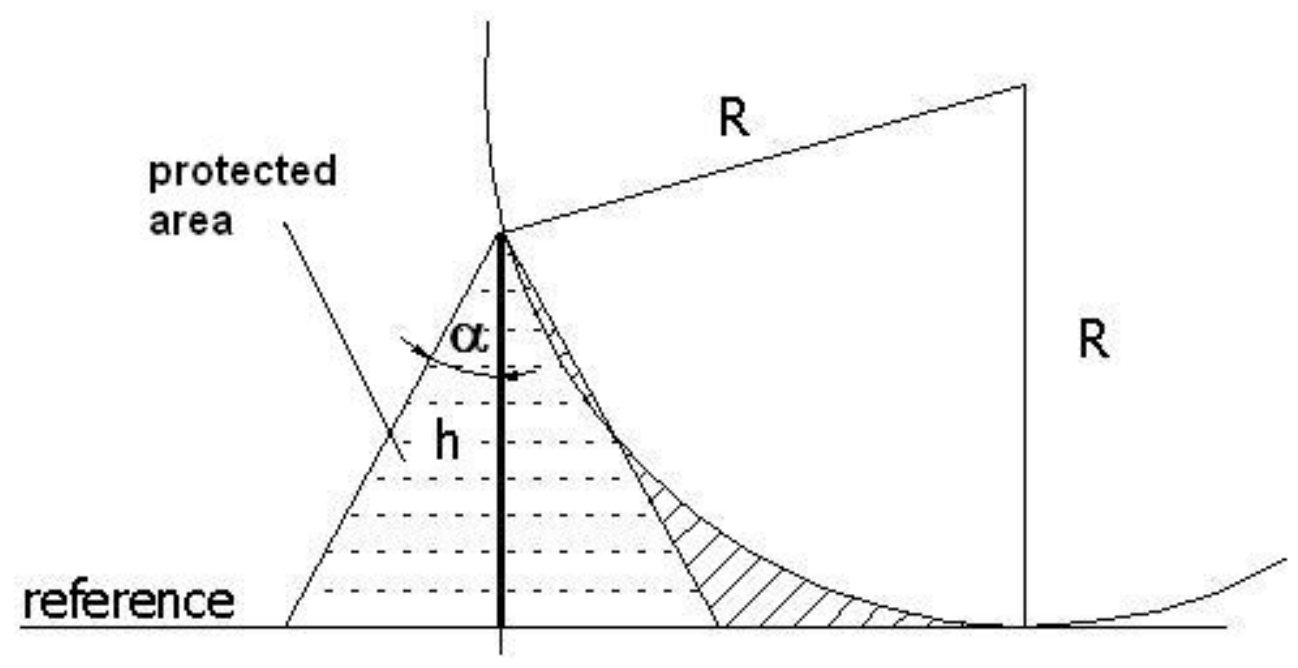

Figure 3.6 Sample for Derivation of Shielding Angles of Franklin Rod

It should be noted that in Figure 3.7, the protected area border of shielding angle is perpendicular to the rolling sphere. Therefore, the protected area by angle is out of the area protected by rolling sphere and area protected by rolling sphere covers the area protected by angle. J. Wiesinger uses this modelling for conservative calculation. However, in Figure 3.8 
given for the equalizing calculation, some part of the protected area by angle is in the area protected by rolling sphere.

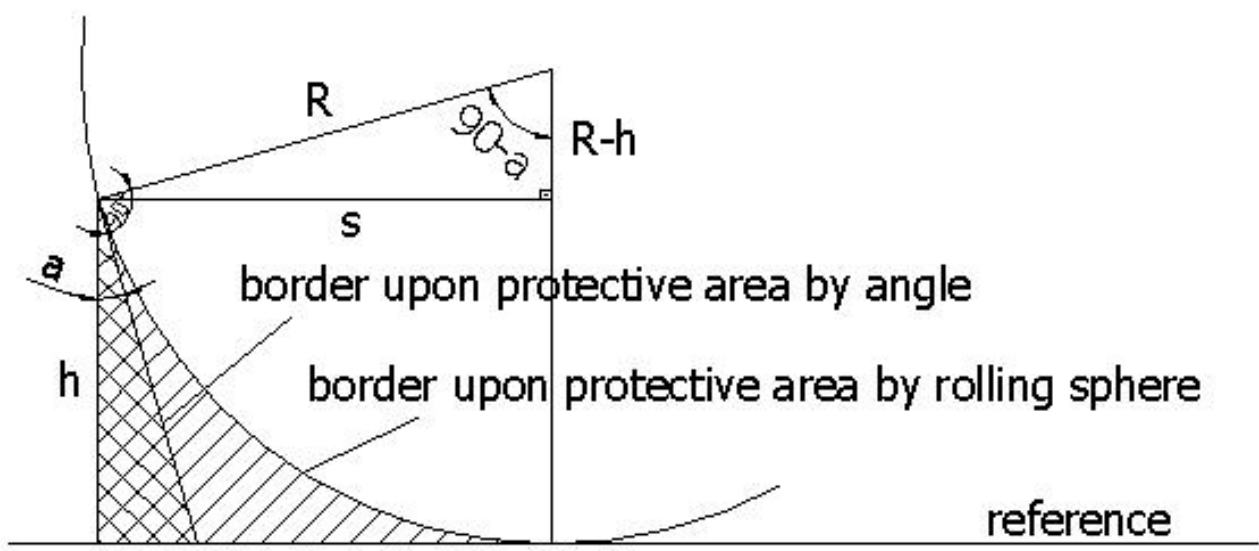

Figure 3.7 Figure used for Conservative Calculation

From Figure 3.7, the conservative calculation is done by the equations given below with the assumption that $R \geq h$. The hypothesis is that the border upon protective area by angle is tangent to the border upon protective angle by rolling sphere.

$S=\left(R^{2}-(R-h)^{2}\right)^{1 / 2}$

$a=\arctan [(\mathbf{R}-\mathbf{h}) / \mathrm{S}]$

In equalizing calculation, the hypothesis is that the protective area by angle ( $\mathrm{Aa}$ ) is equal to the protective area by rolling sphere (As), i.e., $\mathrm{Aa}=\mathrm{As}$. Then the derivation is given below:

$A a=1 / 2 * h^{2 *} \tan b$

(Eq. 3.7)

$A r=s^{*} h+1 / 2^{*} s^{*}(R-h)-\pi^{*} R^{2 *}(c / 2 \pi)$

(Eq. 3.8)

$C=\arccos [(R-h) / R]$

(Eq. 3.9) 


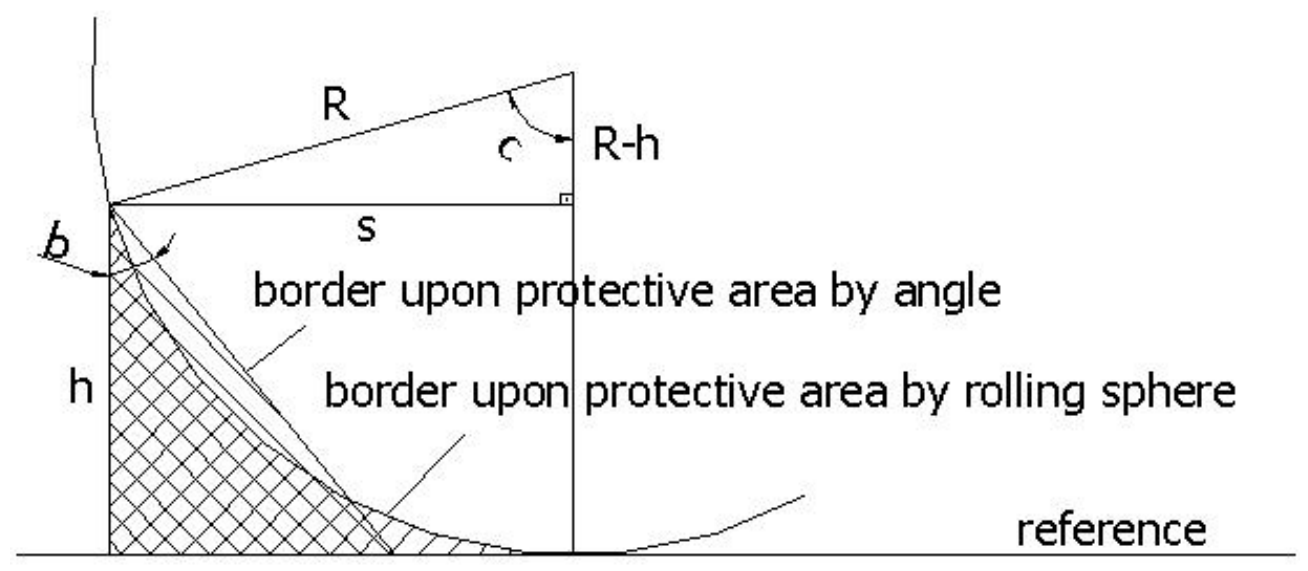

Figure 3.8 Figure used for Equalizing Calculation

To obtain a general formula for the shielding angle depending on the $R$ and $h$ values, Eq. 3.7 and Eq. 3.8 are equalized to satisfy the protective area by angle (Aa) is equal to the protective area by rolling sphere (As).

$1 / 2^{*} h^{2 *} \tan b=s^{*} h+1 / 2^{*} s^{*}(R-h)-\pi^{*} R^{2 *}(c / 2 \pi)$

$b=\arctan \left\{s / h+s^{*} R / h^{2}+R^{2} / h^{2 *} \arccos [(R-h) / R]\right\}$

Table 3.1 Shielding angles $a, b$ as a function of $R$ and $h$

\begin{tabular}{|c|c|c|c|c|c|c|c|}
\hline \multicolumn{2}{|c|}{$\mathbf{R}(\mathbf{m})$} & $\mathbf{1 0}$ & $\mathbf{2 0}$ & $\mathbf{3 0}$ & $\mathbf{4 0}$ & $\mathbf{5 0}$ & $\mathbf{6 0}$ \\
\hline $\mathbf{a}$ & 20 & 30.0 & 0 & $*$ & $*$ & & \\
$\mathbf{b}$ & & 45.2 & $23.2^{*}$ & & & & \\
\hline $\mathbf{a}$ & \multirow{2}{*}{30} & 41.8 & 19.5 & 0 & $*$ & & \\
b & & 54.0 & 37.4 & $23.2^{*}$ & & & \\
\hline a & \multirow{2}{*}{40} & 48.6 & 30.0 & 14.5 & 0 & & \\
b & & 59.0 & 45.2 & 33.8 & $23.2^{*}$ & & \\
\hline a & \multirow{2}{*}{50} & 53.1 & 36.9 & 23.6 & 11.5 & 0 & \\
b & & 62.4 & 50.3 & 40.5 & 31.6 & 23.2 & \\
\hline a & \multirow{2}{*}{60} & 56.4 & 41.8 & 30.0 & 19.5 & 9.59 & 0 \\
b & & 64.9 & 54.0 & 45.2 & 37.4 & 30.2 & 23.2 \\
\hline
\end{tabular}


According to derived formulas given in Eq. 3.6 and Eq. 3.11, the table given below is obtained as a function of $R$ and $h$, i.e., $f(R, h)=a, b$ where $R$ is the radius of rolling sphere and $\mathrm{h}$ is the height of air termination.

\subsubsection{Application of Shielding Angles}

It should be noted that the shielding angle $\alpha$ given in Table 3.2, which is taken from IEC $1024-1$, is the angle $b$ derived from the equalizing calculation. For $R<h$, the shielding angle is not used. Instead, rolling sphere and cage method is recommended which will be studied at the end.

Table 3.2 Positioning of simple rod according to protection level

\begin{tabular}{|c|c|c|c|c|c|}
\hline \multirow{2}{*}{$\begin{array}{c}\text { Protection } \\
\text { level* }^{*}\end{array}$} & \multirow{2}{*}{$R(m)$} & 20 & 30 & 45 & 60 \\
\hline & & $\alpha^{(0)}$ & $\alpha^{(0)}$ & $\alpha^{(0)}$ & $\alpha^{(0)}$ \\
\hline$I$ & 20 & 25 & * & * & * \\
\hline II & 30 & 35 & 25 & * & * \\
\hline III & 45 & 45 & 35 & 25 & * \\
\hline IV & 60 & 55 & 45 & 35 & 25 \\
\hline
\end{tabular}

For application of shielding angles, the area, structure etc. to be protected is covered by $\alpha$ angle between the air termination conductors in vertical space forming a conical shape per one tip.

The protection area changes in accordance with the protection level of the imaginary shielding angle around the sharp end, the length and the height of the rod that can be interpreted from Table 3.2. In Figures 3.9, 3.10 and 3.11, some applications are shown:

where
A: the tip of air termination conductor
$B$ : the reference plane
OC: radius of the protected area
$h_{t}$ : height of air termination conductor with respect to reference plane
$\alpha$ : shielding angle 


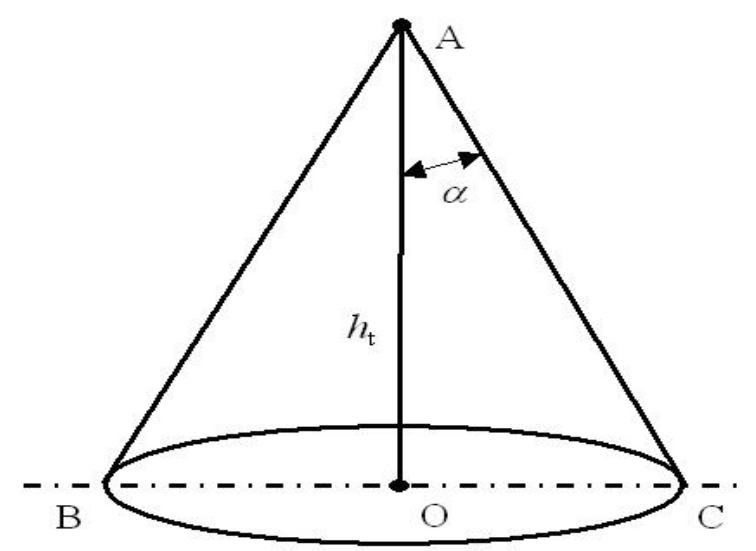

Figure 3.9 One conical protected area per one conductor

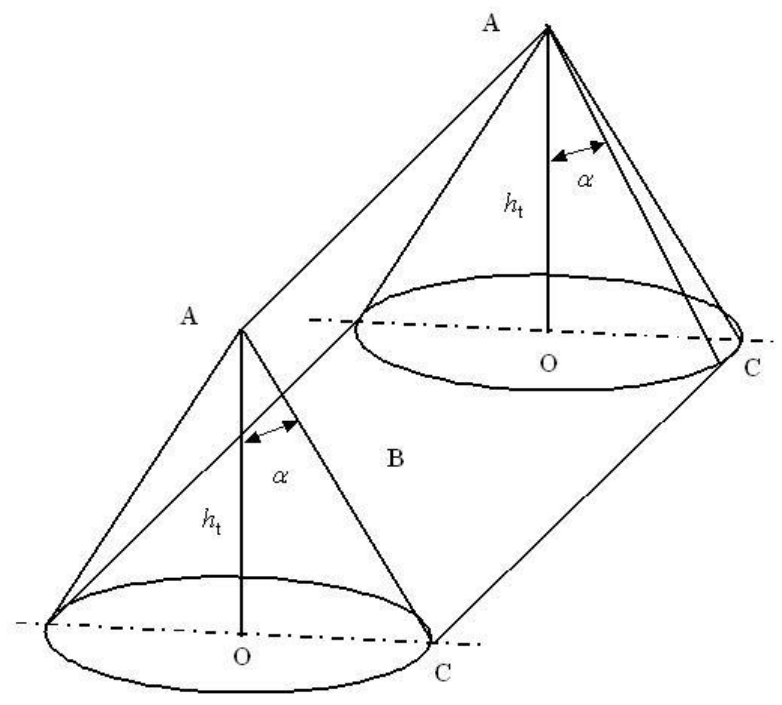

Figure 3.10 Protected area for horizontal conductor between A-A tips

Figure 3.11 shows choosing different angles for different heights of conductor tips with respect to reference planes.

where

$h_{t}$ : physical height of air termination conductor

$\alpha_{1}$ corresponds to $h_{1}$ height of conductor

$\alpha_{2}$ corresponds to $h_{2}$ height $\left(h_{t}+H\right)$. 


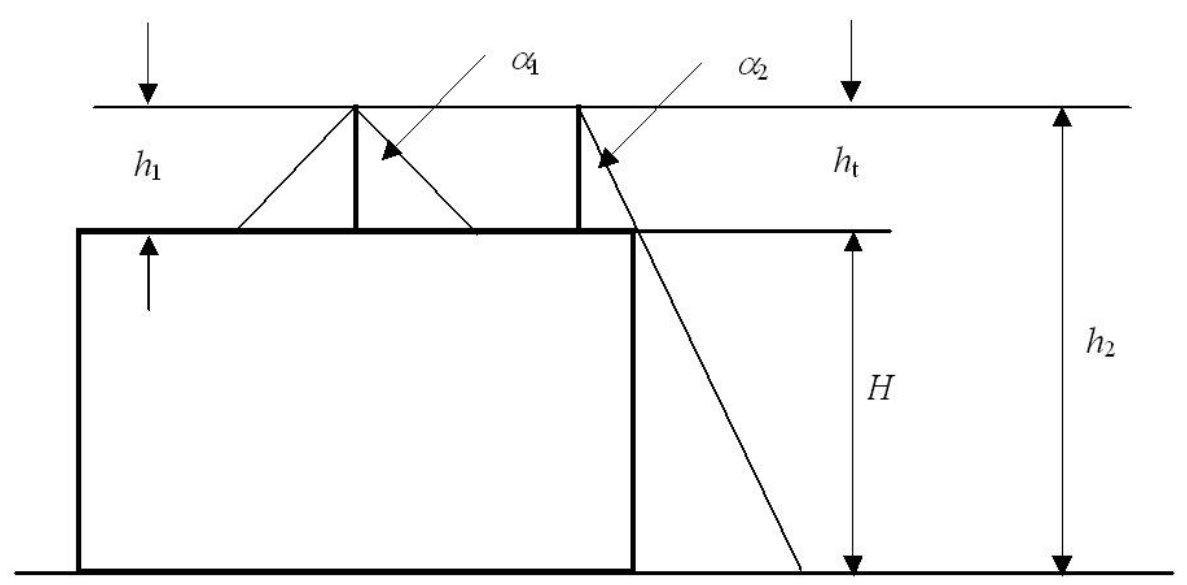

Figure 3.11 LPS design

using protection angle method with different heights

\subsection{Early Streamer Emission (ESE) Air Terminals}

The main objective of the ESE air terminals is to produce ionisation around the lightning rod and to attract strokes before hitting the earth or the structures. The claimed function of an active ESE device is the triggering of an early upwards streamer/leader at a time, $\Delta \mathrm{T}$, earlier than the triggering time of a simple lightning rod. The time difference, $\Delta \mathrm{T}$, is defined as the time advantage. It is proposed that this time advantage be multiplied by a constant velocity of the upwards-progressing discharge. The velocity multiplied by $\Delta T$ determines the length, $\Delta$ $\mathrm{L}$, of the triggered discharge. There are a few type of ESE air terminals developed to increase the effectiveness of simple Franklin rods.

\subsubsection{Radioactive Lightning Arresters}

In 1914, the Hungarian physicist L. Szillard raised the question of whether the attractive effect of a normal lightning rod could be increased by the addition of a radioactive source. In the application of his theory, the lightning rod was fitted with Am-241 isotope.

The radiated Alpha particles (Berio in 1970 stated that the emission is $1.4^{*} 10^{22}$ ion pairs per second) of Am-241 isotope produce high ionisation currents around the sharp end of the rod. According to theory, this increases the capture discharge and would ensure protection within a radius of $250 \mathrm{~m}$. 
However, Cassie showed that the space charged produced by Alpha-rays cannot affect the path of the leader and that the ion density at the cloud base due to a radioactive source is negligible compared with that arising from the background ionisation level. ${ }^{24}$ In addition, he calculated that with increasing height, the number of radiated ions decreased rapidly.

The investigations showed that the radioactive lightning conductors are no more effective than usual conductors are. This conclusion is supported with many lightning disasters that structures having a radioactive lightning arrester on top was not protected. It was seen that the lightning stroke a distance near $150 \mathrm{~m}$ of a radioactive lightning arrester was not caught while in the theory it was being thought to have a protection within a radius of $250 \mathrm{~m}$.

In Europe, the usage of radioactive lightning arresters was prohibited. In Turkey, the usage of type Ra-226 was forbidden in 2001. Since then, active type of ESE air terminals were developed.

\subsubsection{Active type ESE Air Terminals}

There are two types of active type ESE air terminals one of which is Active Lightning Arrester with Piezoelectric Crystal and the other is Active Lightning Arrester Having Atmospheric Field Effect. A piezoelectric crystal-Zirkotitanat (placed in the head of the lightning arrester) produces high voltage pulses (it is from $2.5 \mathrm{kV}$ to $6.5 \mathrm{kV}$ ) when it is vibrated (In the thunderstorm, the head goes under turbulence that causes vibration). The crystal in the head carries these pulses to the head through an isolated cable and it is claimed to produce ionisation to catch the strokes.

On the other hand, active lightning arresters having atmospheric field effect are claimed to work according the principle similar with the radioactive lightning arresters. Before the lightning stroke, with the effect of rapid increase in the electrical field, the head produces high voltage for ionisation. In some products ${ }^{25}$, the ion generator is covered with a sphere. There is a disc around this sphere producing high ionisation current with the effect of the atmospheric field in thunderstorms.

It should be necessary to compare the ESE type air terminals with simple Franklin rods. According to rolling sphere method, in the case of using Franklin rods, the possible strike points are $A$ and $C$ as shown in Figure 3.12 with a protection radius $R_{P}$.

$R_{p}{ }^{2}=R^{2}-(R-h)^{2}$ 
where

$R$ is the striking distance

$\mathrm{h}$ is the Franklin rod tip height above the surface to be protected.

$\mathrm{R}_{\mathrm{P}}$ is the Franklin rod protection radius

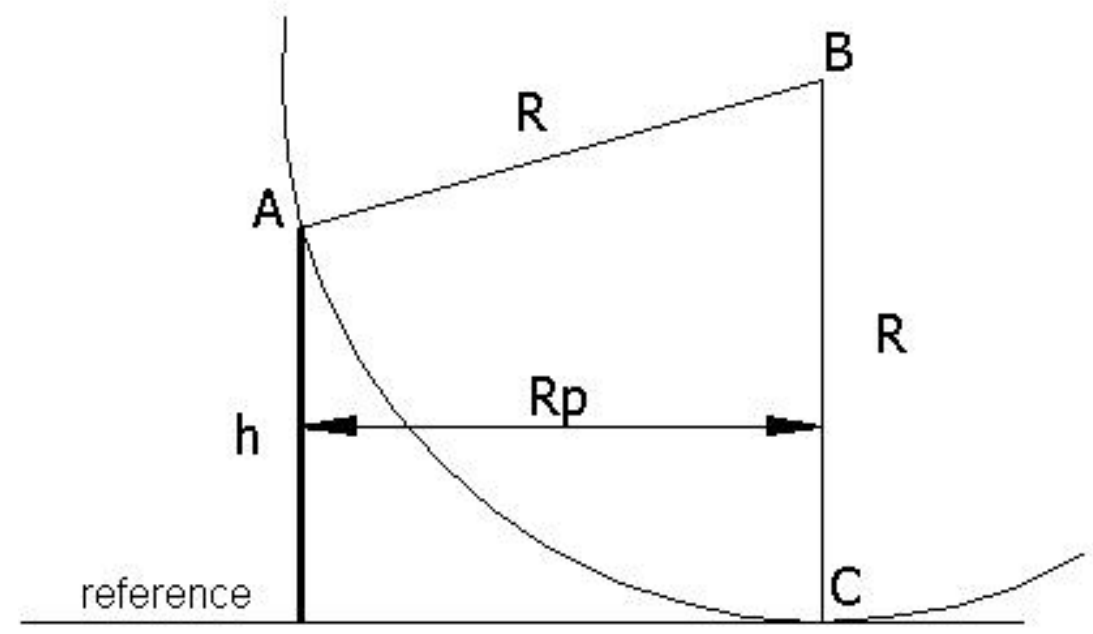

Figure 3.12 Protection Radius of Franklin Rod (simple rod)

On the other hand, the philosophy of the promoters of ESE rods is, that an ESE rod of the length $L$ gives the same protection as a simple lightning rod (Franklin rod) of length, $L$, plus the above-mentioned $\Delta \mathrm{L}$, i.e., $\mathrm{L}+\Delta \mathrm{L}$ as shown in Figure 3.13. It should be noted that the difference from the simple Franklin rod is claimed to be $\Delta R_{p}$. If Figure 3.13 is compared with Figure 3.12, with the triggering advance of $\Delta \mathrm{L}$, the protection radius is increased from $R_{P}$ to $\mathrm{R}_{\mathrm{P}}$. Therefore, the protected area is increased. According to ESE method and theory, this is the advantage of ESE lightning conductor compared to Franklin rods.

Since 1995, the scientific tests for measuring the $\Delta \mathrm{T}$ early ionisation (streamer) time under laboratory conditions. The Spanish Standard describes the protection radius of an ESE lightning conductor as follows:

In the case of an ESE lightning conductor of triggering advance $\Delta \mathrm{T}$, and with $\Delta \mathrm{L}=\mathrm{V}^{*} \Delta \mathrm{T}$, and the possible strike points are $A$ and $C^{\prime}$ as shown in Figure 3.13 with a protection radius $\mathrm{R}_{\mathrm{P}}$ such that: 
$\mathbf{R}_{\mathrm{p}}^{\prime}{ }^{2}=\mathbf{2} \mathbf{R} \mathbf{h}-\mathbf{h}^{2}+\Delta \mathbf{L}^{*}(\mathbf{2} \mathbf{R}+\Delta \mathbf{L})$ for $\mathrm{h} \geq 5 \mathrm{~m}$

where

$R$ is the striking distance

$\Delta \mathrm{L}$ is the upward leader length gain defined by $\Delta \mathrm{L}=\mathrm{v}^{*} \Delta T$,

$h$ is the ESE lightning conductor tip height above the surface to be protected.

$R_{P}^{\prime}$ is the ESE lightning conductor protection radius,

$\Delta \mathrm{T}$ is the triggering time of advance for the ESE lightning conductor.

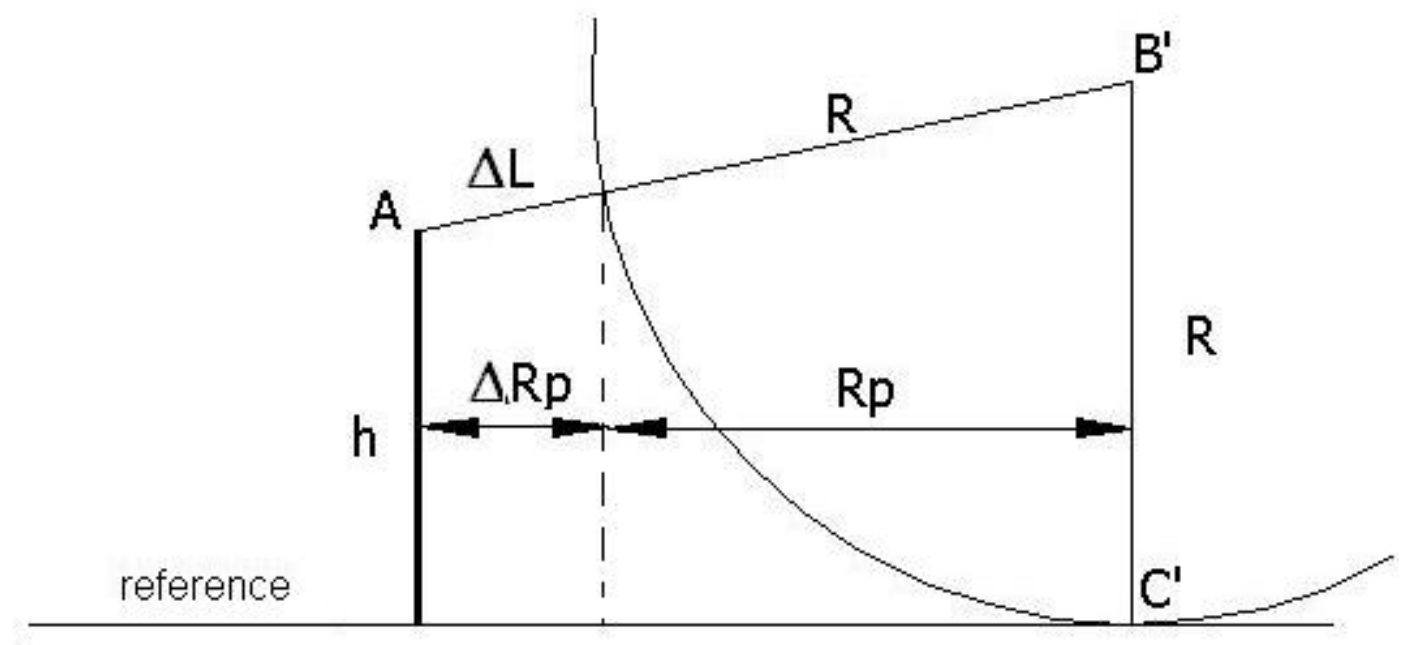

Figure 3.13 Protection Radius of an ESE Lightning Conductor

$\Delta \mathrm{L}$, the triggering advance of the ESE lightning conductor considered is selected from the product sheets of the manufacturers some examples of which are given in Tables 3.3 and 3.4.

The comparison between ESE type ATS's and simple Franklin Rods are given in Figures 3.14 and 3.15. The $\Delta R p$ magnitude should be noted that from these figures. For $(h, R)=(40$ $\mathrm{m}, 60 \mathrm{~m}$ ) and protection level $3, R_{p}$ is obtained as $57 \mathrm{~m}$ for a simple rod while it increases to $89 \mathrm{~m}$ for $\Delta \mathrm{L}=31 \mathrm{~m}$, where the protection angles are corresponding to $55^{\circ}$ and $65^{\circ}$ respectively as shown in figures. The manufacturers claim that there is significantly an 
increase in the protected area if Tables 3.3 and 3.4 are analysed for other values. According to conservative calculation, the shielding angle is increased from $19.5^{\circ}$ to $61^{\circ}$ with the increasing protected area radius from $14 \mathrm{~m}$ to $74 \mathrm{~m}$ where $\Delta R p=60 \mathrm{~m}$ which is a significant advantage being claimed.

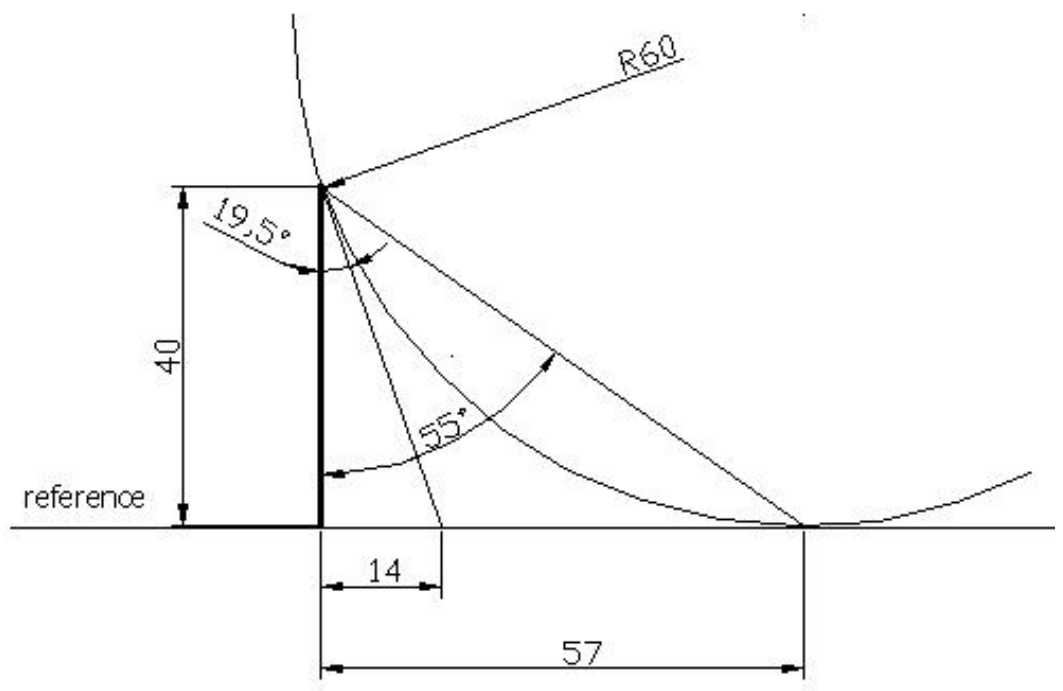

Figure 3.14 Protected area according to Franklin Rod

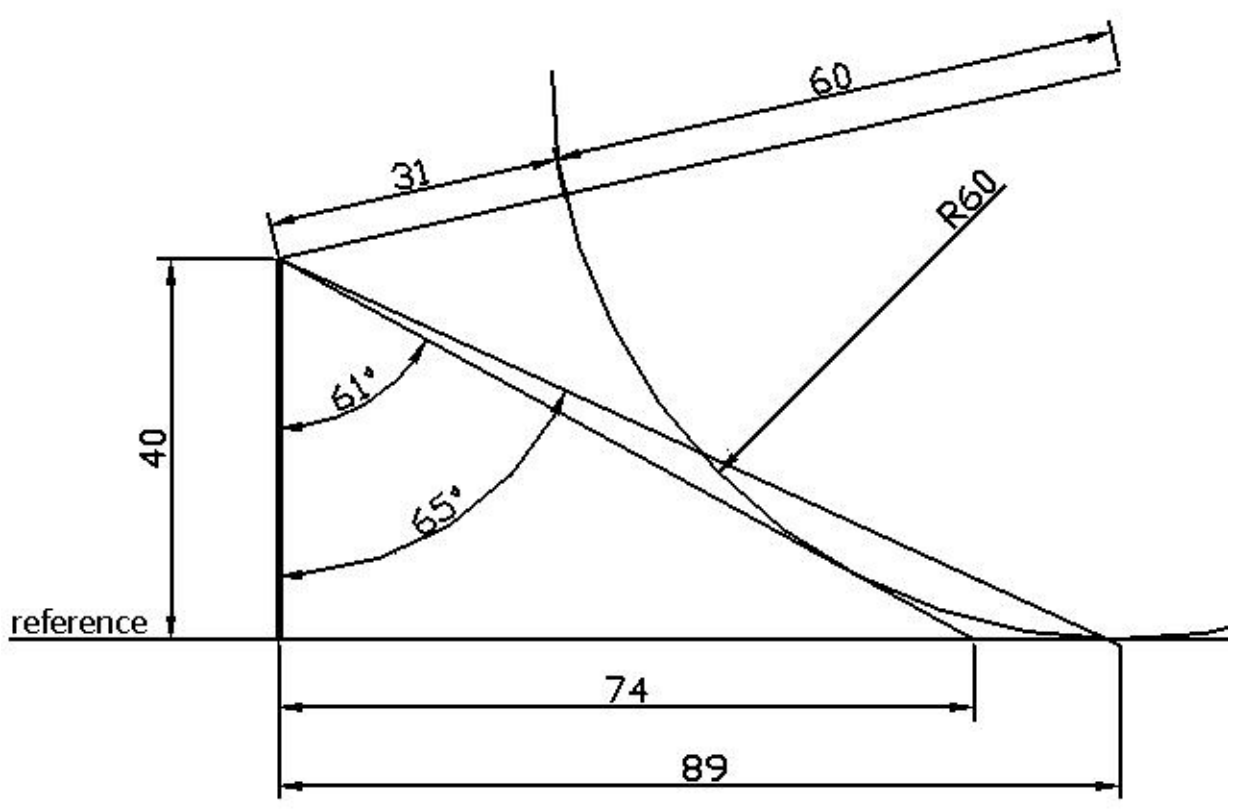

Figure 3.15 Protected area according to ESE type lightning arrester 
Table 3.3 Manufacturer ${ }^{26}$ sheet for Active Lightning Arrester with Piezoelectric Crystal

\begin{tabular}{|r|c|c|c|c|c|c|}
\hline \multirow{2}{*}{$\mathbf{H}(\mathbf{m})$} & \multicolumn{3}{|c|}{$\Delta \mathrm{L}=\mathbf{3 0} \mathbf{~ m}$} & \multicolumn{3}{c|}{$\Delta \mathrm{L}=\mathbf{6 0} \mathbf{~ m}$} \\
\cline { 2 - 7 } & $\mathbf{I}$ & II & III & I & II & III \\
\hline 2 & 19 & 25 & 28 & 31 & 39 & 43 \\
\hline 4 & 38 & 51 & 57 & 63 & 78 & 85 \\
\hline 6 & 48 & 64 & 72 & 79 & 97 & 107 \\
\hline 8 & 49 & 65 & 73 & 79 & 98 & 108 \\
\hline 10 & 49 & 66 & 75 & 79 & 99 & 109 \\
\hline 20 & 50 & 71 & 81 & 80 & 102 & 113 \\
\hline 30 & 50 & 73 & 85 & 80 & 104 & 116 \\
\hline 60 & 50 & 75 & 90 & 80 & 105 & 120 \\
\hline
\end{tabular}

Table 3.4 Manufacturer ${ }^{27}$ sheet for Active Lightning Arrester Having Atmospheric Field Effect

\begin{tabular}{|c|c|c|c|c|c|c|}
\hline \multirow{2}{*}{$\mathbf{h}(\mathbf{m})$} & \multicolumn{3}{|c|}{$\Delta \mathbf{L}=\mathbf{3 1} \mathbf{~ m}$} & \multicolumn{3}{c|}{$\Delta \mathbf{L}=\mathbf{7 6} \mathbf{~ m}$} \\
\cline { 2 - 7 } & $\mathbf{I}$ & II & III & $\mathbf{I}$ & II & III \\
\hline 5 & 49 & 65 & 72 & 95 & 114 & 124 \\
\hline 10 & 50 & 67 & 76 & 95 & 116 & 126 \\
\hline 15 & 51 & 70 & 79 & 96 & 117 & 128 \\
\hline 20 & 51 & 72 & 82 & 96 & 118 & 130 \\
\hline 30 & & 75 & 86 & & 120 & 133 \\
\hline 40 & & 76 & 89 & & 121 & 135 \\
\hline 50 & & & 90 & & & 136 \\
\hline 60 & & & 91 & & & 136 \\
\hline
\end{tabular}

\subsubsection{Comparison of ESE type Lightning Arresters with Franklin Rods}

The need for examining this subject under a new topic is that; nowadays, many scientists and manufacturers discuss the usage and effectiveness of Active type Lightning Arresters. It can be said that there are two camps: Supporters and opposers. 
IEC standards do not accept the usage of these types and they are forbidden due to the continuing discussions. The national standards of France (NF C 17-102: July 1995) and Spain (UNE 21-186: June 1996) still cover the Active type Lightning Arresters. The Spanish Standard related with this type claims that they are effective and tested in laboratory conditions. However, the laboratory conditions are different from nature and the opposers' claim is that due to this difference and many observations, the ESE type of lighting protection systems do not have scientific base and not have the claimed functions.

"The most significant of the recent laboratory testing reported is that provided by the University of Manchester Institute of Science and Technology. The summarized results are as follows: With one ESE device the Franklin rod was struck 27 times and the ESE device was struck 22 times. With the second ESE device the Franklin rod was struck 72 times and the ESE device was struck 42 times. The evaluation between the third ESE device and the Franklin rod resulted in each of the devices being struck 101 times, with eight discharges striking neither device. During the entire evaluation program in the laboratory a total of 420 electrical discharges were generated, with 200 of these discharges striking the Franklin rod for 47.6 per cent, 165 discharges striking the ESE device for 39.3 per cent and 55 discharges did not strike either device for 13.1 percent of the discharges". ${ }^{28}$

Moreover, many scientists claim that there is no superior advantage of ESE systems when compared to Franklin Rods. 17 scientists who are members of the Scientific Committee of ICLP ${ }^{29}$ issued a joint statement opposing ESE lightning rod technology after analysing the ESE devices and with the basis of the latest results within the fields of lightning physics and the individual lightning processes, and the results of field tests ${ }^{30}$ The following paragraphs are quoted from the declaration:

- Unfortunately, the above-mentioned function claimed for the operation of the ESE rod has never been proven correct under natural lightning conditions. Independent researchers have been unable to demonstrate the expected advantages determined by means of the specified laboratory tests. On the contrary, the ESE rod and the simple Franklin rod do not show any major difference in the protection distance and the difference in the number of flashes to the Franklin and the ESE rods in competition tests.

- The specified laboratory test does not consider the immense difference in scale for the laboratory set-up and the actual dimensions in the field. Due to these differences, the different field conditions in a high voltage laboratory versus the ones under natural lightning conditions, and due to the non-linear nature of the different 
discharge phenomena, it is impossible in the laboratory to determine the development of a stable progressing hot leader, as it develops under natural conditions.

When considering the above-mentioned information, and considering that the lightning protection is a matter of achieving safety, it is evident that the concept of the ESE rods is inadequate to provide the safety such as defined in the draft standard ${ }^{31}$.

The philosophy is the same in ESE type systems that to catch the lightning stroke and divert the lightning current to the ground. In addition, there is a discussion between scientists interrogating the effectiveness of ESE air terminals and they claim that there is no difference between these types and simple Franklin rods. Therefore, all the systems developed since Franklin could be called Franklin type protection systems.

\subsubsection{Application of Franklin Rods in Lightning Protection}

Vertically installed interception rods are called vertical conductors (VC) and they are used on the roof or / and isolated from the structure.

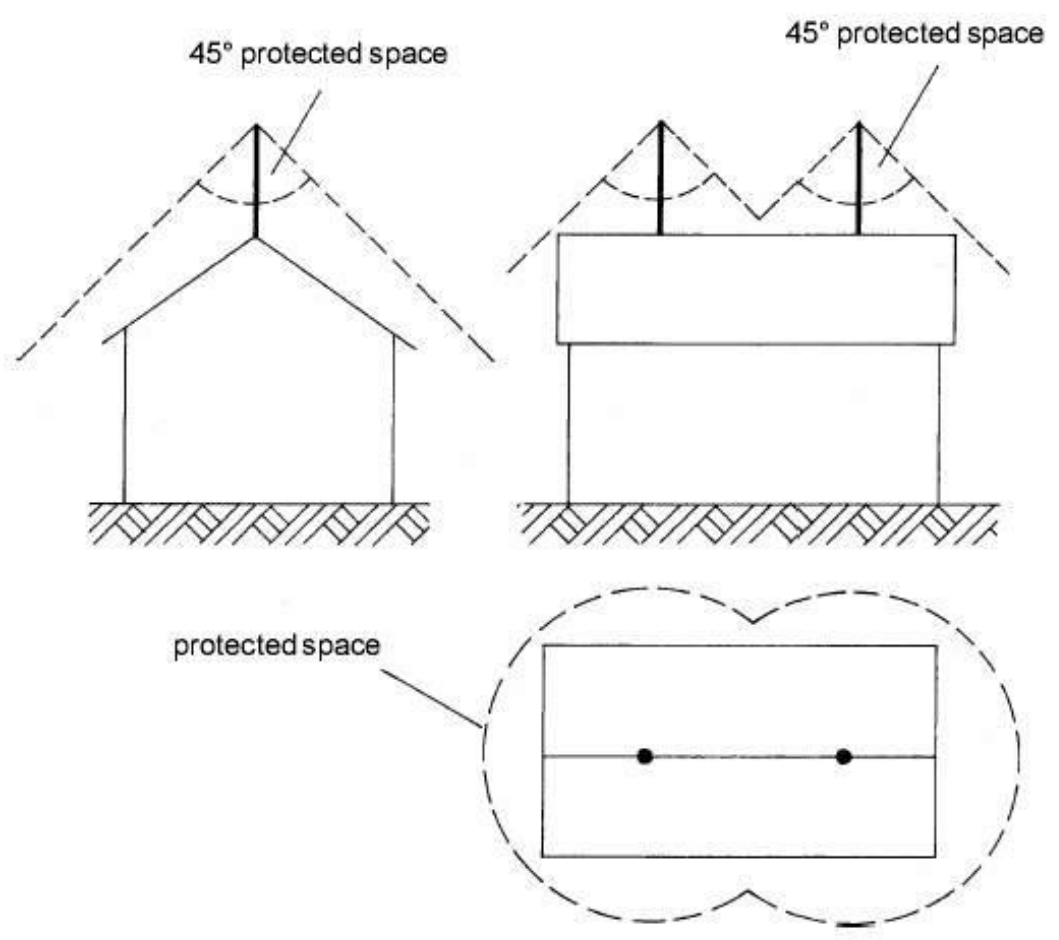

Figure 3.16 Vertical Conductors mounted on the Roof (non-isolated type) 
VC's used on the roof are called non-isolated interception rods. In Figure 3.16 given below, the application of non-isolated type VC's are shown. It should be noted that shielding angle is taken as $45^{\circ}$. The longer the length of the VC, the larger the protected space is according to Figure 3.16. To satisfy full protection to cover the structure totally, two VC's are used on the roof. Instead of two conductors, only one longer conductor can be used. This is up to engineering application and cost.

On the other hand, VC's used apart from the structure are called isolated interception rods. In some cases where there is an explosion risk due to the materials inside the structures containing such as explosives, radioactive materials, dangerous gases etc., current flowing through the conductors around the building can result temperature increase on the surface of structure. In this case, some precautions should be taken such as isolation between the structure surface and the conductors or using sufficiently thick material to prevent heat transfer into the structure. Otherwise, it is recommended to use isolated air termination systems like simple Franklin rods for the lightning protection of these type structures.

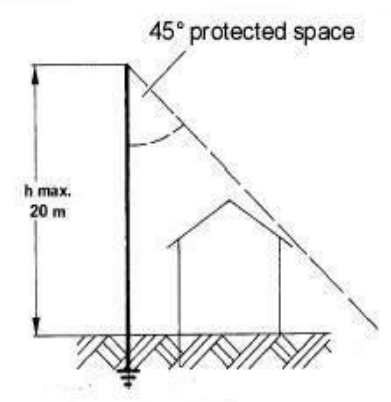

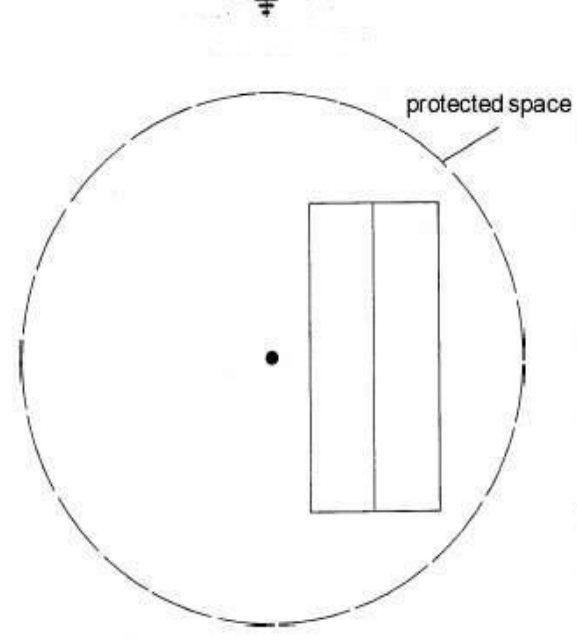

a

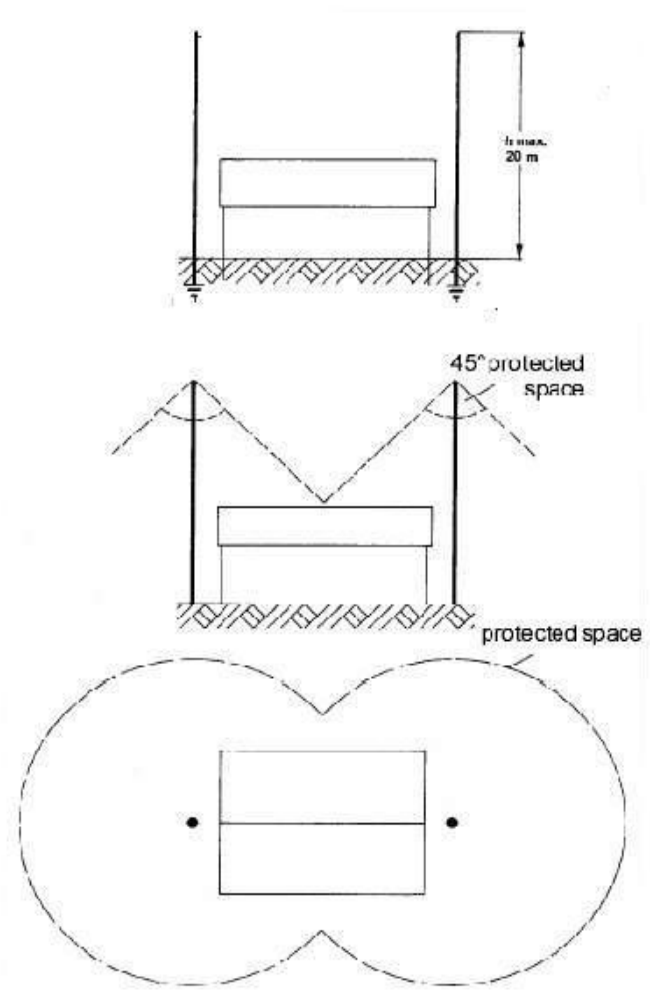

b

Figure 3.17 Vertical Conductors apart from the Structure (isolated type) 
It should be noted that in Figure 3.17, protected spaces are shown according to the shielding angle of $45^{\circ}$. The maximum length of $\mathrm{VC}$ is taken as 20 meters given in standards. Figure 3.17.a shows a single isolated VC while two VC's are shown in Figure 3.17.b to satisfy complete protection of the structure.

Isolated LPS is recommended for structures subject to risk of major damage or subject to risk of damage causing environmental hazards if there is an or no effective internal LPS to prevent dangerous sparking inside or on the structure. ${ }^{32}$ The IEC TC 81 continues in the same report that partially isolated LPS is recommended for structures subject to risk of minor damage, if the area to be protected can not sustain the consequences of the lightning stroke intercepted by the air termination system without suffering damage (e.g. if the roof is flammable). ${ }^{33}$

\subsection{Introduction to Cage Method}

In 1876, the physicist J. C. Maxwell set the basics of the cage method. Enclosing the structure to be protected totally within an electrically conductive shell was suggested for a complete protection against lightning damage. Unfortunately, lightning protection developers ignored Maxwell's suggestion for over 100 years and concentrated primarily on Franklin-type protection.

The quoted part following from the work of IEC TC $81^{34}$ : could be interpreted as the recognition of Maxwell by IEC. "Three methods of establishing the required protected area are considered:

- Covering the area to be protected with a number of conductors (normally vertical and horizontal) of a given shielding angle.

- Covering the area to be protected with a mesh of lightning conductors of a given mesh width.

- Covering the area to be protected with a number of lightning conductors in such a way that a rolling sphere with a given radius can roll over the lightning conductors without touching the area to be protected."

Today, crucial electronic systems and more storage and processing of volatile compounds make Maxwell's early suggestion urgently important to many facilities and industries. The Faraday concept is accepted as a modern method; however, the idea is advocated before ESE lightning arresters. ${ }^{35}$ 
The requirements in lightning protection were changed due to the wide usage of electronics. The changing philosophy in lightning protection is not only divert the lightning stroke to the ground, but also to minimize the effects of lightning current flow through the down conductors. The induced voltages and electrical field produced around the lightning current carrying conductor forced scientists and engineers to develop cage method to prevent lightning consequences.

Because of the characteristics of a lightning current, voltage sustained by a conductor (thus, electric field produced) is proportional to the product of the rise time of the lightning current and the inductance of the conductor according to the following formula:

$V=R^{*} I+L^{*}(d i / d t)$

Voltage Sustained has two components; one is the product of the current and the resistance to earth $\left(V=I^{*} R\right)$ and the other is the product of the rate of change of current and the inductance of the down conductor $\left(V=L^{*} \mathrm{di} / \mathrm{dt}\right)$.

In normal case, the simple addition of these two products gives the voltage which should be then used in the calculation of the electric field produced in the following example data of which are given as follows:

A typical down conductor might have a resistance of $0.2 \mathrm{milliohms} / \mathrm{m}$ and an inductance of 1000 nanoHenry/meter. For a 5.0 meter high building, $R=1.0$ milliohm and $L=5000$ nanoHenry. Using the lightning parameters given in Appendix $A$, the maximum rate of rise for subsequent negative strokes is $162-\mathrm{kA} / \mu \mathrm{s}$. For this extreme lightning strike, the maximum electric field generated is calculated as given below:

$$
\begin{aligned}
V & =V_{R}+V_{L} \\
V & =R^{*} I+L^{*}(d i / d t) \\
& =\left(1.0^{*} 10^{-3}\right)^{*}\left(200^{*} 10^{3}\right)+\left(5000^{*} 10^{-9}\right)^{*}\left(162^{*} 10^{3} / 10^{-6}\right) \text { volts } \\
& =200+810,000 \mathrm{~V} \\
& =810.20 \mathrm{kV}
\end{aligned}
$$

It should be noted in the example that the $V_{R}$ component is negligible compared to $V_{L}$ value. This results in measuring only the grounding resistance of a LPS is not sufficient. The important factor comes from the di/dt characteristics of lightning. Minimizing the resistance has no meaning when compared to the high inductance value. This is another critical point while designing a LPS. 
When the calculated voltage is used to obtain the electric field for the $5 \mathrm{~m}$ high building, voltage sustained is divided by the height of the building. As a result, the electric field would be $810.20 / 5=162.04 \mathrm{kV} / \mathrm{m}$.

This amount of electric field can cause arcing and it is hazardous to electronics technology. In modern life, as noted in the effects of lightning topic, the electronics is very important. If offices are thought, nearly in every room, there is at least one computer. Besides, the communication technologies are widely used. The disrupting effect due to the electrical field produced by a lightning current flowing through a down conductor near the building or attached to the building can seriously damage daily life:

The public services based on electronics can be damaged when the induced voltages or electric field produced by the lightning current damages the devices. When lightning directly strikes a building it can cause electric fields inside the building that can damage or disrupt electronics and can cause internal arcing. In industrial sites, disruption of controlling electronics can have extremely costly consequences including long down time and destroyed equipment. ${ }^{36}$ Due to side flashing, people would be killed. Step or touch voltages would injure people. These examples can be increased.

The scientists oppose the ESE type lightning arresters have an argument that The ESE type has never been proven correct under natural lightning conditions. To use a protection system against lightning, the protection system should be proven. According to the changing philosophy in lightning protection, these types are not usable as noted before.

In modern techniques, to draw the current from air termination system to ground is not sufficient. The EM effects of a lightning discharge must be minimized. This cannot be done using a simple rod. It can be concluded that in modern life, the basic Franklin rods or ESE type air terminals are not sufficient to satisfy protection against lightning.

A mesh must be formed to reduce the high inductance of the current path and to minimize the electric field and electromagnetic interference effects of lightning. This is the new philosophy in lightning protection that force to use cage method as a modern protection technique.

A wire mesh covering the top of the structure may play the role of the air terminals. ${ }^{37}$ Instead of single rods, the structure is covered by down conductors and horizontal conductors forming a mesh around the structure. The roof is covered by mesh also with vertical conductors similar to Franklin rods but shorter. 


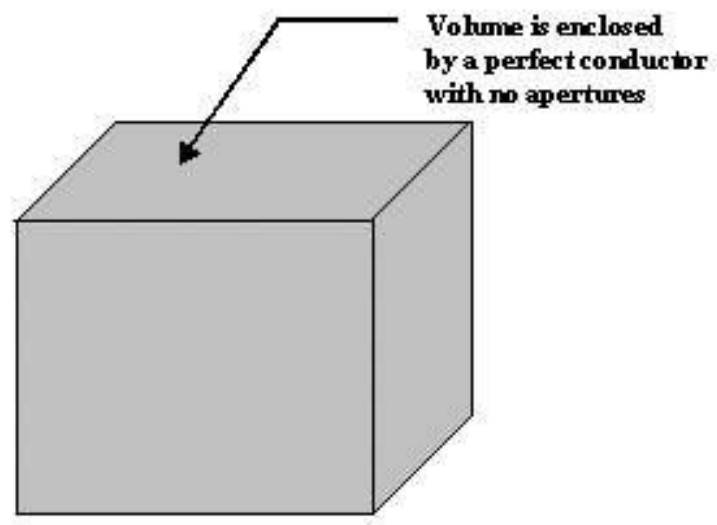

Figure 3.18 Example of a Faraday Cage

It should be noted that this method is not a Faraday Cage. The idea comes from Faraday Cage. The correct name would be mesh method or cage method. Faraday Cage protects the structure against external electric and magnetic field. However, when the cage is struck by a lightning, the cage itself becomes a current source and the current flowing through the mesh conductors produce electric fields. The idea here is to protect the structure from lightning effects by minimizing the flowing current and increase the possibility to catch the lightning by the mesh.

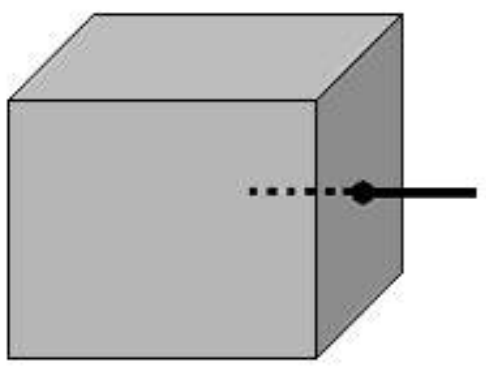

Figure 3.19 Faraday Cage with Bonded Metallic Penetration 
A Faraday cage is an enclosure with no apertures (holes, slits, windows or doors) made of a perfectly conducting material. No electric fields are produced within the Faraday cage if no electrical energy sources are within the Faraday cage. ${ }^{38}$

In Figure 3.19, the Faraday Cage shown in Figure 3.18 is penetrated and there is a bonding resulting with no hole on the surface that does not violate existing system. Therefore, the Faraday Cage preserved has ability to protect the inside from electric fields.

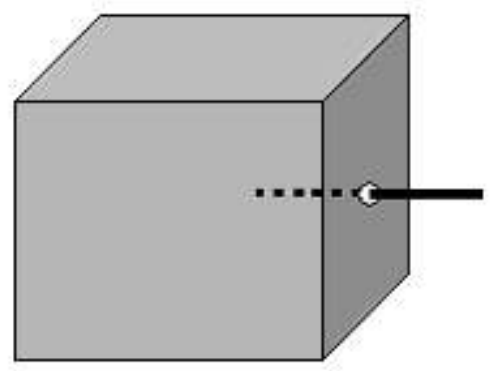

Figure 3.20 Faraday Cage with Unbonded Metallic Penetration

On the other hand, in Figure 3.20, the penetration is not bonded and there exist a hole on the Faraday cage violating the existing system. Therefore, it is not a Faraday Cage anymore and electric fields can be transmitted to inside.

The Cage Method used for lightning protection is based on the Faraday Cage theory. In application, the structures cannot be totally enclosed by conductors to form a Faraday Cage. It should be noted that screen rooms are typically designed to shield the enclosed area from low-energy, high frequency transmitted electromagnetic waves (e.g., AM/FM radio waves), but not to shield from directly attached lightning flashes. Welded sheet metal screen rooms can provide extraordinary protection from lightning if the metal is thick enough. ${ }^{39}$ For the protection of structures against lightning, the engineers must decide on the mesh to be applied to the structures.

According to the conclusions of the analysis and experimentation of Sandia National Laboratories held in the early 90's, the typical building of reinforced concrete is intrinsically a very effective shield (an elemental Faraday cage) against a direct lightning strike if its rebar 
is well-bonded (good electrical connections for rod-to-rod, mesh-to-mesh, and roof-to-floor) and if metallic penetrations (e.g., electrical conduits) are bonded to this mesh. That is, the building itself conducts nearly all the lightning energy to ground with very little energy transmitted into the building. If not well bonded, however, the building is an ineffective shield, and significant electric fields can be transmitted into the building by a directly attached lightning flash. For a poorly bonded building, these electric fields can be high enough to cause arcs and/or voltage surges that damage or disrupt the building contents. ${ }^{40}$ 


\section{CHAPTER 4}

\section{APPLICATION OF THE CAGE METHOD}

\subsection{Introduction}

The Cage Method is used not only for external protection, also internal protection is considered to satisfy full and complete protection against lightning. Internal protection could be thought because of this method. Because the structure is covered by conductors forming mesh or cage around and the lightning current flowing through these conductors form electrical field. Occurring of voltage differences inside the building is unavoidable if internal protection and equipotential bonding is not installed.

In this thesis, Cage Method is taken as the basic method for protection of structures against lightning. The application of cage method will be done by using the rolling sphere method.

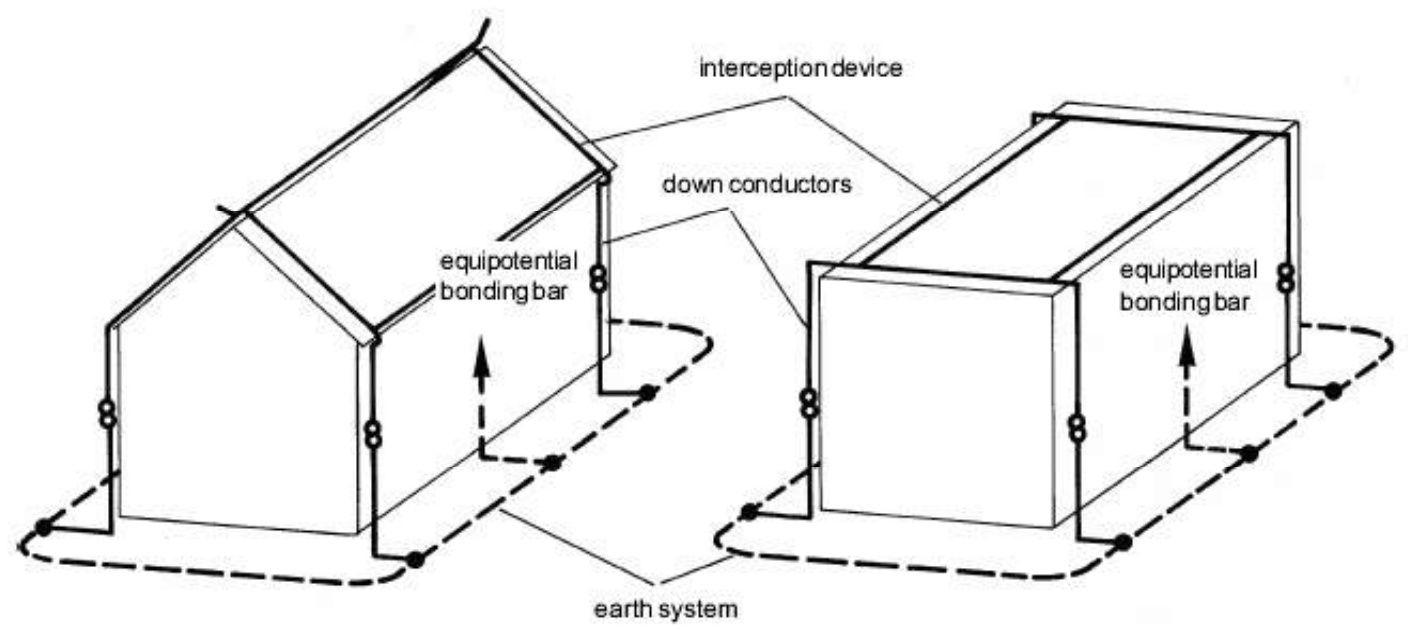

Figure 4.1 Parts of the Cage Method 


\subsection{Basis of Cage Method}

The Cage design consists of the following parts:

- Air Termination System (Interception Device)

- Down Conductors

- Grounding System

- Equipotential Bonding

The aim is to intercept the lightning strike by air termination systems on the highest point of the structure and conduct the lightning current by the use of down conductors to the grounding system. Equipotential bonding should be satisfied to prevent the effects due to voltage differences that would be produced by the lightning current.

To install a satisfactory protection system, all these four parts should be done according to regulations. Malfunction of any part will result failure of the protection system against lightning.

It should be noted that equipotential bonding is thought to be separately from grounding system. The importance of equipotential bonding is mostly related with the internal lightning protection and it provides the connection of external and internal LPS's (i.e., equalizing the potentials of all conducting parts in the systems).

\subsubsection{Air Termination System}

The interception device, (air termination system) is the entirely of metal components (e.g. interception conductors, interception rods) on, above, alongside or next to the building to be protected. ${ }^{41}$ It is used to intercept the lightning strike. The air termination system may consist of vertical or horizontal conductors, combinations, or both.

Mesh type of air termination systems are used on the roof of structures. It should be noted that horizontally installed conductors on the roof are called horizontal conductors $(\mathrm{HC})$ and they are used to form a mesh on the roofs. HC's should be jointed at the interconnections. The network of the air termination on a roof is recommended to be in the form of a mesh to reduce the effect of a flashover caused by large induction loops.

An air termination network mesh is usually installed on the roof surface regardless of the height of the building. The mesh size is selected according to the protection level. The smaller the mesh size, the higher the safety factor is. BS 6651:1999 states that no part of the 
roof should be more than $5 \mathrm{~m}$ from the nearest horizontal conductor except that an additional $1 \mathrm{~m}$ may be allowed for each meter by which the part of to be protected is below the nearest conductor. This corresponds to a mesh size of approximately $10 \mathrm{~m} \times 20 \mathrm{~m}$ for the maximum size given in standards.
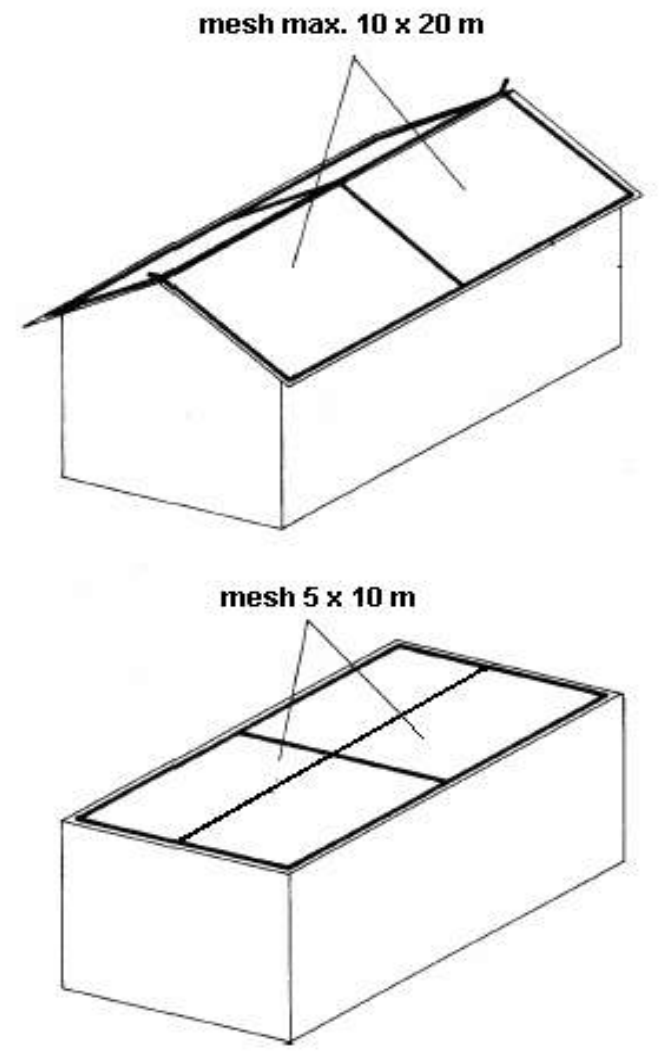

Figure 4.2 Mesh Interception Nets

In Figure 4.2, examples of air termination network meshes installed on the roofs are shown. A simple horizontal air termination consisting of a roof conductor is used around the periphery of a rectangular building. It should be noted that, no part of the roof is more than 5 $\mathrm{m}$ from the nearest horizontal conductor.

It could be thought that there is no requirement for the vertical conductors while there is a mesh on the roof. When the cage method is used with other methods such as protective angle method forming a combination, the usage of VC's on the roofs will be effective to 
increase the protection zone. This application should be considered as a deviation from cage method. In cage method, only mesh is used for the air terminals. However, although in suitable cases advantage may be taken of the increased protection zone, there can be no certainty about the precise shape of the envelope since this is only a statistical concept. ${ }^{42}$

\subsubsection{Down Conductors}

Down conductors (DC) are used to satisfy the electrical conductor connection between the interception devices and the grounding system shown in Figure 4.1. They can be strip, rod, reinforcing bars or structural steel stanchions etc. The conductor part of the building joint between the air terminals and the grounding system can be used as a DC if it has a good conductivity. DC's must have capability of carrying lightning current without any deformation.

Steel framed or reinforced concrete structures might themselves serve as a down conductor and there is no need to use down conductors, while the non-conducting material made structures need down conductors.

In Cage Method, in addition to the mesh on the roof of the structure, down conductors play an important role. The ideal way is to create a Faraday Cage around the structure; however, it is not practical. So to idealize the protection, the down conductors are placed around the outside walls of the structure starting from the corners and the structure is covered like a cage. The increased number of parallel down conductors reduces the lightning current flowing on conductors.

It should be noted that the down conductors per one structure must be minimum 2 ea and mounted symmetrical. An equal spacing of the down conductors is preferred around the perimeter. A down conductor should be near to each corner of the structure where this is possible. Down conductors are distributed around the perimeter of the space to be protected in such a way that the average value of the distance between them is not more than the values indicated in Table 4.1 given in the application of cage method topic.

Where more than one conductor is used, consideration should be given to symmetrical arrangement as evenly as practicable around the outside walls of the structure starting from the corners. For tall structures, where testing and inspection are potentially difficult, at least two down conductors are suggested for such tests.

A down conductor should follow the most direct and shortest path possible between the air termination network and the earthing system. Practical reasons do not always allow the most 
direct route to be followed. While routing the down conductors, attention must be paid when passing near doors, windows or other openings in the building not to cause any side-flashing effects.

Forming loops could result in side flashing. "Whilst sharp bends, such as those that arise at the edge of a roof, are permissible, re-entrant loops in a conductor can produce high inductive voltage drops so that the lightning discharge may jump across the open side of the loop." ${ }^{43}$ Appendix F should be analysed for the safety distance concept and calculations given in the standards.

Equipotential bonding must be done above ground at vertical intervals not exceeding $20 \mathrm{~m}$ for structures of more than $20 \mathrm{~m}$ in height. Bonding bars should be connected to the horizontal ring conductors that bond the down conductors as shown in Figure 4.3 to satisfy equipotential bonding.

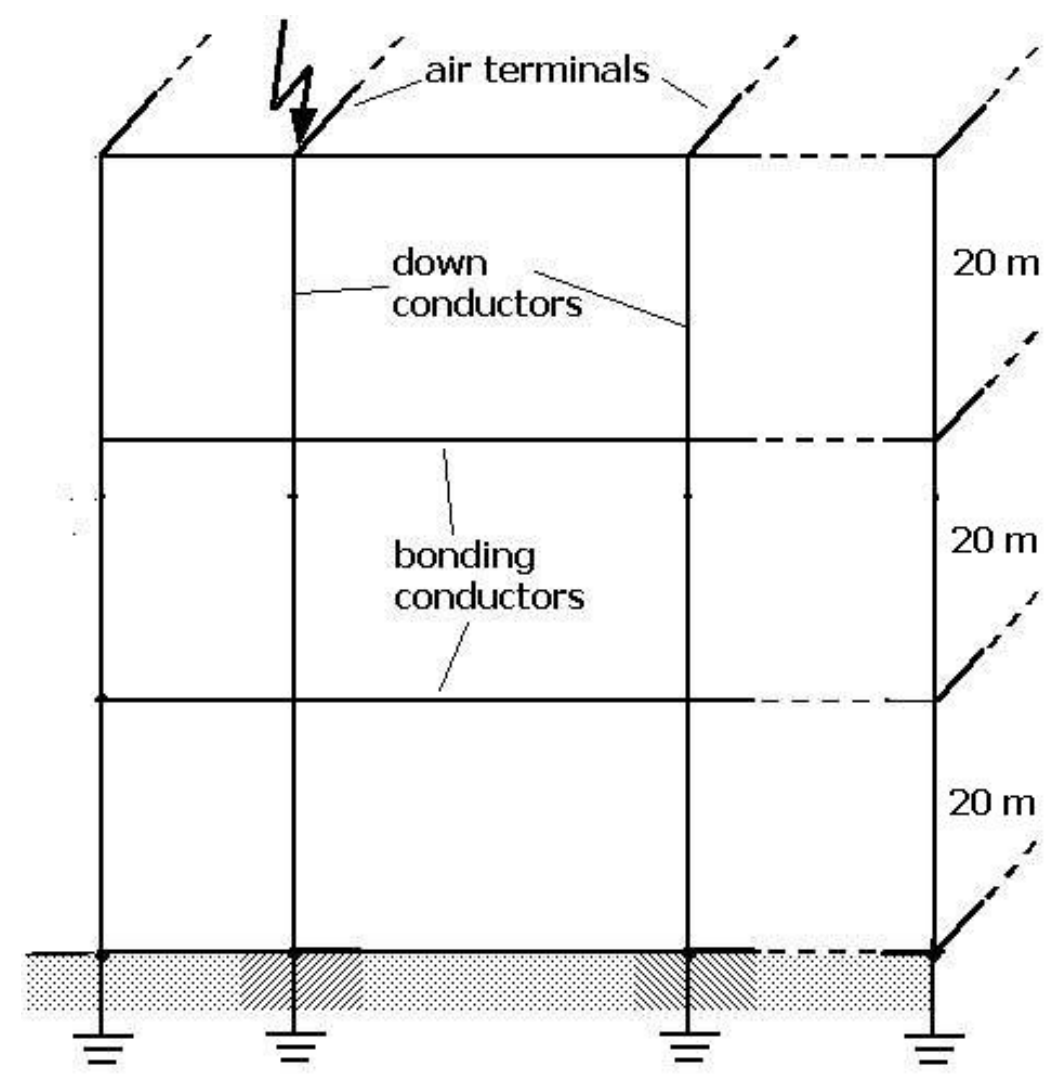

Figure 4.3 Equipotential bonding of down conductors for a $60 \mathrm{~m}$ high building 


\subsubsection{Grounding System}

A well-designed grounding system is essential to ensure protection of personnel and equipment from danger associated with fault currents or lightning. The basic is KCL (Kirchoff Current Law) which states that the current prefers the least resistant way. The aim in a grounding system is to ensure minimum earth resistance so that the lightning current or fault currents can pass through this earthing conductor as fast as possible.

To achieve an efficient grounding system it is essential that a low electrical resistance to earth be achieved, using good quality conductors with sufficient cross sectional area to carry the expected current flow. The conductors must also have a high corrosion protection.

An earth electrode should be connected to each down conductor of a LPS. Earth rods are used in most applications and are driven into the ground as close as is practicable to the structure and down conductor. There should be a ring conductor around the structure for grounding purpose and the electrodes should be connected to this ring.

Equipotential grounding is achieved when all equipment within the structure(s) are referenced to a master bus bar which in turn is bonded to the external grounding system. Earth loops and consequential differential rise times must be avoided. The grounding system should be designed to reduce $A C$ impedance and DC resistance. The use of counterpoise or crow's foot radial techniques can lower impedance as they allow lightning energy to diverge as each buried conductor shares voltage gradients. Ground rings connected around structures are useful. Proper use of concrete footing and foundations (Ufer grounds) increase volume. Where high resistance soils or poor moisture content or absence of salts or freezing temperatures are present, treatment of soils with carbon, Coke Breeze, concrete, natural salts or other low resistance additives may be useful. These should be deployed on a case-by-case basis where lowering grounding impedances are difficult an/or expensive by traditional means. ${ }^{44}$

The useful part of grounding is reducing the resistance and impedance. As these decreased, the total voltage sustained by the LPS is decreased.

Eq. 3.14 should be remembered that. $\mathbf{V}=\mathbf{V}_{\mathbf{R}}+\mathbf{V}_{\mathrm{L}}$, which can be written in the open form given below:

$V=R^{*} I+L^{*}(d i / d t)$ 
Reducing the grounding resistance is not enough, by the same time the impedance value must be reduced to minimize the spark voltages and also the electric field effects of lightning current flowing through the down conductors.

\subsubsection{Equipotential Bonding}

Equipotential bonding can be defined as interconnection of metallic parts not to cause any voltage difference. This can be done using an equipotential bus bar and connecting all the metallic parts to this bus bar or directly connecting metal parts to each other with an equipotential conductor. Equipotential bus bar is useful to connect the grounding system to the metallic network.

When lightning current flows through a conductor, differences of potential appear between this conductor and nearby metal parts. Dangerous sparks may be produced across the ends of the resulting open loop. ${ }^{45}$ There are two ways to avoid this problem: establishing an equipotential bonding between the conductor and the metallic parts near this conductor or allowing a safety distance between the conductor and the metallic parts.

The safety distance is the distance beyond which no dangerous sparks can be produced between the down conductor carrying the lightning current and nearby metallic parts.

The equipotential bonding of external metallic networks is an integral part of the outdoor lightning protection installation just like the down conductors and their earths. All conductive metallic networks located at a distance of less than $s$ (safety distance) from a conductor should be connected to the conductor by a conductive material with a like cross-section. ${ }^{46}$

Minimizing the lightning current paths is important. By equipotential bonding of external LPS, the down conductors are interconnected and potentially equalized as well as the current paths are increased. As a result, side flashing, sparking due to voltage differences and electric field effects, induced voltages due to current and di/dt characteristics of lightning are minimized.

The equipotential bonding of internal metallic networks is an integral part of the indoor lightning protection installation. All conductive metallic networks in the structure (steel frameworks, ducts, sheathing, electrical raceways or telecommunication cable trays, etc.) should be connected to the conductor. This is done by using a conductive material with a cross-section of at least $16 \mathrm{~mm}^{2}$ for copper or $50 \mathrm{~mm}^{2}$ for steel to connect to equipotential bonding bars installed inside the structure and connected in turn to the closest point of the 
earthing circuit. Unscreened telecommunication or electrical conductors should be bonded to the LPS via surge arresters. ${ }^{47}$

While lightning current is flowing through the down conductors, the electric field induces voltages nearby metallic parts, even though inside the structure if the structure is not totally steel and cage. This induced voltage is hazardous to human. The life is based on technology and electronic devices. The field effect can harm these equipments and basic utilities can be damaged.

To prevent any problem, the metal parts inside the building must be bonded to the main grounding system through equipotential bonding bus bars. Bonding is simply a matter of taking all of the electrical and metallic masses in a facility and connecting them with conductors, bringing them to the same electrical potential. The primary reason for bonding is personnel safety, so someone touching two pieces of equipment at the same time does not receive a shock by becoming the path of equalization if they happen to be at different potentials. ${ }^{48}$

\subsection{Applications of Cage Method}

The number of the basics of the Cage protection systems can be summarized as interception devices, down conductors, earthing system and equipotential bonding. These can vary according to the protection levels and the size of the structures to be protected (Table 4.1, combination of two tables given in IEC 1024-1).

Table 4.1 Placement of Interception Devices and DC according to Protection Levels

\begin{tabular}{|c|c|c|c|c|c|c|c|}
\hline \multirow[b]{2}{*}{$\begin{array}{c}\text { Protection } \\
\text { level }\end{array}$} & $h(m)$ & 20 & 30 & 45 & 60 & \multirow{2}{*}{$\begin{array}{c}\text { Mesh } \\
\text { size } \\
(\mathrm{m})\end{array}$} & \multirow{2}{*}{$\begin{array}{c}\text { Space } \\
\text { between } \\
\text { down } \\
\text { conductors } \\
\text { (m) }\end{array}$} \\
\hline & $\mathbf{R}(\mathrm{m})$ & $\alpha^{(0)}$ & $\alpha^{(0)}$ & $\alpha^{(0)}$ & $\alpha^{(0)}$ & & \\
\hline $\mathrm{I}$ & 20 & 25 & * & * & * & 5 & 10 \\
\hline II & 30 & 35 & 25 & * & * & 10 & 15 \\
\hline III & 45 & 45 & 35 & 25 & * & 15 & 20 \\
\hline IV & 60 & 55 & 45 & 35 & 25 & 20 & 25 \\
\hline
\end{tabular}




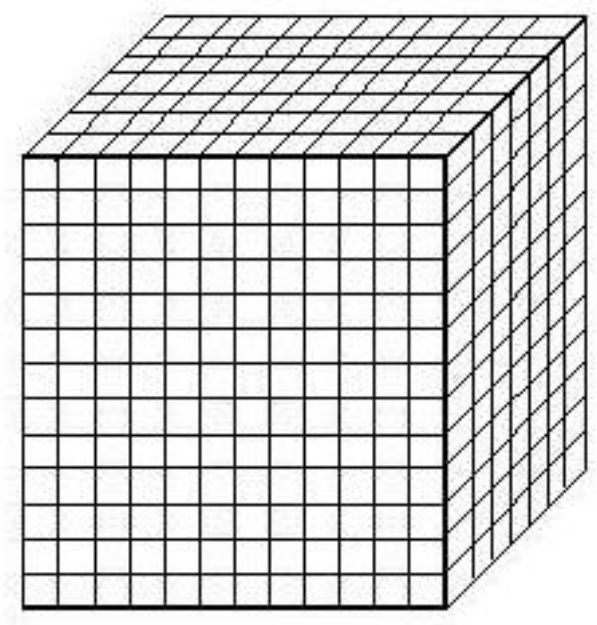

Figure 4.4 Elemental Faraday Cage

If the number of down conductors is increased and the mesh size is selected smaller, the protection system installed can be safer (Figure 4.4). Using only one air terminal on the roof and installing only one down conductor forms a very simple protection system, whereas the numbers are increased to form totally closed Faraday Cage, which is the ideal case.

The application of cage method is done by rolling sphere method. Rolling ball sphere method is introduced briefly in previous chapter. It should be noted that the figures below are taken from the worldwide standards.

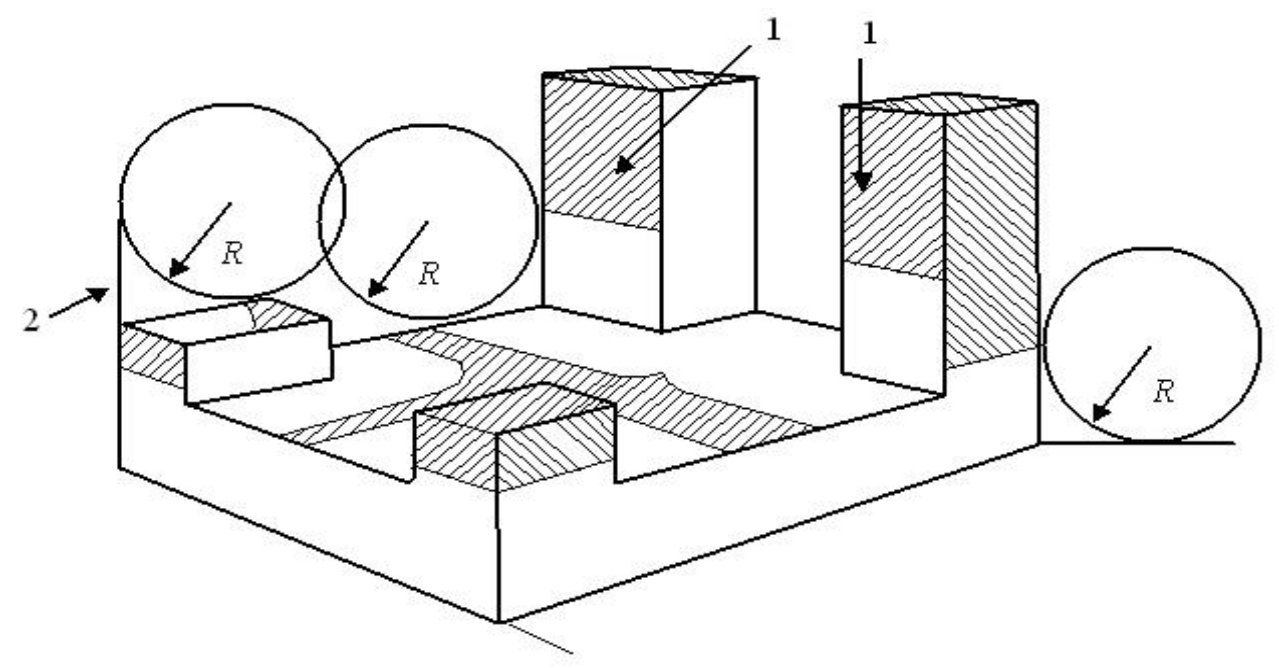

Figure 4.5 Complex shaped structure with rolling ball application 
where

1: the shaded areas are exposed to lightning discharge and must be protected

2: a mast or pole on the structure

$\mathrm{R}$ : radius of rolling ball

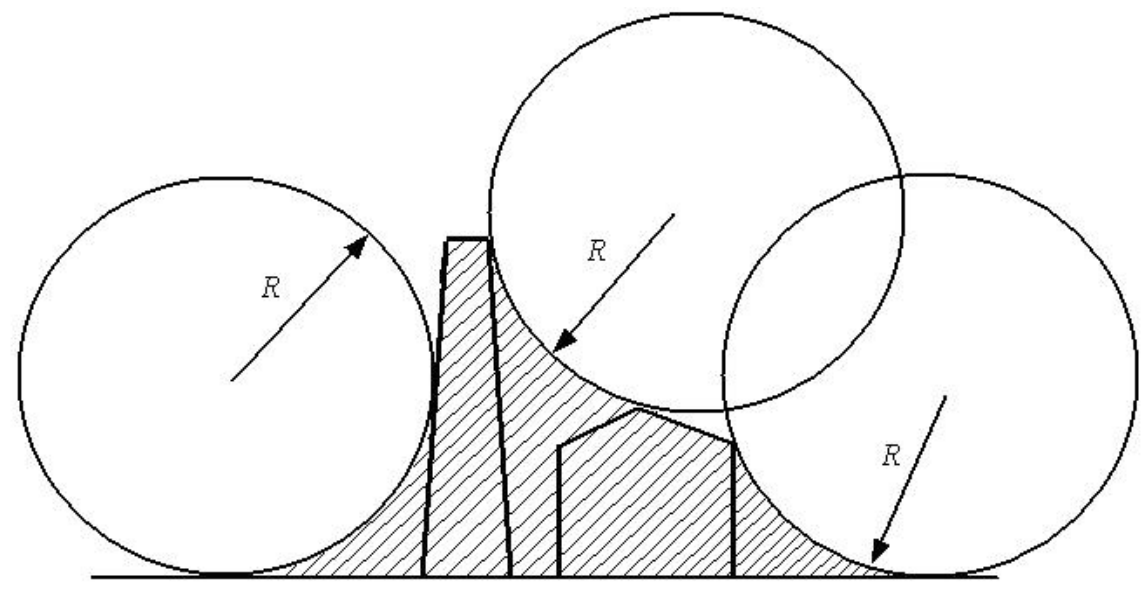

Figure 4.6 Application of Rolling Sphere for two Structures

The main idea of this method is that a sphere, which radius is a function of lightning current and touches the air termination must not intersect the object to defend shown in Figure 4.8. According to this method, interception devices should be installed to the points touching the rolling sphere. Therefore, the lightning will strike the air termination systems instead of the structure. The region not touching the imaginary sphere of radius $R$ given in Table 4.1 is thought to be protected. In Figures 4.5 and 4.6, applications of this method are shown.

\subsection{Comparison of the Standards using Cage Method Application}

Apart from the figures given above which are taken from standards, the application of cage method on a sample structure would be helpful to understand the case. It should be remembered that different standards determine different protection levels before the modifications of the formulas used in protection requirement procedure for the sample structure shown in Figure 2.4 in Chapter 2. To analyse the difference between different protection levels, the protection systems applied to the same structure according to all protection levels should be examined. The results would be compared by economic cost of the protection system installed. 


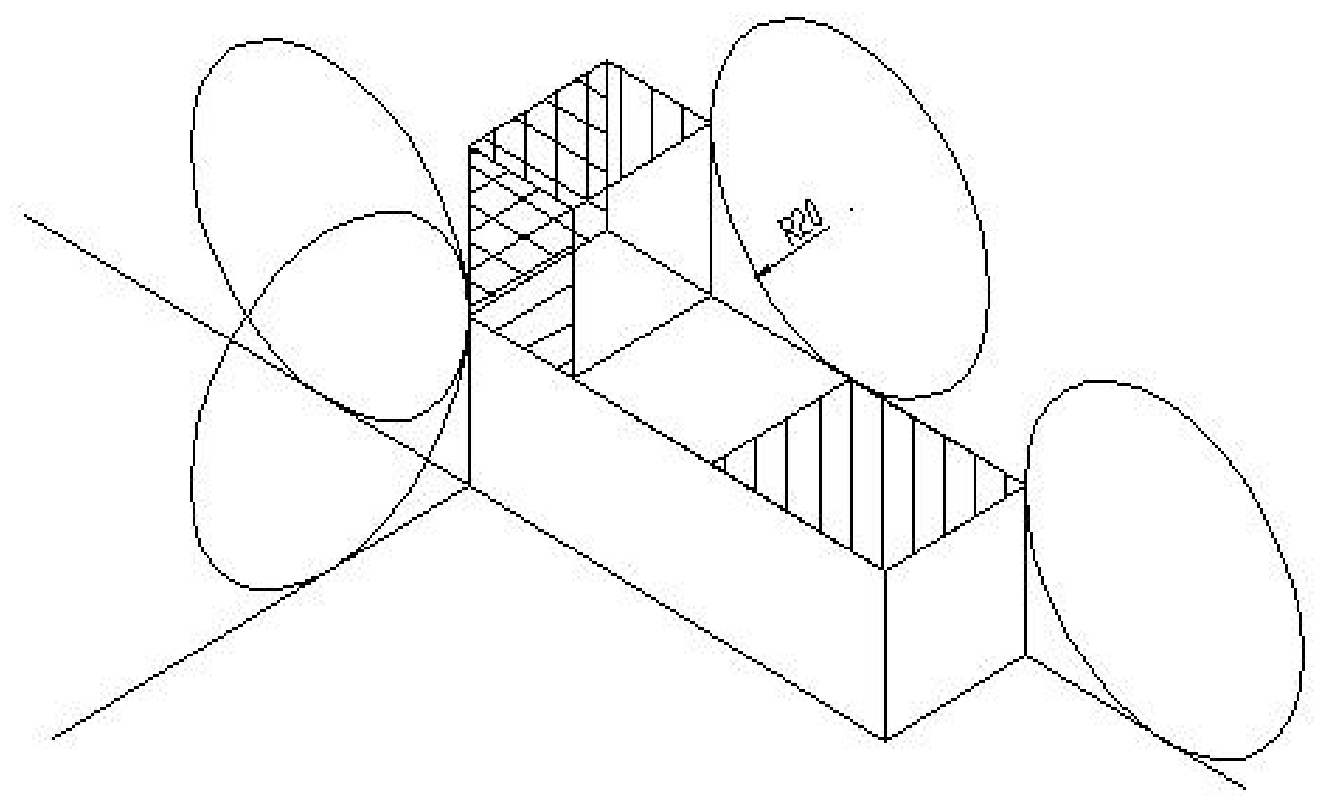

Figure 4.7 Rolling sphere application according to protection level $1(R=20)$

The radius of the rolling sphere to be applied is given as $20 \mathrm{~m}$ in Table 4.1 for protection level 1. In accordance with the application of rolling sphere with radius of $20 \mathrm{~m}$, the shaded areas of the structure must be protected with cage method and a mesh must be installed on top of these parts. According to Table 4.1, the mesh size is given as $5 \mathrm{~m}$ and the space between down conductors is $10 \mathrm{~m}$ corresponding to protection level 1 .

The cage method application for the protection of the structure against lightning is shown in Figure 4.8. The bold lines are the conductors. It should be noted that the mesh sizes on the top of the structure are not greater than $5^{\star} 5 \mathrm{~m}^{2}$ for the parts require protection according to rolling sphere method as shown in Figure 4.7. The space between the down conductors is within the limits not greater than $10 \mathrm{~m}$. There is an equipotential bonding on the middle side where there is no protection requirement and the left side of the structure is equally bonded once per $20 \mathrm{~m}$ in height. The earthing system is not shown. However, it should be a ring conductor connecting all the down conductors and earthing rods driven in the ground.

If Figure 4.8 is analysed, the conductors needed to satisfy the required protection level 1 is given as following: The total length of down conductors is $520 \mathrm{~m}$ while the total of horizontal conductors are $530 \mathrm{~m}$ in length. The total number of the earthing rods needed is 19. 


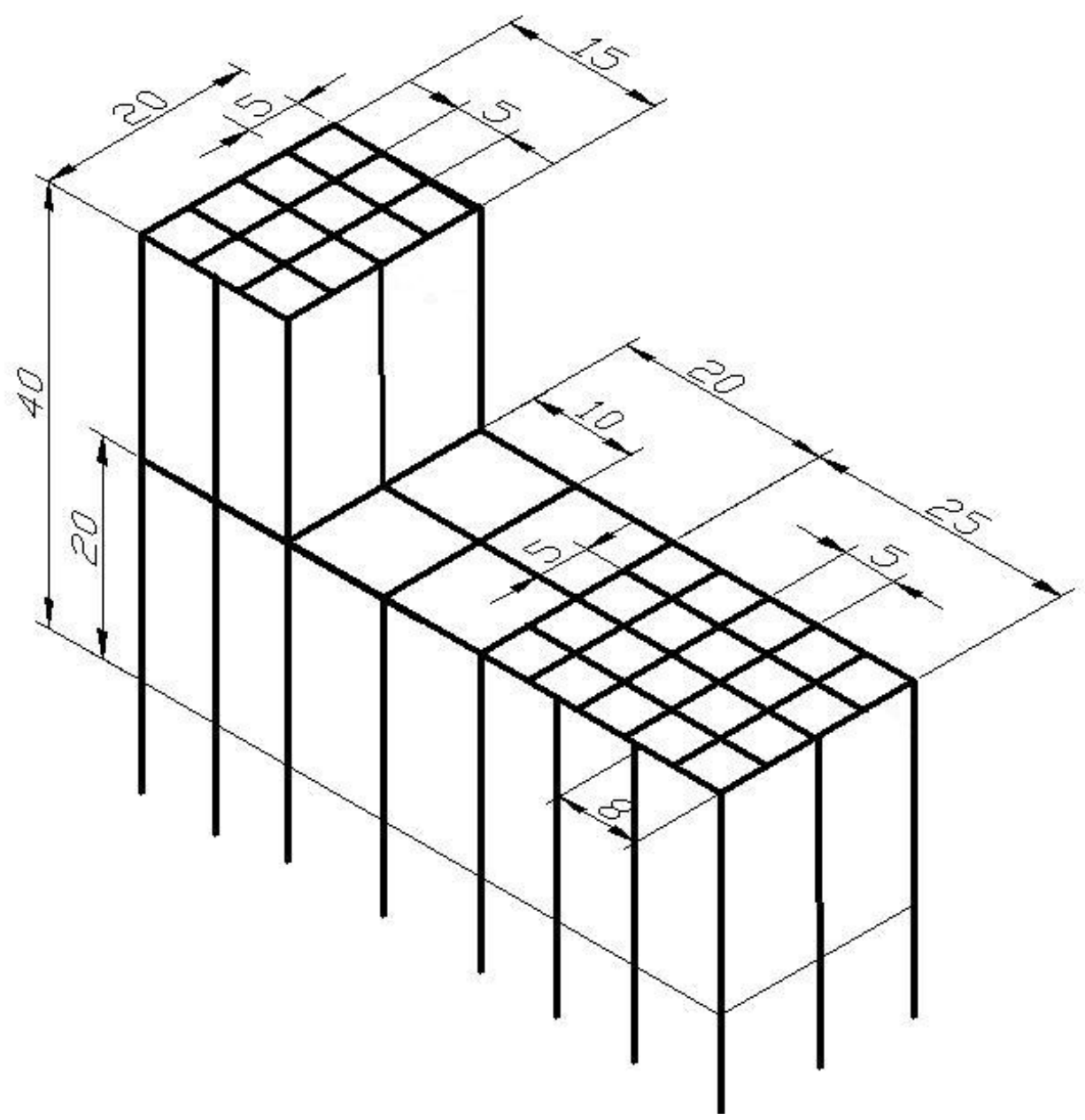

Figure 4.8 Cage method application according to protection level 1

On the other hand, the structure shown in Figure 2.4 is applied rolling sphere method with a radius of $30 \mathrm{~m}$ that corresponds to protection level 2 as given in Table 4.1. The shaded areas shown in Figure 4.9 are exposed to lightning discharge and must be protected.

For the protection of shaded areas of the structure, mesh must be formed. According to Table 4.1, the mesh size is given as $10 \mathrm{~m}$ and the space between down conductors is $15 \mathrm{~m}$ in accordance with protection level 2.

The cage method application for the protection of the structure against lightning in accordance with protection level 2 is shown in Figure 4.10. It should be noted that the mesh sizes on the top of the structure are not greater than $10 * 10 \mathrm{~m}^{2}$. The space between the down conductors is within the limits not greater than $15 \mathrm{~m}$. Similar to previous application, there is an equipotential bonding on the left side of the structure one per $20 \mathrm{~m}$. 


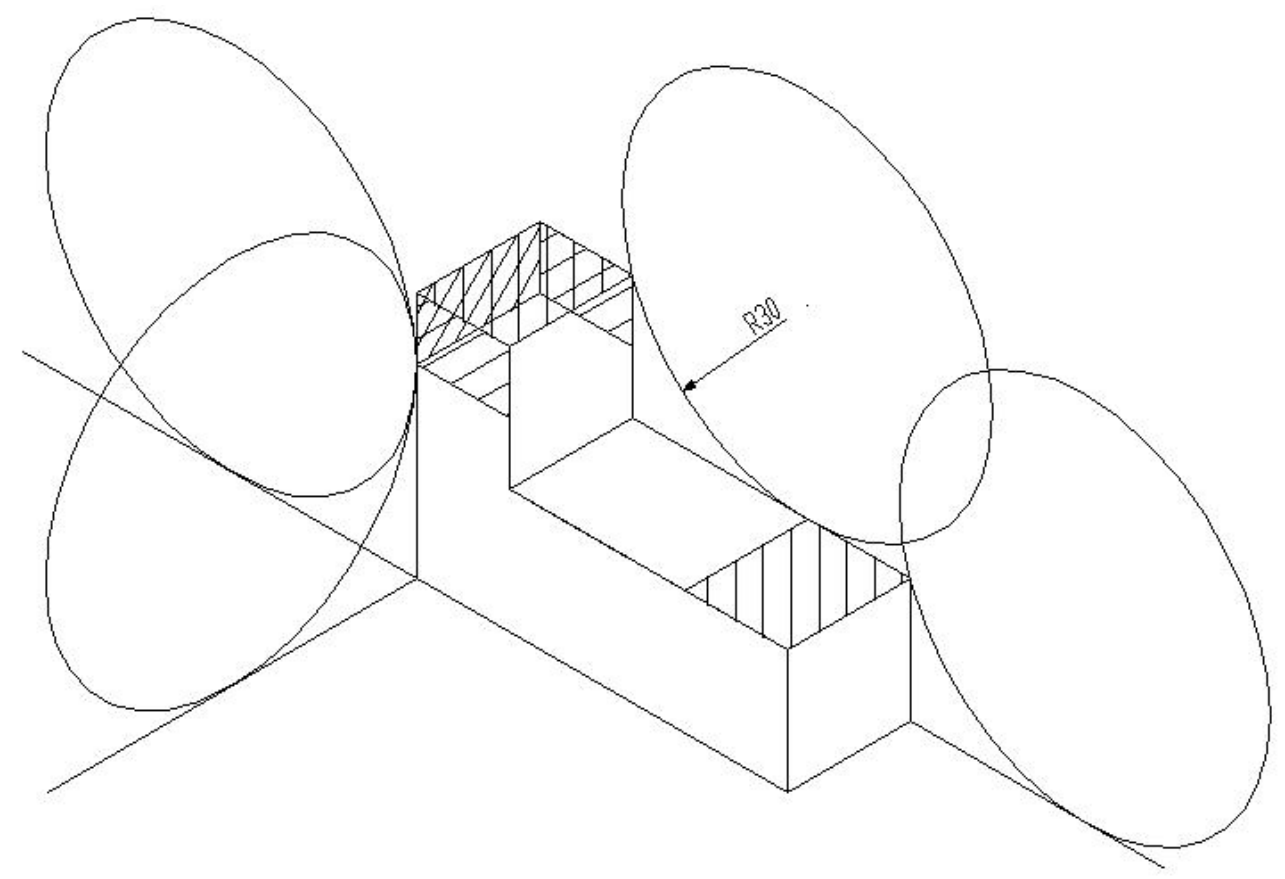

Figure 4.9 Rolling sphere application according to protection level $2(R=30 \mathrm{~m})$

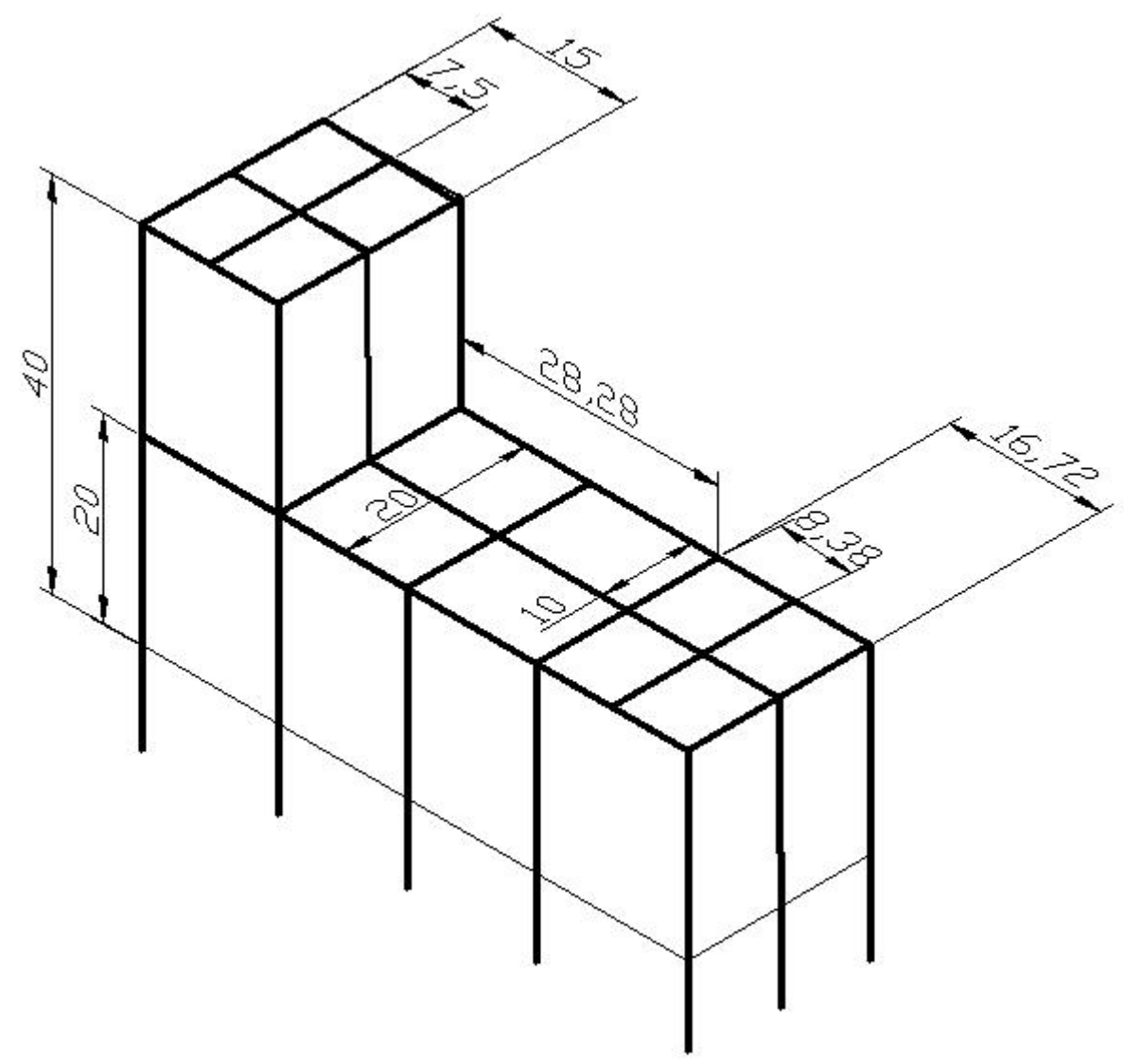

Figure 4.10 Cage method application according to protection level 2 
It should be noted that the middle part of the structure is protected against lightning strokes according to rolling sphere method. However, this part is covered by a mesh to satisfy equipotential bonding as shown in Figure 4.10.

If Figure 4.10 is analysed, the total length of down conductors is $360 \mathrm{~m}$ while the total length of the horizontal conductors is $370 \mathrm{~m}$. The total number of the earthing rods required is decreased to 13.

When the analysis is done according to protection level 3 with rolling sphere radius of $45 \mathrm{~m}$, Figure 4.11 is obtained. The shaded areas show the parts of the structure require protection against lightning strokes. The mesh size is $15 \mathrm{~m}$ and the space between the down conductors is $20 \mathrm{~m}$ for protection level 3 .

Figure 4.12 shows the application of cage method under these conditions. Again, equipotential bonding is satisfied on the higher side of the structure one per $20 \mathrm{~m}$ and except the shaded areas that, equipotential bonding is performed to connect the meshes installed.

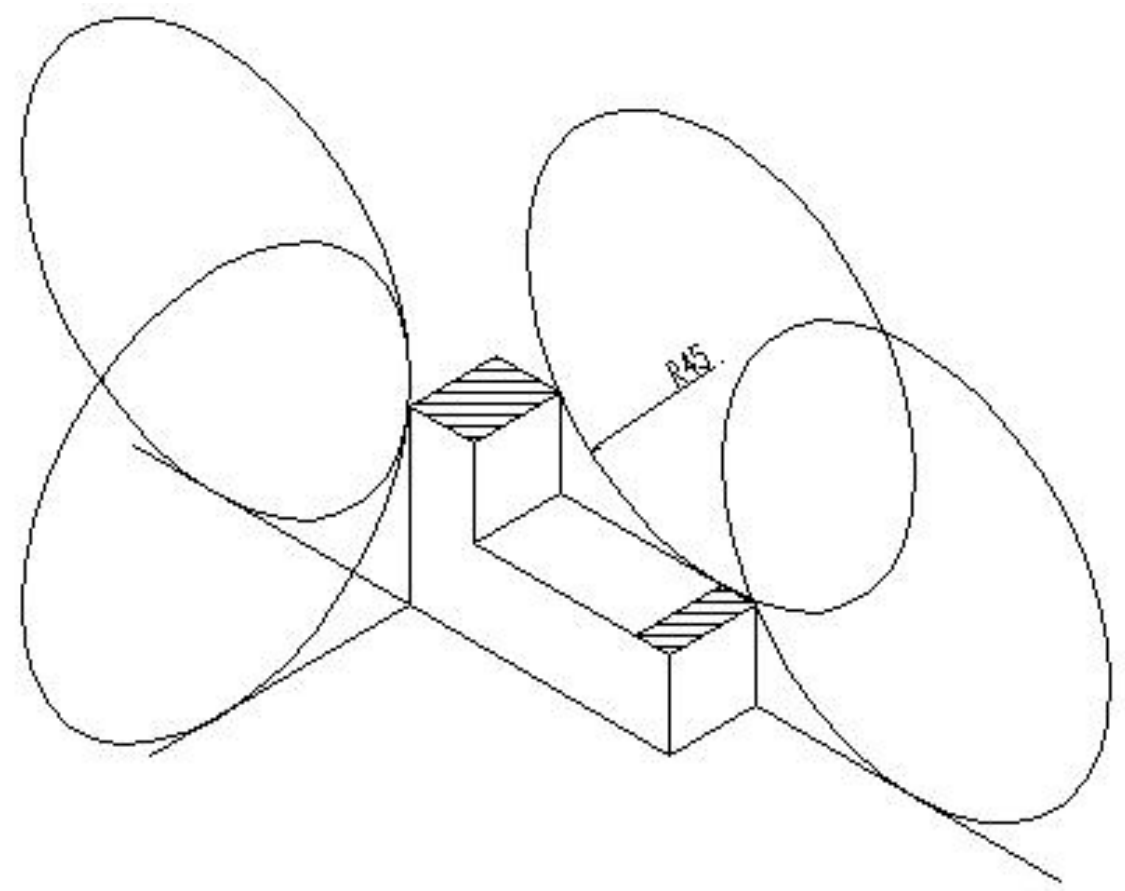

Figure 4.11 Rolling sphere application according to protection level $3(R=45)$ 


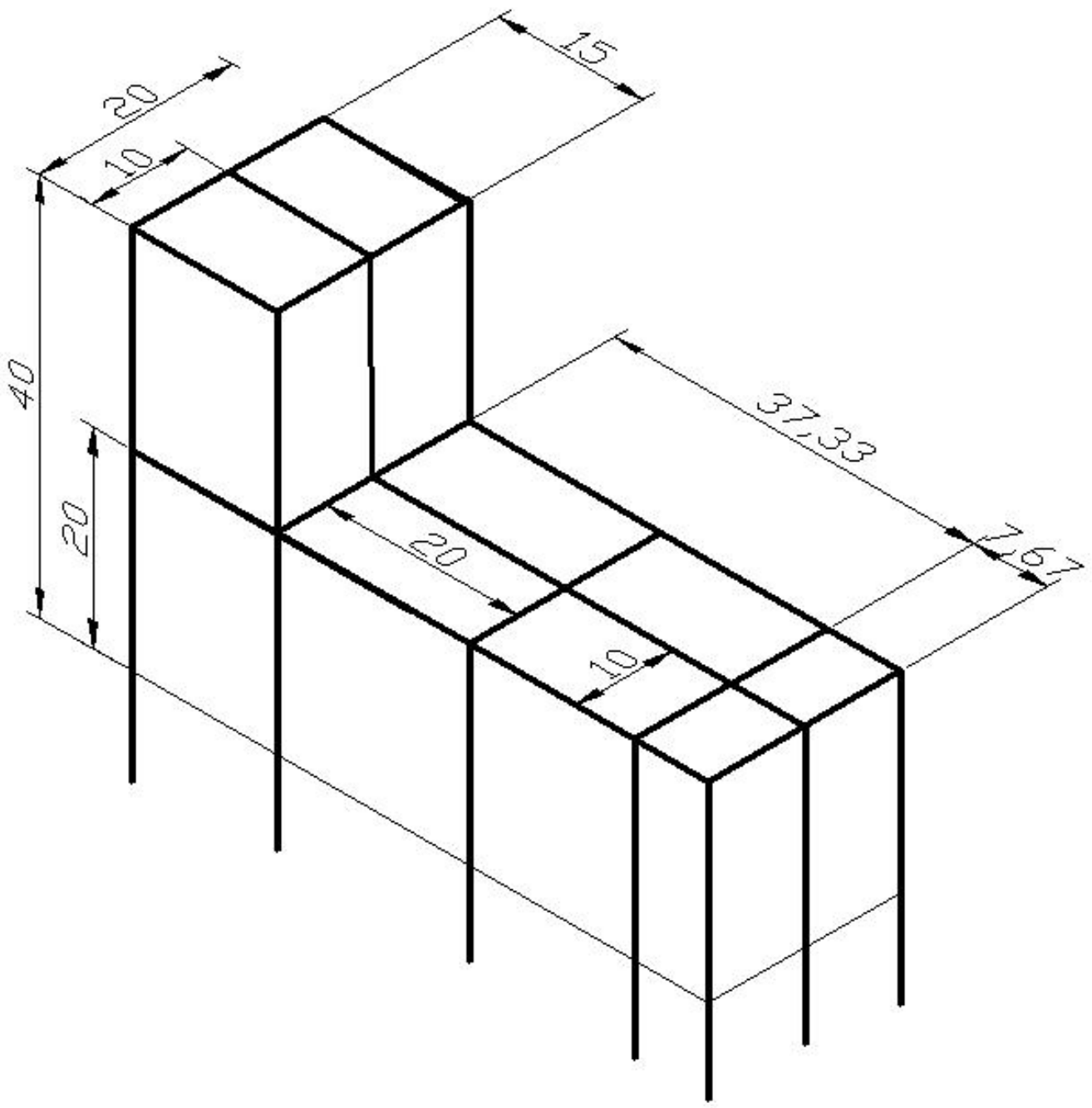

Figure 4.12 Cage method application according to protection level 3

It should be noted that the total length of down conductors is $360 \mathrm{~m}$ as it is in the application according to protection level 2. However, the total length of the horizontal conductors is decreased to $330 \mathrm{~m}$. The total number of the earthing rods remains the same, which is equal to 13 .

It should be noted here that for every down conductor, a single earthing rod is used. It is understandable that the number of earthing rods does not change due to the same number of down conductor used in both application according to protection levels 2 and 3 . 


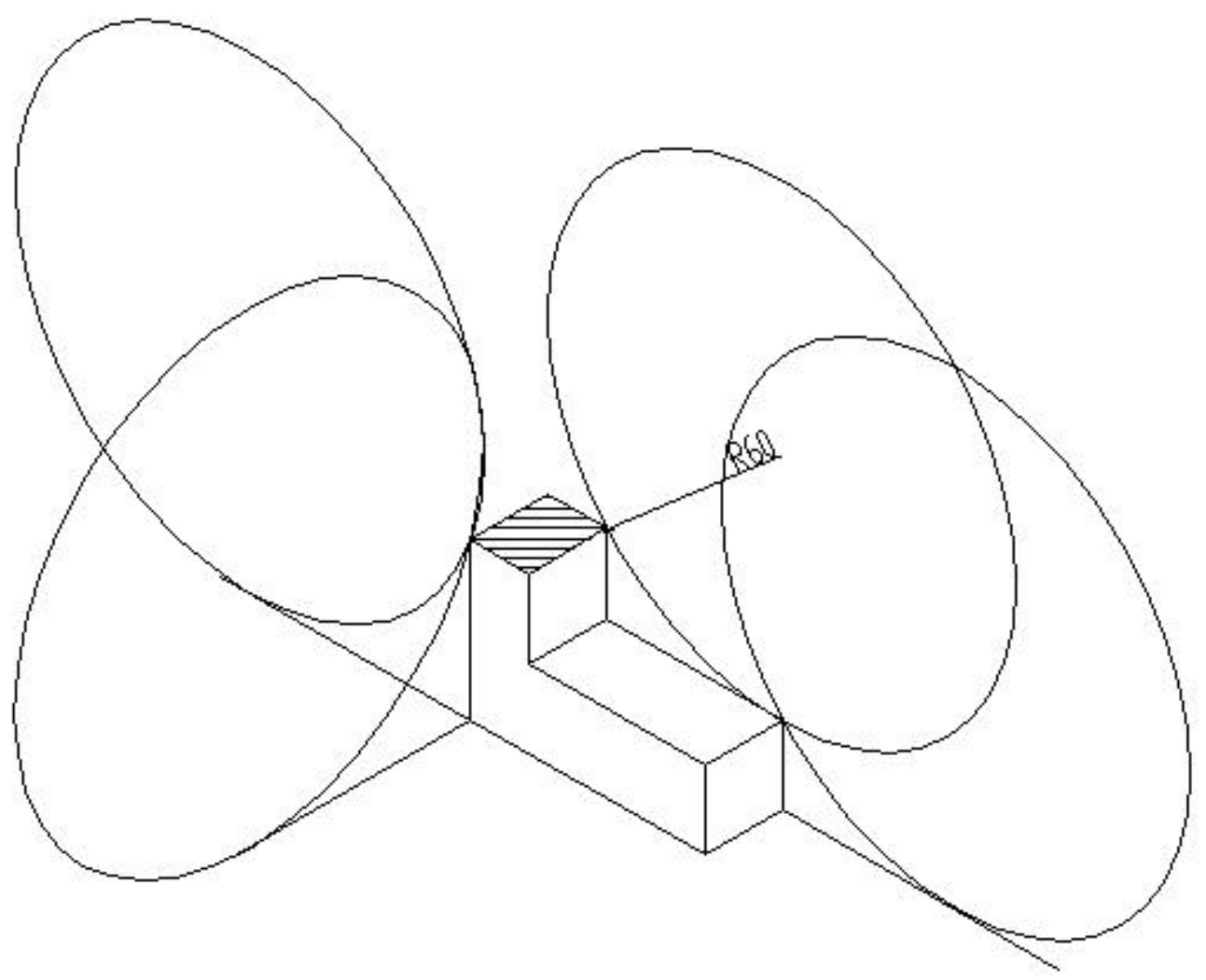

Figure 4.13 Rolling sphere application according to protection level $4(R=60)$

Finally, the area exposed to lightning discharges is shown in Figure 4.13 in accordance with the application of rolling sphere method with radius equal to $60 \mathrm{~m}$. The shaded area should be protected against lightning strokes. According to Table 4.1, the mesh size is $20 \mathrm{~m}$ and the space between down conductors is given as $25 \mathrm{~m}$.

The application of cage method to the structure is shown in Figure 4.14. The mesh is applied only on top of the higher part of the structure. The rest of the structure is protected when horizontal conductor are installed on the edges of the roofs. Moreover, to satisfy equipotential bonding, the roof of the lower part of the structure is covered by a mesh where the mesh size is determined by the down conductors that are connected to the mesh.

It should be noted that the total length of down conductors is 240 and the total length of the horizontal conductors are found to be $250 \mathrm{~m}$. The total number of the earthing rods is the minimum in this case, which is equal to 8 as shown in Figure 4.14. 


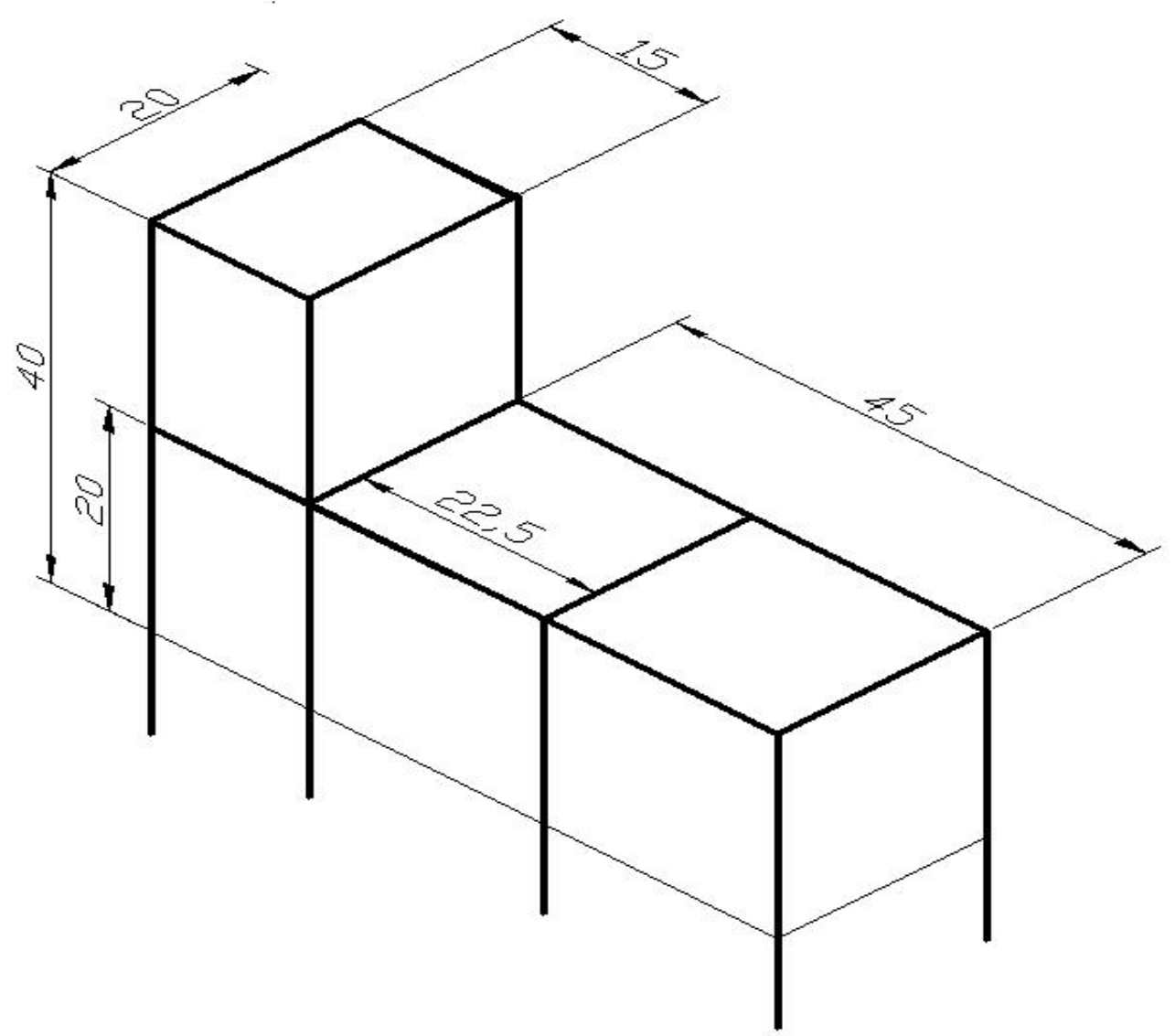

Figure 4.14 Cage method application according to protection level 4

Table 4.2 Comparison of Materials used in accordance with different protection levels

\begin{tabular}{|c|c|c|c|c|}
\hline $\begin{array}{c}\text { Applied } \\
\text { Protection } \\
\text { Level }\end{array}$ & $\begin{array}{c}\text { Down } \\
\text { Conductors } \\
\text { total length }(\mathbf{m})\end{array}$ & $\begin{array}{c}\text { Horizontal } \\
\text { Conductors } \\
\text { total length }(\mathbf{m})\end{array}$ & $\begin{array}{c}\text { Total } \\
\text { conductor } \\
\text { length }(\mathbf{m})\end{array}$ & $\begin{array}{c}\text { Number } \\
\text { of } \\
\text { Earthing Rods }\end{array}$ \\
\hline 1 & 520 & 530 & 1,050 & 19 \\
\hline 2 & 360 & 370 & 730 & 13 \\
\hline 3 & 360 & 330 & 690 & 13 \\
\hline 4 & 240 & 250 & 490 & 8 \\
\hline
\end{tabular}

As it could be interpreted that from protection level 1 to 4 , the quantity of the materials used to satisfy the protection system required is decreased which is given in Table 4.2 above. 


\section{CHAPTER 5}

\section{CONCLUSION}

Lightning is a non-linear phenomenon although there have been many observations and developments. Therefore, the lightning protection techniques are still being developed to prevent the consequences of lightning strokes since Franklin and the philosophy of protection against lightning is modified in accordance with the new requirements. However, the tendency in humans is to use the safest protection system against lightning.

\subsection{Discussion of Standards}

The standards give the procedures and set the criterion about lightning protection to apply a LPS. Because of the review of the worldwide standards in this thesis, it can be concluded that the national standards have different priorities that results in different weighting factors assigned for the determination of protection requirements.

Moreover, the variation of the weighting factors for a certain application differs very highly between the minimum and maximum assigned coefficients. However, only four protection levels are given in all standards. As a result, all protection systems are considered for level 1 which is the safest protection level due to the tendency in humans to apply safer systems.

However, if the required protection level for a certain structure or case is not determined, the aim is mostly choosing protection level 1 in designs and applications of LPS's.

In comparison of standards, all the reviewed standards resulted in different protection levels. When the protection level is not defined properly, the expenditure for a LPS can change very greatly as analysed in Chapter 4 . From protection level 4 to 1 , the cost for the LPS increases due to the increasing number of conductors and earthing rods.

The dilemma of an engineer is whether to apply the safest protection system or the less expensive system. In engineering, safety and cost are the most important two items to be taken into consideration. However, safety is mostly chosen due to the non-linear 
phenomenon of lightning which result in waste of money if the applied LPS is not in accordance with the proper and required protection level. Therefore, the weighting factors should be re-arranged numerically to cover less ground, and maybe introduced new weighting factors so that it can be detailed, to obtain the required protection level for any case.

The significant effect of the high range of weighting factors is observed in the Turkish draft. Table 5.1 given above is obtained using the equations and tables given in Turkish draft for the limits of collection area. In this analysis, the isoceraunic map of Turkey given in Figure 1.2 is used.

Table 5.1 Required Ac values according to the computed effectiveness $E$

\begin{tabular}{|c|c|c|c|c|}
\hline $\begin{array}{c}\text { Protection } \\
\text { level }\end{array}$ & E & Nc/Nd & $\begin{array}{c}\text { Min Ac } \\
\left(\mathbf{m}^{2}\right)\end{array}$ & $\begin{array}{c}\text { Max Ac } \\
\left(\mathbf{m}^{2}\right)\end{array}$ \\
\hline $\begin{array}{c}\text { I + } \\
\text { additional } \\
\text { measures }\end{array}$ & 0.98 & 0.02 & $4.0^{*} 10^{-10}$ & $5.3^{*} 10^{10}$ \\
\hline I & 0.95 & 0.05 & $1.6^{*} 10^{-10}$ & $2.1^{*} 10^{10}$ \\
\hline II & 0.90 & 0.10 & $8.0^{*} 10^{-11}$ & $1.1^{*} 10^{10}$ \\
\hline III & 0.80 & 0.20 & $4.0^{*} 10^{-11}$ & $5.3^{*} 10^{9}$ \\
\hline IV & $0<\mathrm{E}<0.80$ & $1>\mathrm{Nc} / \mathrm{Nd}>0.2$ & $\begin{array}{c}4.0^{*} 10^{-11}> \\
\mathrm{Ac}>8.0^{*} 10^{-12}\end{array}$ & $\begin{array}{c}5.3^{*} 10^{9}> \\
\mathrm{Ac}>1.1^{*} 10^{9}\end{array}$ \\
\hline $\begin{array}{c}\text { No } \\
\text { protection }\end{array}$ & $\mathrm{E}<0$ & $\mathrm{Nc} / \mathrm{Nd}>1$ & $8.0^{*} 10^{-12}>\mathrm{Ac}$ & $1.1^{*} 10^{9}>\mathrm{Ac}$ \\
\hline
\end{tabular}

To obtain the minimum collection area, $\mathrm{Nc}_{\min }=5^{*} 10^{-17}, \mathrm{Ce}=2 ; \mathrm{Ng}=3.128$ when $\mathrm{Nk}$ is taken as 32.7 which is the maximum ceraunic level in Muğla, Turkey according to Table 1.2. On the other hand, for maximum collection area, $\mathrm{Nc}_{\max }=800, \mathrm{Ce}=0.25, \mathrm{Ng}=0.3$ when $\mathrm{Nk}$ is taken as 5 which is the minimum ceraunic level in Hakkari, Turkey.

When Table 5.1 is analysed, the minimum values of the collection areas are clearly observed to be very small values and they have no meaning in practice. The maximum values are too 
high to be the area of any structure. It should be noted that the high range of Nc values in Turkish draft would probably results in protection level I and additional measures.

On the other hand, for the average case, Nc was calculated as $2.4^{*} 10^{-3}$. This corresponds to the collection area limits given in Table 5.1. When Table 5.2 is analysed, this time, the analysis of protection requirement results in generally protection level IV or no protection if an average structure in Turkey is thought to be $400 \mathrm{~m}^{2}\left(4 * 100 \mathrm{~m}^{2}\right)$ for houses.

Table 5.2 Required Ac values for $\mathrm{Nc}=2.4^{*} 10^{-3}$ corresponding to the average case

\begin{tabular}{|c|c|c|c|c|}
\hline $\begin{array}{c}\text { Protection } \\
\text { level }\end{array}$ & E & Nc/Nd & $\begin{array}{c}\text { Min Ac } \\
\left(\mathbf{m}^{2}\right)\end{array}$ & $\begin{array}{c}\text { Max Ac } \\
\left(\mathbf{m}^{2}\right)\end{array}$ \\
\hline $\begin{array}{c}\text { I + } \\
\text { additional } \\
\text { measures }\end{array}$ & 0.98 & 0.02 & 22,000 & $1,760,000$ \\
\hline I & 0.95 & 0.05 & 8,800 & 704,000 \\
\hline II & 0.90 & 0.10 & 4,400 & 352,000 \\
\hline III & 0.80 & 0.20 & 2,200 & 176,000 \\
\hline IV & $0<\mathrm{E}<0.80$ & $1>\mathrm{Nc} / \mathrm{Nd}>0.2$ & $\begin{array}{c}2,200> \\
\mathrm{Ac}>440\end{array}$ & $\begin{array}{c}176,000> \\
\mathrm{Ac}>35,200\end{array}$ \\
\hline $\begin{array}{c}\text { No } \\
\text { protection }\end{array}$ & $\mathrm{E}<0$ & $\mathrm{Nc} / \mathrm{Nd}>1$ & $440>\mathrm{Ac}$ & $35,200>\mathrm{Ac}$ \\
\hline
\end{tabular}

The other important point is that the Turkish standards are prepared either by translation of IEC standards or by combination of different standards. In lightning protection, the problem begins when determining the lightning flash density. Turkish Standard and new draft use the same formula given in IEC Standard directly although it is noted that the lightning flash density changes with the climatic changes.

This is the critical point due to different climatic conditions of Turkey. If the American Standard is taken into account, it recommends an additional coefficient due to the differences between the different regions of the country. The reason is that the storm characteristics are different. It should be noted that there are seven different regions in Turkey. 
Due to the different climatic conditions, the storm characteristics are different. Instead of a formulation belonging to Turkey and assigning different coefficients for the different regions, taking the same formula from IEC is meaningless. Therefore, Turkey should prepare its own standards according to its own conditions and requirements. The calculations and analysis should be done with Turkey's own procedure prepared to Turkey's conditions.

Another point is the slopes used in the calculation of collection areas. Spanish Standard uses 1:3 slopes while it is $1: 1$ in BS. 1:3 and 1:1 slopes correspond to the shielding angles of $72^{\circ}$ and $45^{\circ}$, respectively. In rolling sphere method, there is no correspondence for $1: 3$ slopes. For $(h, R)=(10,60)$; the shielding angle according to equalized calculation in the derivation of shielding angles is nearly $65^{\circ}$. It can be obtained only when the difference between the height and the radius is increased, i.e., $\mathrm{R}$ would be increased or $\mathrm{h}$ would be decreased.

On the other hand, $45^{\circ}$ which corresponds to $1: 1$ slope is only satisfied when $R=2^{*} h$ in accordance with the equalized calculation. Besides BS, $45^{\circ}$ are accepted as the shielding angle for a single rod in many standards and applications. However, this is a wrong assumption if the rolling sphere method is analysed and applied. Especially, German Standard, which is not reviewed in this thesis, defines $45^{\circ}$ as the shielding angle of a VC.

\subsection{Changing Philosophy in Lightning Protection}

Since Franklin, many developments were done in lightning protection methods. The recent and widely used system is ESE type lightning arresters, which are claimed to increase the effectiveness of Franklin rods. However, if the discussions about ESE type lightning arresters carried out and the experiments done to compare the effectiveness of ESE types with the simple Franklin rods, ESE type of lightning arresters although claimed to be very efficient by manufacturers, are not verified and many important scientist claim that the ESE types do the same job as Franklin rods do.

From a different view, they can be thought to be Franklin type lightning arresters in accordance with the changing philosophy in lightning protection. The new requirements are not satisfied by catching and grounding the lightning stroke only. In additions to these, EMI should be prevented.

Recent and sound scientific analyses and experiments now reveal 1) that the Franklin type LPS is effective at preventing fires in non-conducting structures, 2) that it is ineffective for the protection of sensitive contents, such as electronics or explosives, from high electric fields 
and arcing within conducting structures (modern structures with a steel skeleton and/or metallic skin), and 3) that the Franklin LPS and its variants do not effectively dissipate electric charge from clouds and thus do not prevent lightning flashes. ${ }^{49}$

Due to the still continuing discussions on ESE type arresters which have not been scientifically proven in natural observations and tests; scientists and engineers developed the oldest method called cage method the basis of which is set by James Maxwell nearly 150 years ago before ESE type lightning arresters.

The best protection could be obtained by a totally closed cage that is the Faraday Cage. However, the consequence of this application is no signal transfer into the structure such as radio waves etc. Besides this result, the cost would be very high to form a totally closed cage. In practical, by forming meshes and adjusting the space between the conductors a cage is obtained but not a Faraday Cage. This could be thought as an approximation to the ideal case.

Only cage method is sufficient to prevent the consequences of a lightning stroke such as EMI, flash over and induced voltage problems, thermal effects by increasing the number of current paths to minimize the lightning currents flowing through the conductors by forming meshes and equipotential bonding.

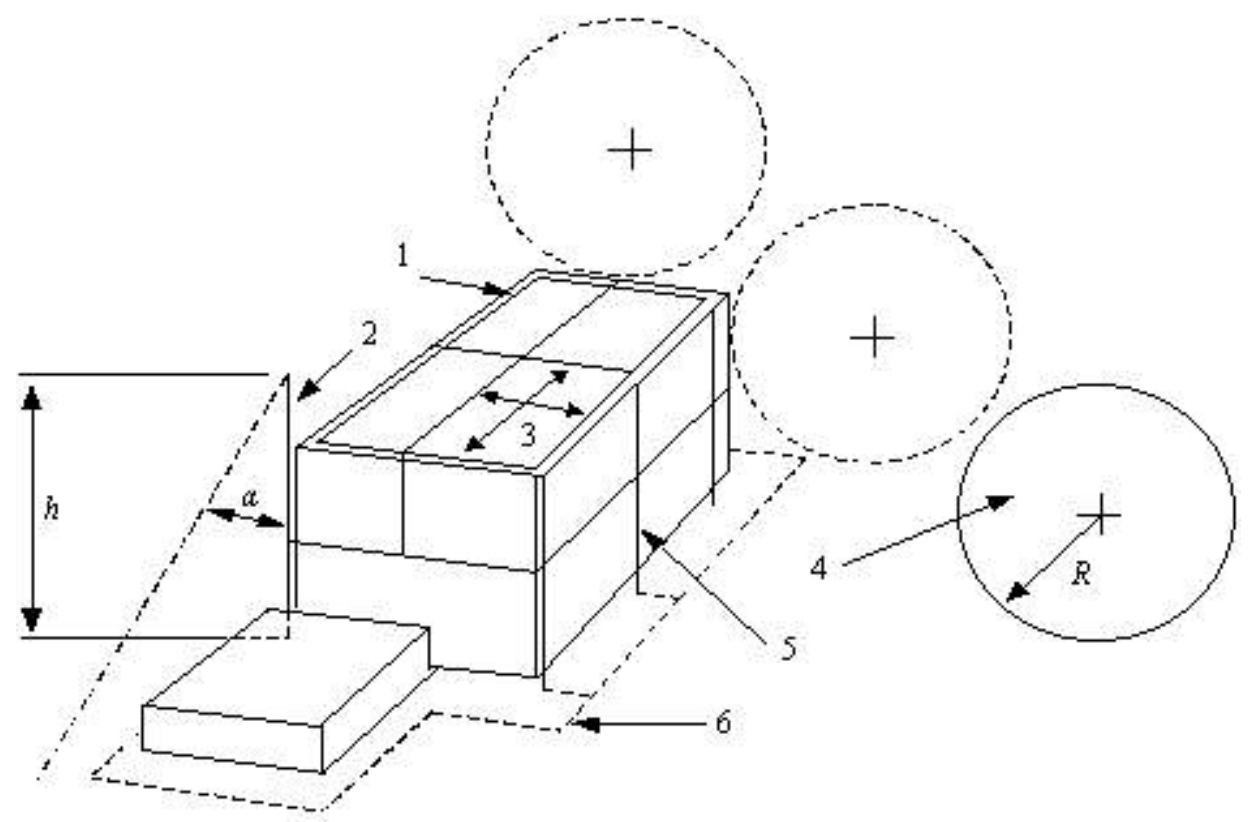

Figure 5.1 Combinations of Methods to Establish the Safest LPS 


\subsection{Deviations from Cage Method}

In a pure cage method, there are only mesh on the top of structures and down conductors to make the connection between the mesh and the grounding system. To prevent flashover problems, equipotential bonding is satisfied in addition to these.

However, today, the engineers use a combination of methods; the cage method taken as the basis and modified by Franklin type of rods which is assumed to make the structure safer although there are no theoretical back ground with the basis of cage method.

A typical application is shown in Figure 5.1. If it is analysed, the parts numbered by 1, 3, 5 and 6 are the basis of a cage method. The VC indicated by 2 with a shielding angle $\alpha$ and conductor length $h$ is a Franklin type LPS. Number 4 shows the rolling sphere with radius $R$.

These types of applications show how much work to be done in the future that can only be obtained by more observation of the lightning phenomenon, as it is a very complicated process and cannot be duplicated in the laboratories. 


\section{REFERENCES}

${ }^{1}$ V.A. Rakov and M.A. Uman, Lightning: Physics and Effects, Cambridge U. Press, 2003. M.A. Uman, The Lightning Discharge, Academic Press, London 1987.

M.A.Uman, Understanding Lightning, BEK Technical Publications, Carnegie, PA 1971.

M.A.Uman, Lightning, McGraw-Hill Book Company, New York, 1969.

R.H. Golde, Lightning, V1-V2, Academic Press, 1977.

${ }^{2}{ }^{3}$ Access on Jan. 30, 2004, BOLT Lightning Protection, About Lightning "Lightning Damage", http://www.boltlightningprotection.com/lightning_damage.htm.

${ }^{4}$ BOLT, Inc -Business of Lightning Technology is a start-up service company whose purpose is to advise customers on the robustness or vulnerability of their facilities to lightning strikes and to guide improvements on customers' facilities.

${ }^{5}$ Access on Jan. 30, 2004, BOLT Lightning Protection, About Lightning "Lightning Damage", http://www.boltlightningprotection.com/lightning_damage.htm.

${ }^{6}$ Electric Power Research Institute, 1999.

${ }^{7}$ Insurance Information Institute, 1999.

${ }^{8}$ Contemporary Lightning Safety for Environments Containing Sensitive Electronics, Explosives and Volatile Substances, Richard Kithil, President \& CEO National Lightning Safety Institute.

${ }^{9}$ US Dept. Energy - Occurrence Reporting \& Processing System, 2000.

${ }^{10}$ National Lightning Safety Institute, 1999.

11 Contemporary Lightning Safety for Environments Containing Sensitive Electronics, Explosives and Volatile Substances, Richard Kithil, President \& CEO National Lightning Safety Institute.

${ }^{12}$ Access on Jan. 30, 2004, BOLT Lightning protection, About Lightning "Lightning Damage", http://www.boltlightningprotection.com/lightning_damage.htm.

${ }^{13}$ DDESB, Department of Defence (DoD) Explosives Safety Board. 
${ }^{14}$ 21st Century Lightning Safety for Explosives Facilities, Richard Kithil, President \& CEO, National Lightning Safety Institute.

15 Access on Apr. 1, 2004, DEHN + SÖHNE, Introduction into Lightning and Surge Protection, http://www.dehn.de/www_DE/PAGES_E/service/downloads/publikation.html.

${ }^{16}$ In his book of Understanding Lightning, M.A. Uman put some part of a letter of Benjamin Franklin written in May 1749 and published in Gentlemen's Magazine in May 1750.

${ }^{17}$ Chairman Sir Brian Flowers, Nuclear Power and the Environment Royal, Sixth Report, Commission on Environmental Pollution.

${ }^{18}$ Access on Jan. 30, 2004, BOLT Lightning protection, Conventional Protection "History and Overview", http://www.boltlightningprotection.com/history_overview.htm.

${ }^{19}$ Protection of structures and of open areas against lightning using early streamer emission air terminal, Spanish Standard UNE 21-186, June 1996.

20 M.Darveniza, F. Popolansky and E: R: Whitehead: "Lightning Protection of UHV Transmission Lines", ELECTRA No 41, 1975.

21 IEC TC 81:Lightning Protection, Comments of the Danish National Committee on Document 81 Secretariat 21c: Draft Standard on Lightning Protection of Structures, Part A., Vol.2; July 1986.

${ }^{22}$ Protection of structures and of open areas against lightning using early streamer emission air terminal, Spanish Standard UNE 21-186, June 1996.

23 IEC TC 81:Lightning Protection, Comments of the Danish National Committee on Document 81 Secretariat 21c: Draft Standard on Lightning Protection of Structures, Part A., Vol.2; July 1986, Appendix. It is used as an appendix to the present paper by courtesy of Prof, Dr. Ing. Johannes Wiesinger.

${ }^{24}$ R.H. Golde, Lightning, V2, Academic Press, 1977.

${ }^{25}$ Forend Europe ESE Lightning Conductor.

${ }^{26}$ Saint-Elmo ESE Lightning Conductor of Franklin France.

${ }^{27}$ Tesla-S ESE Lightning Conductor. 
${ }^{28}$ The Basis of Conventional Lightning Protection Technology, A Review of the Scientific Development of Conventional Lightning Protection Technologies and Standards, Report of the Federal Interagency Lightning Protection User Group, June 2001.

${ }^{29}$ International Conference on Lightning Protection.

${ }^{30}$ Scientists Oppose Early Streamer Air Terminals, Prof. Dr. Ing. C. Mazzetti, President of ICLP, Prof. Dr. Zdobyslaw Flisowski, Vice President of ICLP and Abdul M. Mousa; Burnaby, BC Canada.

${ }^{31}$ The NFPA draft Standard 781.

32-34 IEC TC 81:Lightning Protection, Comments of the Danish National Committee on Document 81 Secretariat 21c: Draft Standard on Lightning Protection of Structures, Part A., Vol.2; July 1986, Appendix 2.

${ }^{35}$ R.H. Golde, Lightning, V2, Academic Press, 1977.

${ }^{36}$ Access on Jan. 30, 2004, BOLT Lightning Protection, About Lightning "Lightning Damage", http://www.boltlightningprotection.com/lightning_damage.htm.

${ }^{37}$ M. A. Uman and V. A. Rakov, A Critical Review of Nonconventional Approaches To Lightning Protection, American Meteorological Society, December 2002.

38-39 Access on Jan. 30, 2004, BOLT Lightning Protection, Modern Protection "Elemental Faraday Cage", http://www.boltlightningprotection.com/Elemental_Faraday_Cage.htm.

${ }^{40}$ Access on Jan. 30, 2004, BOLT Lightning protection, Conventional Protection "History and Overview", http://www.boltlightningprotection.com/history_overview.htm.

${ }^{41}$ Access on Dec. 25, 2003, DEHN + SÖHNE, Principles for Designing External LPS's, http://www.dehn.de/www_DE/PAGES_E/service/downloads/publikation.html.

${ }^{42-43}$ Code of Practice for Protection of Structures against Lightning, BS 6651, 1999.

${ }^{44}$ Richard Kithil-President \& CEO of NLSI, Contemporary Lightning Safety for Environments Containing Sensitive Electronics, Explosives and Volatile Substances.

${ }^{45}$ Protection of structures and of open areas against lightning using early streamer emission air terminal, Spanish Standard UNE 21-186, June 1996.

${ }^{46-47}$ Access on Jan. 30, 2004, BOLT Lightning Master, Bonding and Grounding, http://www.lightningmaster.com/bonding-grounding.htm. 
${ }^{48}$ Access on Jun. 21, 2004, BOLT Lightning Master, Bonding and Grounding, http://www.lightningmaster.com/bonding-grounding.htm.

${ }^{49}$ Access on Jan. 30, 2004, BOLT Lightning Protection, Conventional Protection "History and Overview", http://www.boltlightningprotection.com/history_overview.htm.

${ }^{50}$ Access on Jan. 30, 2004, BOLT Lightning Protection, Martin A. Uman, About Lightning, "Lightning Physics", http://www.boltlightningprotection.com/lightning_physics.htm.

${ }^{51}$ Peter E. Viemeister, The Lightning Book, the MIT Press, 1972.

${ }^{52}$ Access on Jan. 30, 2004, BOLT Lightning Protection, Martin A. Uman, About Lightning, "Lightning Physics", http://www.boltlightningprotection.com/lightning_physics.htm.

${ }^{53}$ J.L.Marshall, Lightning Protection, a Wiley-Interscience Publication.

${ }^{54}$ Burçin Renda, Electrical Eng, Kaynak Elektrik, Jan 2004.

${ }^{55-58}$ J.L.Marshall, Lightning Protection, a Wiley-Interscience Publication.

${ }^{59}$ Access on Jan. 30, 2004, BOLT Lightning Protection, Martin A. Uman, About Lightning, "Lightning Physics", http://www.boltlightningprotection.com/lightning_physics.htm.

${ }^{60}$ M.A. Uman, Lightning, McGraw-Hill Book Company, New York, 1969.

${ }^{61}$ M.A.Uman, Understanding Lightning, BEK Technical Publications, Carnegie, 1971.

${ }^{62}$ R.H.Golde, Lightning Protection, Edward Arnold Publishers Ltd, London, 1973.

${ }^{63}$ M.A.Uman, Understanding Lightning, BEK Technical Publications, Carnegie, 1971.

${ }^{64}$ Yıldırımdan Korunma ve Topraklama, Radsan AŞ.

65 Contemporary Lightning Safety for Environments Containing Sensitive Electronics, Explosives and Volatile Substances, Richard Kithil, President \& CEO, National Lightning Safety Institute.

${ }^{66}$ J.L.Marshall, Lightning Protection, a Wiley-Interscience Publication.

${ }^{67}$ Access on Mar. 09, 2004, National Lightning Safety Institute, R.T. Hasbrouck, Determining the Probability of Lightning Striking a Facility http://www.lightningsafety.com/nlsi_lhm/prbshort.html, Revised on Apr 18, 2004. 


\section{APPENDIX A}

\section{LIGHTNING}

Here, the lightning concept is held in details covering the formation of a lightning, the discharge process, steps of discharge and its characteristics.

\section{A.1 History of Understanding Lightning}

"Benjamin Franklin, more than 200 years ago, proved that lightning was an electrical discharge and measured the sign of the cloud charge that produced it. Modern research on the physics of lightning began in the early 20th century with the work of C.T.R. Wilson, the same scientist who received the Nobel Prize for his invention of the cloud chamber. Wilson, by making and analysing remote measurements of thunderstorm electric fields, was the first to infer the charge structure of the thundercloud and the amount of charge involved in lightning. In the 1930's, lightning research was motivated primarily by the need to reduce the effects of lightning on electric power systems and by the desire to understand an important meteorological process. The pace of that research was fairly steady until the 1960s when there was renewed interest because of the generally unexpected vulnerability of solid state electronics to damage from lightning-induced voltages and currents with the resultant hazard to both modern ground-based and airborne systems. ${ }^{50}$

\section{A.2 Sources and the Nature of Lightning}

The lightning is not a mystery anymore. It is not the weapon of Zeus as early Greeks believed or it is not the flash of thunderbird's eye as one of the myths of the American Indians. ${ }^{51}$ However, these are normal beliefs if the ancient history or tribal cultures are thought. Modern thoughts left behind these myths. With the development of science and technology, the reasons of the natural events have been understood.

"The classic model for the charge structure of a thundercloud was developed in the 1920's and 1930's from ground-based measurements of both thundercloud electric fields and the electric field changes that are caused when lightning occurs. In this model, the thundercloud 
forms a positive electric dipole as shown in Figure A.1 (a, b) and Figure A.2; that is, a primary positive charge region is found above a primary negative charge region. By the end of the 1930's, this overall structure had been verified from measurements made with sounding balloons inside clouds and had also identified a small localized region of positive charge at the base of the cloud. Subsequent measurements of electric fields both inside and outside the cloud have confirmed the general validity of this double-dipole structure."52

As in the definitions, lightning is an electrical discharge and begins with electric dipoles in the atmosphere. This basic electrical event in the thunderclouds should be understood before continuing with the nature of lightning and its characteristics.

The place, the pre-condition for a lightning is a thundercloud. Usually this cloud is cumulonimbus. There have been limited studies of the electrical properties of other types of clouds that might potentially produce lightning. Most research has been focused on cumulonimbus, the familiar thundercloud. Because this cloud type produces most of the lightning. The development of a thundercloud requires air movement, moisture and a rather specific temperature change.

For brief generation process of thunderclouds, J.L.Marshall notes that "they start with warm moist air rising from the surface and cooling (because of expansion) then mixing with less moist surrounding air that has been at a height of several kilometers for a period of hours. Clouds are mixture of air with different histories and include mixtures of a variety of "hydrometeors" (i.e., particles of solid or liquid water); the mixing activity continues through the few-hours' lifetime of the cloud or storm... The charge separation is related to the super cooling, and in some cases the freezing, of droplets; and the disposition of charge concentrations in the mature thundercloud is due, in some part, to the vertical circulation... The counter flow of air in the developing thundercloud carries a positive charge upward and a negative charge downward... This positioning of the charges is sometimes referred to as bipolar, or dipoles of charge. ${ }^{.53}$ The small particles carry negative, the bigger ones carry positive charges. ${ }^{54}$

J.L.Marshall continues, "A normal thundercloud will comprise of several dipoles of charge. The whole cloud may have lateral dimensions of several kilometers; its base may be 1 or 2 $\mathrm{km}$ above ground, and its top, 10 to $14 \mathrm{~km}$ above ground. ${ }^{55}$

Up to this point, Marshall's ideas about dipole generation are accepted throughout the scientists. When a dipole of charge is occurred, there is an electric field and thus a potential difference. After some while of dipole generation process, there is an increase observed in 
the concentrations of charge due to separation of charge events. As these amounts of charge are increased, "the potential drop across any vertical unit distance of the charged mass similarly increases." ${ }^{56}$ This increase continues until a saturation point or "mature stage" that discharges becomes.

"The steady electrical field is about $3 \mathrm{~V} / \mathrm{cm}$ near ground level under fair weather conditions. During thunderstorm development this can rise to 500 or $600 \mathrm{~V} / \mathrm{cm}$ beneath the thunderclouds and too much higher values near ground level below a stepped leader... At the mature stage, the total potential difference between the main charge centres is $10^{8}$ to $10^{9}$ V." ${ }^{57}$

In his same book, J.L.Marshall summarizes the process as follows: "The electrical charge that develops in a thundercloud to an intensity sufficient to initiate lightning usually has a concentration of negative charge near the cloud base and a positive charge near its top." ${ }^{58}$
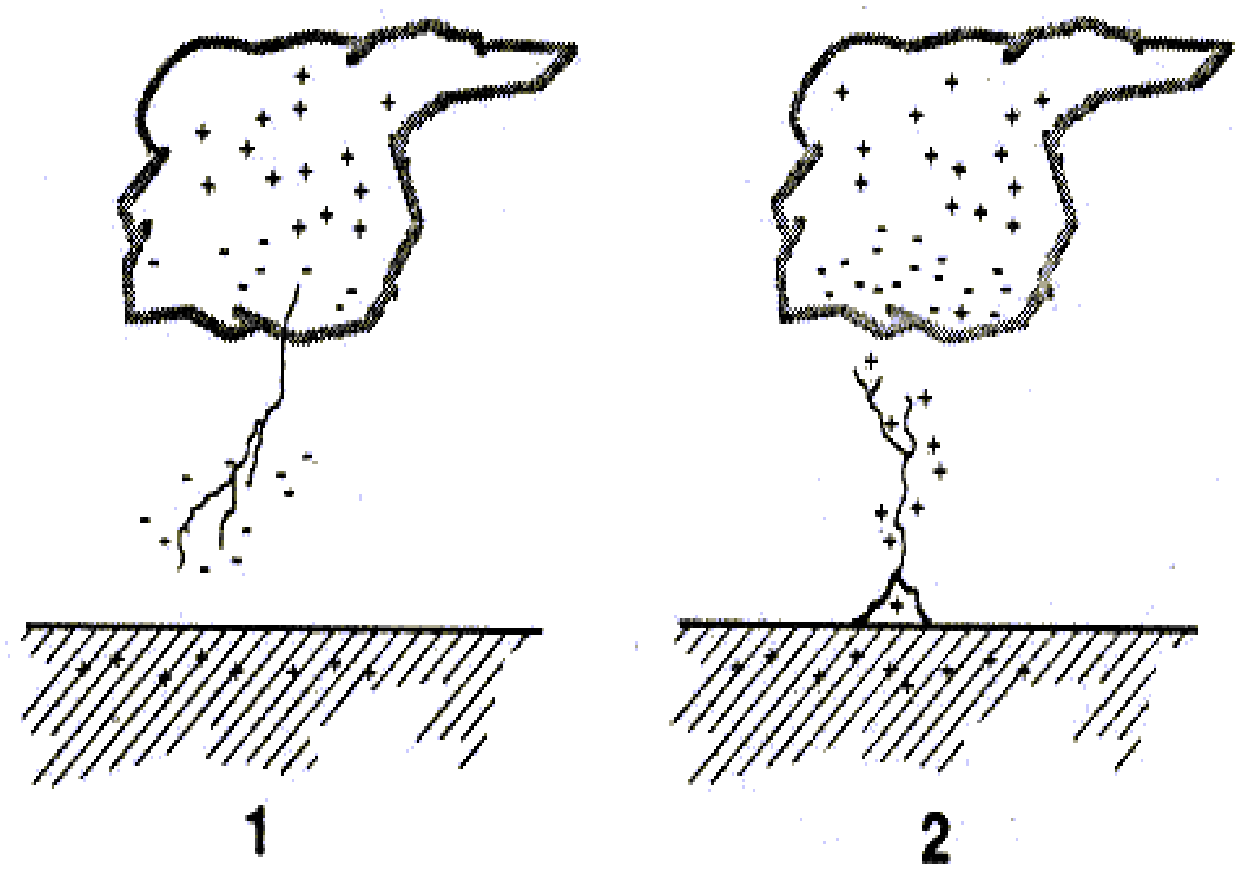

Figure A.1.a Thundercloud charge distribution and categorization of the four types of lightning between cloud and ground. 


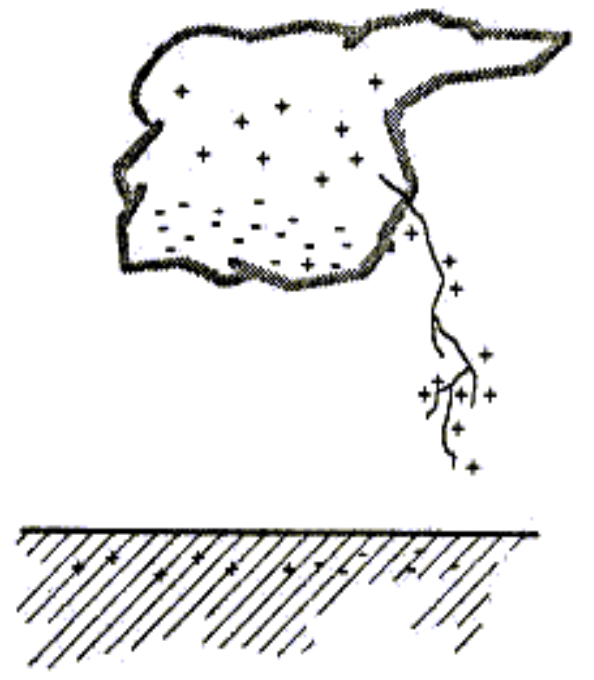

3

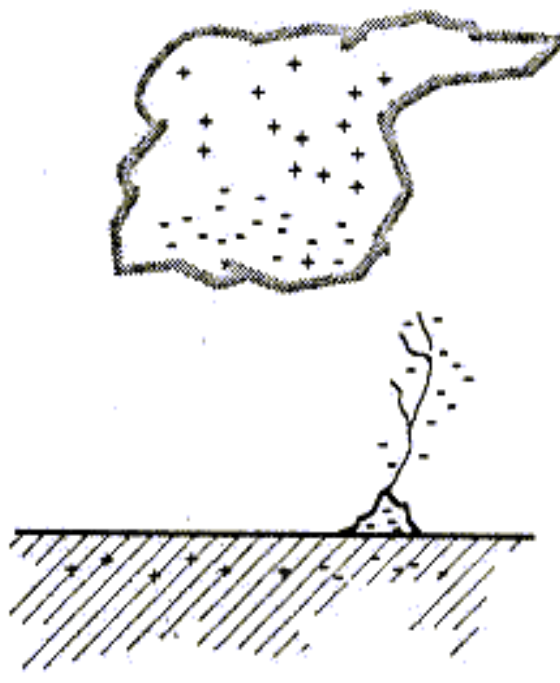

4

Figure A.1.b Thundercloud charge distribution and categorization of the four types of lightning between cloud and ground.

"Four different types of lightning between cloud and Earth have been identified, the ways by which these are initiated being shown in Figure A.1 (a, b). Cloud to Ground (CG) flashes initiated by downward-moving negatively-charged leaders probably account for about $90 \%$ of the CG discharges worldwide (Figure A.1.a, category 1 ), while less than $10 \%$ of lightning discharges are initiated by a downward-moving positive leaders (Figure A.1.b, category 3). Ground-to-cloud discharges are also initiated by leaders of either polarity that move upwards from the Earth (Figure A.1.a, category 2; Figure A.1.b, category 4). These upward-initiated flashes are relatively rare and usually occur from mountain peaks and tall man made structures." 59

This thesis is based on Cloud to Ground (CG) flashes initiated by downward-moving negatively charged leaders of nearly $90 \%$ of the CG discharges worldwide (Figure A.1.a, category 1).

"A CG lightning discharge is made up of one or more intermittent partial discharges. We shall call the total discharge (whose time duration is of the order of $0.2 \mathrm{sec}$ ) a flash; we shall call each component discharge (whose luminous phase is measured in tenths of milliseconds) a 
stroke. There are usually three or four strokes per flash, three strokes being separated by 40 msec or so."

\section{A.3 General Steps of Lightning Discharge}

From a CG discharge, forming a channel like a conductor wire should be understood. Through this channel Coulombs of charge is transferred to ground. While moving negative charges downwards, positive charges induced on Earth. When the negative charges come near to the Earth (or high Electrical Fields), the discharge occurs. Both negative and positive charges neutralize each other. The general properties of this process is quoted from Martin A. Uman:

"The usual lightning flash between Cloud and Ground begins with a visually-undetected downward-moving travelling spark called the stepped leader. Since the lightning flash begins with a downward-moving discharge, lightning moves from the cloud to the ground.

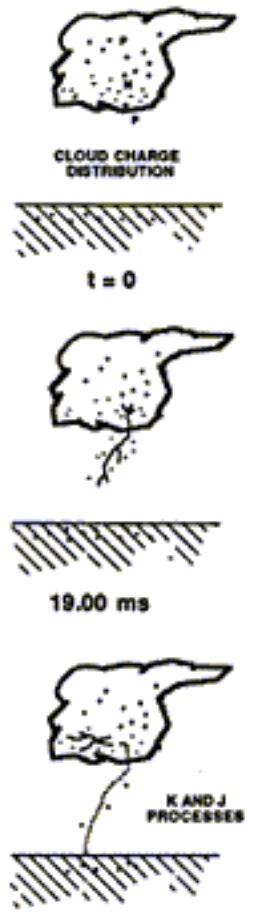

$40.00 \mathrm{~ms}$

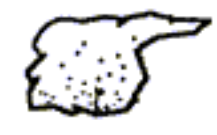

Bequinowary

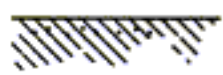

$1.00 \mathrm{~ms}$

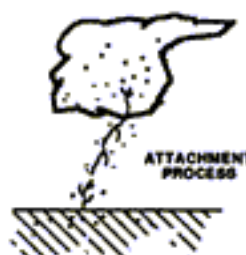

$20.00 \mathrm{~ms}$

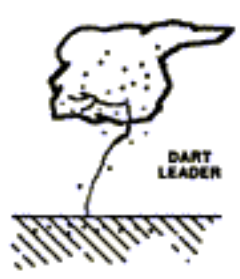

$60.00 \mathrm{~ms}$

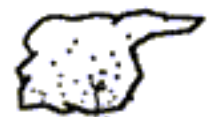

itepeso

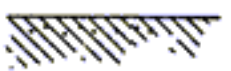

$1.10 \mathrm{~ms}$

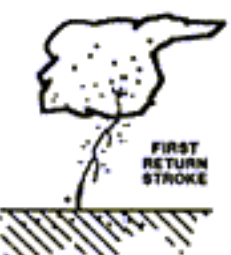

$20.10 \mathrm{~ms}$

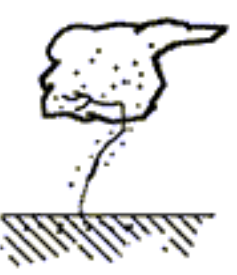

$61.00 \mathrm{~ms}$
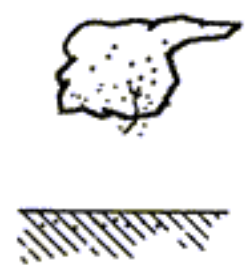

$1.15 \mathrm{~ms}$

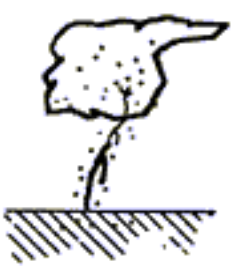

$20.15 \mathrm{~ms}$

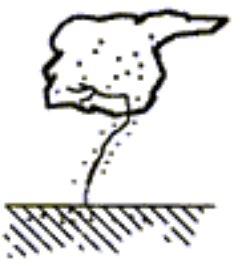

$62.00 \mathrm{~ms}$
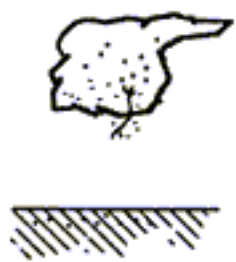

$1.20 \mathrm{~ms}$

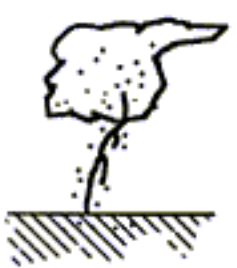

$20.20 \mathrm{~ms}$

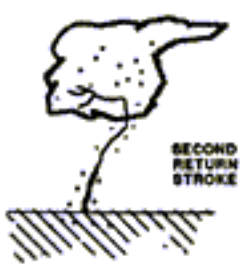

$62.05 \mathrm{~ms}$

Figure A.2 Various processes that make up a negative CG lightning discharge 
When the stepped leader gets closer to ground (20 to $70 \mathrm{~m}$ above ground depending on the existing field potential; whereas J. Sherlock says 50 to $100 \mathrm{~m}$ ), the leader channel first becomes highly luminous at the ground and then at higher and higher altitudes. The bright, visible channel, or so-called return stroke, is formed from the ground up, neutralizing the channel as shown in Figure A.2. The important part of a lightning flash with regard to the resulting damage is the return stroke. The current in this stroke ranges from about $2 \mathrm{kA}$ to about $200 \mathrm{kA}$.

After the stroke current has ceased to flow, the lightning flash may be ended, in which case the discharge is called single-stroke flash. Most flashes contain three or four strokes, typically separated by gaps of 40 or $50 \mathrm{msec}$ [it is $50 \mathrm{~ms}$ to $100 \mathrm{~ms}$ given in BS 6651:1999], if additional charge is available to the channel top by the action of electrical discharges.

When this additional charge is available, a continuous leader, known as a dart leader, moves down the defunct return stroke channel again depositing negative charge from the negative region along the channel. The dart leader thus sets the stage for the second (or any subsequent) return stroke. The dart leader's earth trip takes a few milliseconds." ${ }^{\prime 61}$

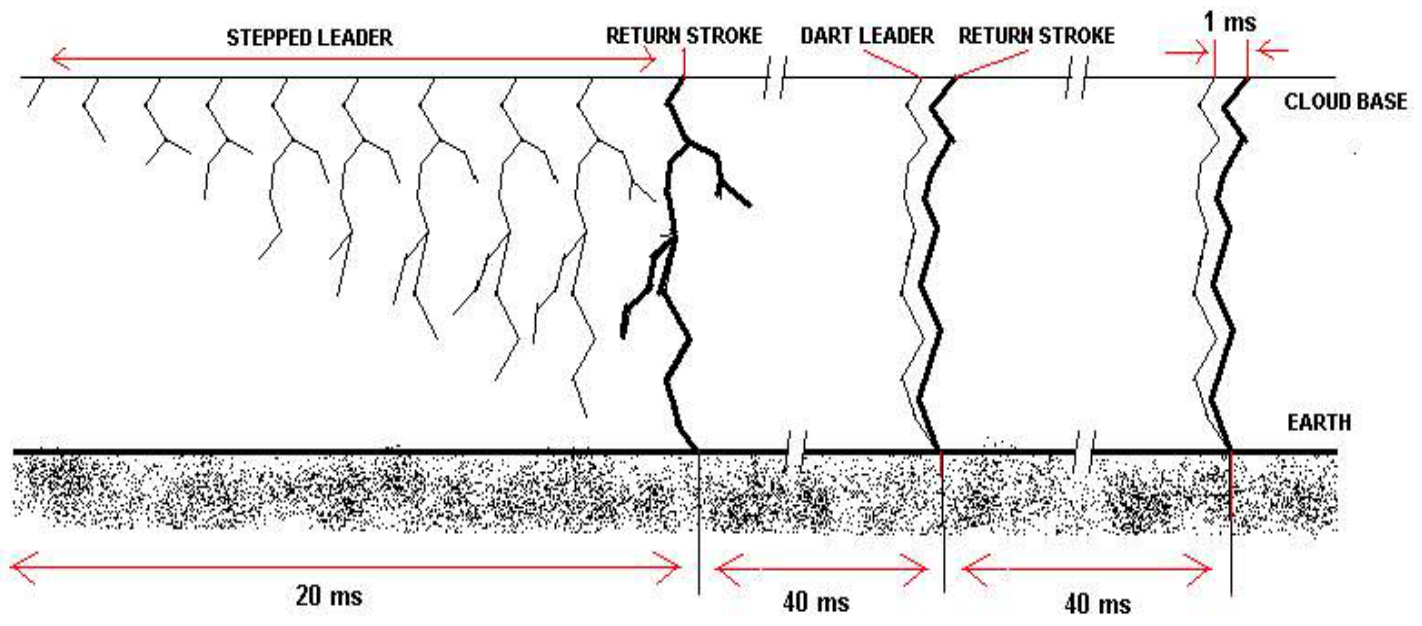

Figure A.3 Discharge process of multiple stroke flash from left to right (according to camera records)

With the time durations given by R.H. Golde ${ }^{62}$, which are nearly the same as that of M.A. Uman given in Figure A.3, the process can be summarized as follows: 
When the discharge begins, the first channel occurs and the stepped leader moves from cloud to earth carrying negative charges. This approximately takes $20 \mathrm{~ms}$ to reach the ground. The return stroke takes 100 microseconds or thereabouts (60-70 microseconds says Uman) to rise up. After $40 \mathrm{~ms}$, the dart leader progresses towards earth. Moreover, in $1 \mathrm{~ms}$, the subsequent return stroke returns back to cloud base. Again after $40 \mathrm{~ms}$, the subsequent dart leader moves downwards to earth. The next return stroke moves upwards in $1 \mathrm{~ms}$. This process continues until no additional charge is available to the channel top.

Although a lightning flash lasting 15 to $20 \mathrm{sec}$ has been reported by Godlonton (1896), the total discharge time duration of a flash is of the order of $0.2 \mathrm{sec}$.

\section{A.4 Lightning Characteristics}

After the discharge process study, the characteristics of a lightning discharge should be examined before the protection against lightning concept. The power of a lightning disaster comes out from these parameters.

Lightning discharge is an impulse and it is mainly characterized by parameters related to an impulse wave. The most important parameters are the following: Amplitude, Rise Time, Decay Time and Time Variation Rate (di/dt). Moreover, Polarity, Charge, Specific Energy and Number of Strikes per Discharge must be thought as lightning parameters.

\section{A.4.1 Definitions}

- Lighting Current (i): The current flowing at the point of strike.

- Peak Value (I): The maximum value of the lightning current in a flash.

- Average stepness of lightning current (di/dt): The difference between the lightning current values at the start and at the end of a specified time interval [i (t2) $\mathrm{i}(\mathrm{t} 1)]$ divided by the specified time interval [t2-t1].

- Flash duration (T): Time for which the lightning current flows at the point of strike.

- Total charge $\left(Q_{\text {total }}\right)$ : The time integral of the lightning current for entire lightning flash duration. 
- Impulse charge $\left(Q_{\text {impulse }}\right)$ : The time integral of the lightning current for the impulse part of the lightning flash duration.

- Specific energy (W/R): The energy dissipated by the lightning current in a unit resistance. It is the time integral of the square of the lightning current for the duration of the lightning flash.

\section{A.4.2 Lightning Current Parameters - Cumulative Frequency Distribution}

Below, the basic values of lightning current parameters - cumulative frequency distribution can be seen which are taken from IEC 1024-1-1.

Table A.1 Cumulative frequency of Peak Current (kA) (min 2 kA)

\begin{tabular}{|l|c|c|c|c|c|}
\hline \multirow{2}{*}{ Lightning Stroke } & \multicolumn{5}{|c|}{ Cumulative frequency } \\
\cline { 2 - 6 } & $\mathbf{9 8 8}$ & $\mathbf{9 9 5}$ & $\mathbf{9 8 0}$ & $\mathbf{\% 5 0}$ & $\mathbf{\% 5}$ \\
\hline First negative strokes & 4 & & $\mathbf{2 0}$ & & 90 \\
\hline $\begin{array}{l}\text { Subsequent negative } \\
\text { strokes }\end{array}$ & & 4.6 & & 12 & 30 \\
\hline Positive flashes & & 4.6 & & 35 & 250 \\
\hline
\end{tabular}

Table A.2 Cumulative frequency of Total Charge (C)

\begin{tabular}{|l|c|c|c|}
\hline \multirow{2}{*}{ Lightning Stroke } & \multicolumn{3}{|c|}{ Cumulative frequency } \\
\cline { 2 - 4 } & \%95 & \%50 & \%5 \\
\hline First negative strokes & 1.1 & 5.2 & 24 \\
\hline $\begin{array}{l}\text { Subsequent negative } \\
\text { strokes }\end{array}$ & 0.2 & 1.4 & 11 \\
\hline Negative flashes & 1.3 & 7.5 & 40 \\
\hline Positive flashes & 20 & 80 & 350 \\
\hline
\end{tabular}


Table A.3 Cumulative frequency of Impulse Charge (C)

\begin{tabular}{|l|c|c|c|}
\hline \multirow{2}{*}{ Lightning Stroke } & \multicolumn{3}{|c|}{ Cumulative frequency } \\
\cline { 2 - 4 } & $\mathbf{\% 9 5}$ & $\mathbf{\% 5 0}$ & $\mathbf{\% 5}$ \\
\hline First negative strokes & 1.1 & 4.5 & $\mathbf{2 0}$ \\
\hline $\begin{array}{l}\text { Subsequent negative } \\
\text { strokes }\end{array}$ & 0.22 & 0.95 & 4 \\
\hline Positive flashes & 2 & 16 & 150 \\
\hline
\end{tabular}

Table A.4 Cumulative frequency of Specific Energy $(\mathrm{J} / \Omega)$

\begin{tabular}{|l|c|c|c|}
\hline \multirow{2}{*}{ Lightning Stroke } & \multicolumn{3}{|c|}{ Cumulative frequency } \\
\cline { 2 - 4 } & $\% 95$ & $\% 50$ & $\% 5$ \\
\hline First negative strokes & $6.0 \times 10^{3}$ & $5.5 \times 10^{4}$ & $5.5 \times 10^{5}$ \\
\hline $\begin{array}{l}\text { Subsequent negative } \\
\text { strokes }\end{array}$ & $5.5 \times 10^{2}$ & $6.0 \times 10^{3}$ & $5.2 \times 10^{4}$ \\
\hline Positive flashes & $2.5 \times 10^{4}$ & $6.5 \times 10^{5}$ & $1.5 \times 10^{7}$ \\
\hline
\end{tabular}

Table A.5 Cumulative frequency of Time intervals between Lightning Strokes (ms)

\begin{tabular}{|l|c|c|c|}
\hline \multirow{2}{*}{ Lightning Stroke } & \multicolumn{3}{|c|}{ Cumulative frequency } \\
\cline { 2 - 4 } & $\% 95$ & $\% 50$ & $\% 5$ \\
\hline Multiple negative strokes & 7 & 33 & 150 \\
\hline
\end{tabular}

Table A.6 Cumulative frequency of Total Flash Duration $(\mu \mathrm{s})$

\begin{tabular}{|l|c|c|c|}
\hline \multirow{2}{*}{ Lightning Stroke } & \multicolumn{3}{|c|}{ Cumulative frequency } \\
\cline { 2 - 4 } & $\mathbf{\% 9 5}$ & $\mathbf{\% 5 0}$ & $\mathbf{\% 5}$ \\
\hline All negative flashes & 0.15 & 13 & 1100 \\
Subsequent negative strokes & 31 & 180 & 900 \\
\hline Positive flashes & 14 & 85 & 500 \\
\hline
\end{tabular}


Table A.7 Cumulative frequency of Rate of Rise (kA/ $\mu \mathrm{s})$

\begin{tabular}{|l|c|c|c|}
\hline \multirow{2}{*}{ First negative strokes } & \multicolumn{3}{|c|}{ Cumulative frequency } \\
\cline { 2 - 4 } & \%95 & \%50 & \%5 \\
\hline Maximum rate of rise & 9.1 & 24 & 65 \\
\hline Average stepness between: & & & \\
$30 \%$ and $90 \%$ of peak current & 2.6 & 7.2 & 20 \\
$10 \%$ and $90 \%$ of peak current & 1.7 & 5 & 14 \\
\hline
\end{tabular}

\begin{tabular}{|l|c|c|c|}
\hline \multirow{2}{*}{ Subsequent negative strokes } & \multicolumn{3}{|c|}{ Cumulative frequency } \\
\cline { 2 - 4 } & $\mathbf{9 5}$ & $\mathbf{9 5 0}$ & $\mathbf{5 5}$ \\
\hline Maximum rate of rise & 10 & 40 & 162 \\
\hline Average stepness between: & & & \\
$30 \%$ and $90 \%$ of peak current & 4.1 & 20 & 99 \\
$10 \%$ and $90 \%$ of peak current & 3.3 & 15 & 72 \\
\hline
\end{tabular}

\begin{tabular}{|l|c|c|c|}
\hline \multirow{2}{*}{ Positive flashes } & \multicolumn{3}{|c|}{ Cumulative frequency } \\
\cline { 2 - 4 } & $\% 95$ & $\% 50$ & $\% 5$ \\
\hline Maximum rate of rise & 0.2 & 2.4 & 32 \\
\hline
\end{tabular}

Table A.8 Cumulative frequency of Stroke Duration ( $\mu \mathrm{s}$ )

\begin{tabular}{|l|c|c|c|}
\hline \multirow{2}{*}{ Lightning Stroke } & \multicolumn{3}{|c|}{ Cumulative frequency } \\
\cline { 2 - 4 } & $\mathbf{\% 9 5}$ & $\mathbf{\% 5 0}$ & $\mathbf{\% 5}$ \\
\hline First negative strokes & 30 & 75 & 200 \\
\hline Subsequent negative strokes & 6.5 & 32 & 140 \\
\hline Positive flashes & 25 & 200 & 2000 \\
\hline
\end{tabular}


Table A.9 Cumulative frequency of Front Time Duration ( $\mu \mathrm{s})$

\begin{tabular}{|l|c|c|c|}
\hline \multirow{2}{*}{ First negative strokes } & \multicolumn{3}{|c|}{ Cumulative frequency } \\
\cline { 2 - 4 } & $\mathbf{9 9 5}$ & $\mathbf{6 5 0}$ & $\mathbf{\% 5}$ \\
\hline Total rise time & 1.8 & 5.5 & 18 \\
\hline Rise time between: & & & \\
$30 \%$ and $90 \%$ of peak current & 1.5 & 3.8 & 10 \\
$10 \%$ and $90 \%$ of peak current & 2.2 & 5.6 & 14 \\
\hline
\end{tabular}

\begin{tabular}{|l|c|c|c|}
\hline \multirow{2}{*}{ Subsequent negative strokes } & \multicolumn{3}{|c|}{ Cumulative frequency } \\
\cline { 2 - 4 } & $\mathbf{\% 9 5}$ & $\mathbf{\% 5 0}$ & $\mathbf{6 5}$ \\
\hline Total rise time & 0.2 & 1.1 & 4.5 \\
\hline Rise time between: & & & \\
$30 \%$ and $90 \%$ of peak current & 0.1 & 0.6 & 3.0 \\
$10 \%$ and $90 \%$ of peak current & 0.2 & 0.8 & 3.5 \\
\hline
\end{tabular}

\begin{tabular}{|l|c|c|c|}
\hline \multirow{2}{*}{ Positive flashes } & \multicolumn{3}{|c|}{ Cumulative frequency } \\
\cline { 2 - 4 } & $\mathbf{9 9 5}$ & $\mathbf{5 5 0}$ & $\mathbf{\% 5}$ \\
\hline Total rise time & 3.5 & 22 & 200 \\
\hline
\end{tabular}

\subsubsection{Lightning Current Amplitudes}

As the protection is concerned, mostly the amplitude of the lightning current will determine the protection level. Below, there are collected ideas about this topic.

"A fully developed stepped leader can effectively lower 10 Coulomb or more of negative charge toward to ground in tens of milliseconds." 63

On the other hand, "the charge amount in a lightning discharge is said to be lower than 1 Coulomb whereas it is $10-20$ Coulomb in intense lightning. Rarely, 75 Coulomb of charge is said to be detected." 64 
"Lightning's characteristics include current levels approaching $400 \mathrm{kA}$ with the $50 \%$ average being about $25 \mathrm{kA}$, temperatures to $15,000{ }^{\circ} \mathrm{C}$ and voltages in the hundreds of millions." 65

"The current in a stroke averages about $20 \mathrm{kA}$, but in exceptionally intense storms it can exceed $100 \mathrm{kA}$. The average charge released per flash is about 25 Coulombs." ${ }^{\prime 66}$

If the other scientists' notes and observations are examined, it can be concluded that current magnitudes can range from several kA up to $200 \mathrm{kA}$. However, current magnitudes over 100 kA are rare. The statistical average is 20-30 kA. The British Standard also verifies this conclusion:

In the "log-normal" distribution of the current of return strokes given in BS 6651:1999, Code of Practice for Protection of Structures against Lightning, the current amplitudes are as follows:

- $1 \%$ of strokes exceed $200 \mathrm{kA}$;

- $10 \%$ of strokes exceed $80 \mathrm{kA}$;

- $50 \%$ of strokes exceed $28 \mathrm{kA}$;

- $90 \%$ of strokes exceed $8 \mathrm{kA}$;

- $99 \%$ of strokes exceed $3 \mathrm{kA}$. 


\section{APPENDIX B}

WEIGHTING FACTORS OF SPANISH STANDARD (UNE 21-186:1996)

Table B.1 Weighting factor C2 (structural coefficient)

\begin{tabular}{|l|c|c|c|}
\hline \multicolumn{2}{|l|}{ C2, structural coefficient } \\
\hline Roof & Metal & Common & Flammable \\
\hline Metal & & & 2.0 \\
\hline Common & 0.5 & 1.0 & 2.5 \\
\hline Flammable & 1.0 & 1.0 & 3.0 \\
\hline
\end{tabular}

Table B.2 Weighting factor C3 (structural contents)

\begin{tabular}{|l|c|}
\hline C3, structural contents \\
\hline No value and non-flammable & 0.5 \\
\hline Standard value or normally flammable & 2.0 \\
\hline High value or particularly flammable & 5.0 \\
\hline Exceptional value, irreplaceable or highly flammable, explosive & 10.0 \\
\hline
\end{tabular}

Table B.3 Weighting factor C4 (structure occupancy)

\begin{tabular}{|l|c|}
\hline C4, structure occupancy & \\
\hline Unoccupied & 0.5 \\
\hline Normally occupied & 3.0 \\
\hline Difficult evacuation or risk of panic & 7.0 \\
\hline
\end{tabular}


Table B.4 Weighting factor C5 (lightning consequences)

\section{C5, lightning consequences}

Service continuity not required, and no consequences on the environment 1.0

Service continuity required, and no consequences on the environment

Consequences on the environment 5.0 
Table C.1 Weighting factor A (use of structure)

\begin{tabular}{|l|c|}
\hline Use to which structure is put & $\begin{array}{c}\text { Value of } \\
\text { factor A }\end{array}$ \\
\hline Houses and other buildings of comparable size & 0.3 \\
\hline Houses and other buildings of comparable size with an outside aerial & 0.7 \\
\hline Factories, workshops and laboratories & 1.0 \\
\hline $\begin{array}{l}\text { Office blocks, hotels, blocks of flats and other residential buildings other } \\
\text { than those below }\end{array}$ & 1.2 \\
\hline $\begin{array}{l}\text { Places of assembly, e.g. Churches, halls, theatres, museums, exhibitions, } \\
\text { department stores, post offices, stations, airports and stadium structures }\end{array}$ & 1.3 \\
\hline Schools, hospitals, children's and other homes & 1.7 \\
\hline
\end{tabular}

Table C.2 Weighting factor B (type of construction)

\begin{tabular}{|l|c|}
\hline Type of construction & $\begin{array}{c}\text { Value of } \\
\text { factor B }\end{array}$ \\
\hline Steel framed enchased or reinforced concrete with metal roof & 0.1 \\
\hline Steel framed enchased with any roof other than metal & 0.2 \\
\hline Reinforced concrete with any roof other than metal & 0.4 \\
\hline Brick, plain concrete or masonry with any roof other than metal or thatch & 1.0 \\
\hline Timber framed or clad with any roof other than metal or thatch & 1.4 \\
\hline Brick, plain concrete, masonry, timber framed but with metal roofing & 1.7 \\
\hline Any building with a thatched roof & 2.0 \\
\hline $\begin{array}{l}{ }^{*} \text { Structures of exposed metal, which are continuous down to ground level, are excluded } \\
\text { from the table, as lightning protection beyond adequate earthing is not needed. }\end{array}$ \\
\hline
\end{tabular}


Table C.3 Weighting factor C (contents or consequential effects)

\begin{tabular}{|l|c|}
\hline Contents or consequential effect & $\begin{array}{c}\text { Value of } \\
\text { factor C }\end{array}$ \\
\hline $\begin{array}{l}\text { Ordinary domestic or office buildings, factories and workshops not } \\
\text { containing valuable or specially susceptible contents* }\end{array}$ & 0.3 \\
\hline Industrial and agricultural buildings with specially susceptible contents* & 0.8 \\
\hline Power stations, gas installations, telephone exchanges, radio stations & 1.0 \\
\hline $\begin{array}{l}\text { Key industrial plants, ancient monuments and historic buildings, museums, } \\
\text { art galleries or other buildings with specially valuable contents }\end{array}$ & 1.3 \\
\hline Schools, hospitals, children's houses and other homes, places of assembly & 1.7 \\
\hline * Specially valuable plant or materials vulnerable to fire or the results of fire \\
\hline
\end{tabular}

Table C.4 Weighting factor $D$ (degree of isolation)

\begin{tabular}{|l|c|}
\hline Degree of isolation & $\begin{array}{c}\text { Value of } \\
\text { factor D }\end{array}$ \\
\hline $\begin{array}{l}\text { Structure located in a large area of structures or trees of the same or greater } \\
\text { height e.g. in a large town or forest }\end{array}$ & 0.4 \\
\hline $\begin{array}{l}\text { Structure located in an area with few other structures or trees of similar } \\
\text { height }\end{array}$ & 1.0 \\
\hline $\begin{array}{l}\text { Structure completely isolated or exceeding at least twice the height of } \\
\text { surrounding structures or trees }\end{array}$ & 2.0 \\
\hline
\end{tabular}

Table C.5 Weighting factor E (type of terrain)

\begin{tabular}{|l|c|}
\hline Type of country & $\begin{array}{c}\text { Value of } \\
\text { factor } \mathrm{E}\end{array}$ \\
\hline Flat country at any level & 0.3 \\
\hline Hill country & 1.0 \\
\hline Mountain country between $300 \mathrm{~m}$ and $900 \mathrm{~m}$ & 1.3 \\
\hline Mountain country above $900 \mathrm{~m}$ & 1.7 \\
\hline
\end{tabular}




\section{APPENDIX D}

WEIGHTING FACTORS OF AMERICAN STANDARD (NFPA 780:1993)

Table D.1 Index A (type of structure)

\begin{tabular}{|c|c|}
\hline Structure & $\begin{array}{l}\text { Index } \\
\text { Value }\end{array}$ \\
\hline Single family residence less than $465 \mathrm{~m}^{2}$ & 1 \\
\hline Single family residence over $465 \mathrm{~m}^{2}$ & 2 \\
\hline $\begin{array}{l}\text { Residential, office, or factory building less than } 15 \mathrm{~m} \text { in height, covering less } \\
\text { than } 2,323 \mathrm{~m}^{2} \text { of ground area }\end{array}$ & 3 \\
\hline $\begin{array}{l}\text { Residential, office, or factory building less than } 15 \mathrm{~m} \text { in height, covering over } \\
\text { than } 2,323 \mathrm{~m}^{2} \text { of ground area5 }\end{array}$ & 5 \\
\hline Residential, office, or factory building from $15 \mathrm{~m}$ to $23 \mathrm{~m}$ high & 4 \\
\hline Residential, office, or factory building from $23 \mathrm{~m}$ to $46 \mathrm{~m}$ high & 5 \\
\hline Residential, office, or factory building from $46 \mathrm{~m}$ or higher & 8 \\
\hline Municipal services buildings, fire, police, water, sewer etc. & 7 \\
\hline Hangars & 7 \\
\hline Power-generating stations, central telephone exchangers & 8 \\
\hline Water towers and cooling towers & 8 \\
\hline Libraries, museums, historical structures & 8 \\
\hline Farm buildings & 9 \\
\hline Golf shelters and other recreational shelters & 9 \\
\hline Places of public assembly such as schools, churches, theatres, stadiums & 9 \\
\hline $\begin{array}{l}\text { Slender structures such as smokestacks, church steeples and spires, control } \\
\text { towers, lighthouses, etc. }\end{array}$ & 10 \\
\hline Hospitals, nursing homes, housing for the elderly or handicapped & 10 \\
\hline Buildings housing the manufacture, handling, or storage of hazardous materials & 10 \\
\hline
\end{tabular}


Table D.2 Index B (type of construction)

\begin{tabular}{|c|c|c|}
\hline $\begin{array}{l}\text { Structural } \\
\text { Framework }\end{array}$ & $\begin{array}{l}\text { Roof } \\
\text { Type }\end{array}$ & $\begin{array}{l}\text { Index } \\
\text { Value }\end{array}$ \\
\hline \multirow{4}{*}{$\begin{array}{l}\text { Non-metallic } \\
\text { (Other than wood) }\end{array}$} & Wood & 5 \\
\hline & Composition (include asphalt, tar, tile, slate, etc ) & 3 \\
\hline & Metal-not continuous & 4 \\
\hline & Metal-electrically continuous & 1 \\
\hline \multirow[t]{4}{*}{ Wood } & Wood & 5 \\
\hline & Composition (include asphalt, tar, tile, slate, etc ) & 3 \\
\hline & Metal-not continuous & 4 \\
\hline & Metal-electrically continuous & 2 \\
\hline \multirow{4}{*}{$\begin{array}{l}\text { Reinforced } \\
\text { Concrete }\end{array}$} & Wood & 5 \\
\hline & Composition (include asphalt, tar, tile, slate, etc ) & 3 \\
\hline & Metal-not continuous & 4 \\
\hline & Metal-electrically continuous & 1 \\
\hline \multirow[t]{4}{*}{ Structural Steel } & Wood & 4 \\
\hline & Composition (include asphalt, tar, tile, slate, etc ) & 3 \\
\hline & Metal-not continuous & 3 \\
\hline & Metal-electrically continuous & 1 \\
\hline
\end{tabular}

Table D.3 Index C (relative location)

\begin{tabular}{|l|c|}
\hline Location & $\begin{array}{c}\text { Index } \\
\text { Value }\end{array}$ \\
\hline $\begin{array}{l}\text { Structures in areas of higher structures, small structures- covering ground area } \\
\text { of less than } 929 \mathrm{~m}^{2}\end{array}$ & 1 \\
\hline $\begin{array}{l}\text { Structures in areas of higher structures, large structures- covering ground area } \\
\text { of more than } 929 \mathrm{~m}^{2}\end{array}$ & 2 \\
\hline $\begin{array}{l}\text { Structures in areas of lower structures, small structures- covering ground area of } \\
\text { less than } 929 \mathrm{~m}^{2}\end{array}$ & 4 \\
\hline $\begin{array}{l}\text { Structures in areas of lower structures, large structures- covering ground area of } \\
\text { more than } 929 \mathrm{~m}^{2}\end{array}$ & 5 \\
\hline Structures extending up to $15.2 \mathrm{~m}$ above adjacent structures or terrain & 7 \\
\hline Structures extending more than $15.2 \mathrm{~m}$ above adjacent structures or terrain & 10 \\
\hline
\end{tabular}


Table D.4 Index D (topography)

\begin{tabular}{|l|c|}
\hline Location & $\begin{array}{c}\text { Index } \\
\text { Value }\end{array}$ \\
\hline On flat land & 1 \\
\hline On hillside & 2 \\
\hline On hilltop & 4 \\
\hline On mountaintop & 5 \\
\hline
\end{tabular}

Table D.5 Index E (occupancy and contents)

\begin{tabular}{|l|c|}
\hline Occupancy and Contents & $\begin{array}{c}\text { Index } \\
\text { Value }\end{array}$ \\
\hline $\begin{array}{l}\text { Non-combustible materials } \\
\text {-unoccupied }\end{array}$ & 1 \\
\hline Residential furnishings & 2 \\
\hline Ordinary furnishings or equipment & 2 \\
\hline Cattle and livestock & 3 \\
\hline $\begin{array}{l}\text { Small assembly of people } \\
\text {-less than 50 }\end{array}$ & 4 \\
\hline Combustible materials & 5 \\
\hline Large assembly of people & 6 \\
\hline -50 or more & 7 \\
\hline High value materials or equipment & 8 \\
\hline Essential services & \\
\hline -police, fire, etc. & 8 \\
\hline Immobile or bedfast persons & 8 \\
\hline Flammable liquids or gases & 10 \\
\hline -gasoline, hydrogen, etc. & 9 \\
\hline Critical operating equipment & 10 \\
\hline Historic contents & \\
\hline Explosives and explosive ingredients & \\
\hline
\end{tabular}


Table D.6 Index F (lightning frequency isoceraunic level)

\begin{tabular}{|l|c|}
\hline Isoceraunic Level & $\begin{array}{c}\text { Index } \\
\text { Value }\end{array}$ \\
\hline $0-5$ & 9 \\
\hline $6-10$ & 8 \\
\hline $11-20$ & 7 \\
\hline $21-30$ & 6 \\
\hline $31-40$ & 5 \\
\hline $41-50$ & 4 \\
\hline $51-60$ & 3 \\
\hline $61-70$ & 2 \\
\hline Over 70 & 1 \\
\hline
\end{tabular}




\section{APPENDIX E}

\section{WEIGHTING FACTORS OF TURKISH DRAFT}

\section{Table E.1 Weighting factor A1 (type of walls)}

\begin{tabular}{|l|c|}
\hline Type of Walls & A1 \\
\hline Continues metal coating on sides, reinforced concrete & 5.0 \\
\hline $\begin{array}{l}\text { Conductively connected prefabricated structure, steel framework or } \\
\text { electrically continuous concrete }\end{array}$ & 4.0 \\
\hline Wall, unmatting concrete, conductively disconnected prefabricated structure & 0.5 \\
\hline Wooden or flammable walls & 0.1 \\
\hline
\end{tabular}

Table E.2 Weighting factor A2 (type of roof)

\begin{tabular}{|l|c|}
\hline Type of Roof & A2 \\
\hline Steel & 4.0 \\
\hline Reinforced concrete & 2.0 \\
\hline Reinforced concrete - prefabricated & 0.5 \\
\hline Wooden & 0.1 \\
\hline
\end{tabular}

Table E.3 Weighting factor A3 (type of roof coating)

\begin{tabular}{|l|c|}
\hline Type of Roof Coating & A3 \\
\hline Matting concrete & 4.0 \\
\hline Galvanized sheet iron & 2.0 \\
\hline Roof tile & 1.0 \\
\hline PVC coating, roof paper, pressed sheet iron & 0.5 \\
\hline Coatings with highly pressed insulating & 0.05 \\
\hline
\end{tabular}


Table E.4 Weighting factor A4 (constructions on the roof such as smoke hole etc.)

\begin{tabular}{|l|c|}
\hline Constructions on the Roof such as smoke hole etc. & A4 \\
\hline Nothing on the roof & 1.0 \\
\hline Un-earthed metal parts, antennas & 0.6 \\
\hline Electrical devices & 0.2 \\
\hline Sensitive electrical devices (camera, heat detectors etc.) & 0.1 \\
\hline
\end{tabular}

Table E.5 Weighting factor B1 (occupancy)

\begin{tabular}{|l|c|}
\hline Occupancy & B1 \\
\hline No panic risk & 1.0 \\
\hline Intermediate panic risk & 0.1 \\
\hline High panic risk & 0.01 \\
\hline
\end{tabular}

Table E.6 Weighting factor B2 (type of materials inside)

\begin{tabular}{|l|c|}
\hline Type of Materials Inside & B2 \\
\hline Non-flammable & 1.0 \\
\hline Flammable & 0.2 \\
\hline Explosion risk & 0.1 \\
\hline Flammable and Explosive materials & 0.01 \\
\hline Nuclear plants & 0.01 \\
\hline
\end{tabular}

Table E.7 Weighting factor B3 (worth of equipment inside)

\begin{tabular}{|l|c|}
\hline Worth of Equipment Inside & B3 \\
\hline Simple, worthless & 1.0 \\
\hline Valuable & 0.2 \\
\hline Specially valuable & 0.1 \\
\hline Very valuable & 0.01 \\
\hline
\end{tabular}


Table E.8 Weighting factor B4 (hazard minimizing precautions)

\begin{tabular}{|l|c|}
\hline Hazard Minimizing Precautions & B4 \\
\hline Automatic fire extinguisher system & 10.0 \\
\hline Fire reducer equipment, system & 5.0 \\
\hline Fire protection system & 2.0 \\
\hline No precaution & 1.0 \\
\hline
\end{tabular}

Table E.9 Weighting factor $\mathrm{C} 1$ (consequences on environment due to materials inside)

\begin{tabular}{|l|c|}
\hline Consequences on Environment due to Materials Inside & C1 \\
\hline No & 1.0 \\
\hline Intermediate & 0.5 \\
\hline High & 0.1 \\
\hline Very high & 0.01 \\
\hline
\end{tabular}

Table E.10 Weighting factor C2 (loss of service continuity in structure due to materials inside)

\begin{tabular}{|l|c|}
\hline Loss of Service Continuity in Structure due to Materials Inside & C2 \\
\hline No loss & 1.0 \\
\hline Partial discontinuity & 0.1 \\
\hline Loss of service continuity & 0.01 \\
\hline
\end{tabular}

Table E.11 Weighting factor C3 (other hazards)

\begin{tabular}{|l|c|}
\hline Other Hazards & C3 \\
\hline Low & 1.0 \\
\hline Intermediate & 0.5 \\
\hline High & 0.1 \\
\hline Very high & 0.01 \\
\hline
\end{tabular}




\section{SAFETY DISTANCE}

While designing and installing a LPS, the distance between the VC's or DC's and the structure parts should be taken into account, which is called safety distance not to cause any flashover problem.

While a VC is to be used for an isolated interception device or routing the down conductors, safety distance is required not to cause any side flashing from the current carrying conductor to the nearest surface, object, window, door, etc. It should be remembered that the most important safeguard against life hazard in the space to be protected is the equipotential bonding studied in Chapter 4.

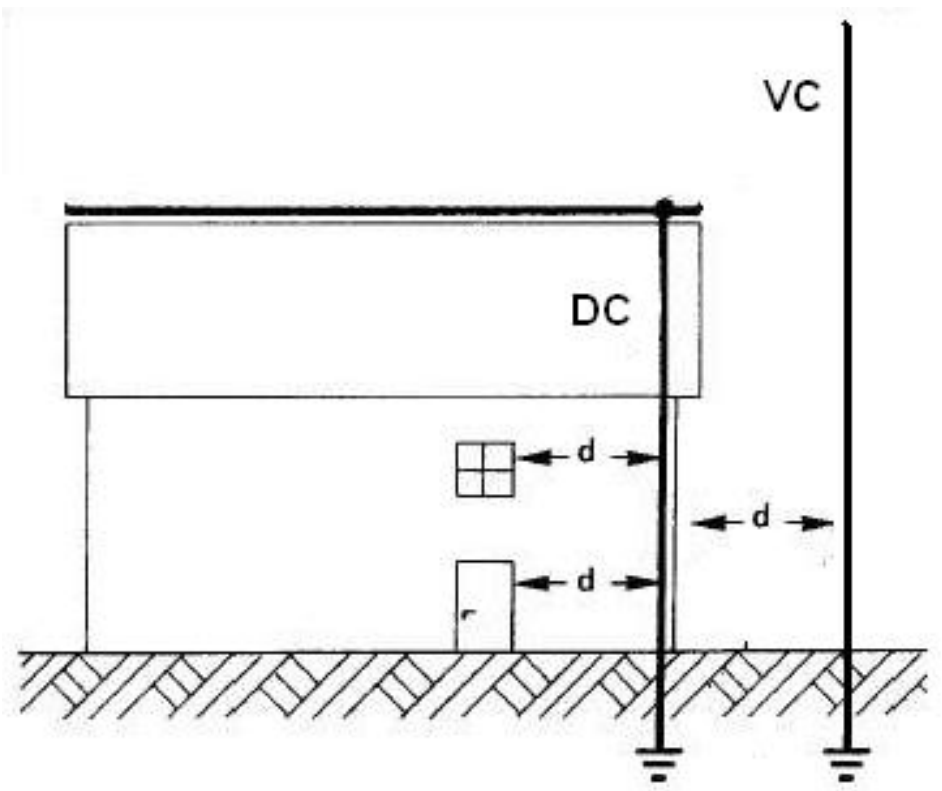

Figure F.1 Safety distance, d when applying DC's and VC's 
The distance between the air-termination system and any metal installation within the space to be protected shall be greater than the safety distance, $d$.

$s \geq d=\left(k_{i} / k_{m}\right){ }^{*} k_{c}{ }^{*} I(m)$

where:

$\mathbf{k}_{\mathbf{i}}$ depends on the selected protection level of LPS given in Table F.1 below,

$\mathbf{k}_{\mathrm{c}}$ depends on dimensional configuration given in Figures F.2 to F.4,

$\mathbf{k}_{\mathbf{m}}$ depends on separation material given in Table F.2 below.

$I(m)$ is the length along the down conductor from the point where the proximity is to be considered to the nearest equipotential bonding point.

Table F.1 The $k_{i}$ coefficient

\begin{tabular}{|c|c|}
\hline Protection level & $\mathbf{k}_{\mathbf{i}}$ \\
\hline I & 0.1 \\
\hline II & 0.075 \\
\hline III and IV & 0.05 \\
\hline
\end{tabular}

Table F.2 The $k_{m}$ coefficient

\begin{tabular}{|c|c|}
\hline Material & $\mathbf{k}_{\mathbf{m}}$ \\
\hline Air & 1.0 \\
\hline Solid & 0.5 \\
\hline
\end{tabular}

It should be noted that IEC 1024-1 states that $k_{c}$ value was calculated with the assumption that the distance between down conductors is in the order of 20 meters.

In the case of reinforced concrete structures with interconnected reinforcing steel and in the case of steel frame structures or of structures with equivalent screening performance, proximity requirements are normally fulfilled. 


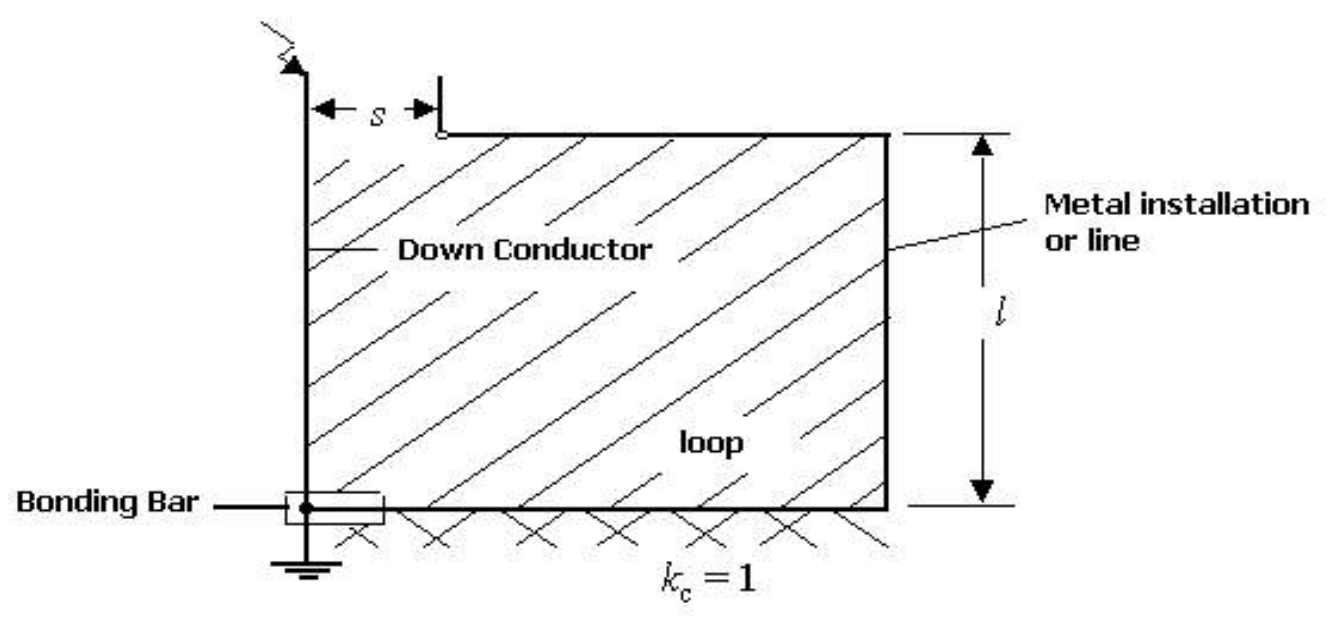

Figure F.2 The coefficient $k c=1$ in a one-dimensional configuration

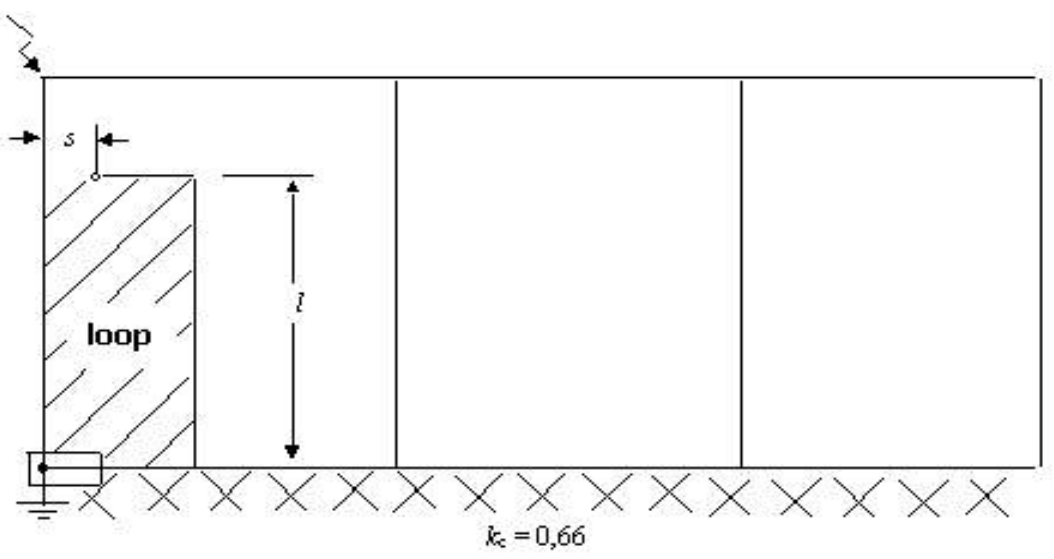

Figure F. 3 The coefficient $k_{c}=0.66$ in a two-dimensional configuration

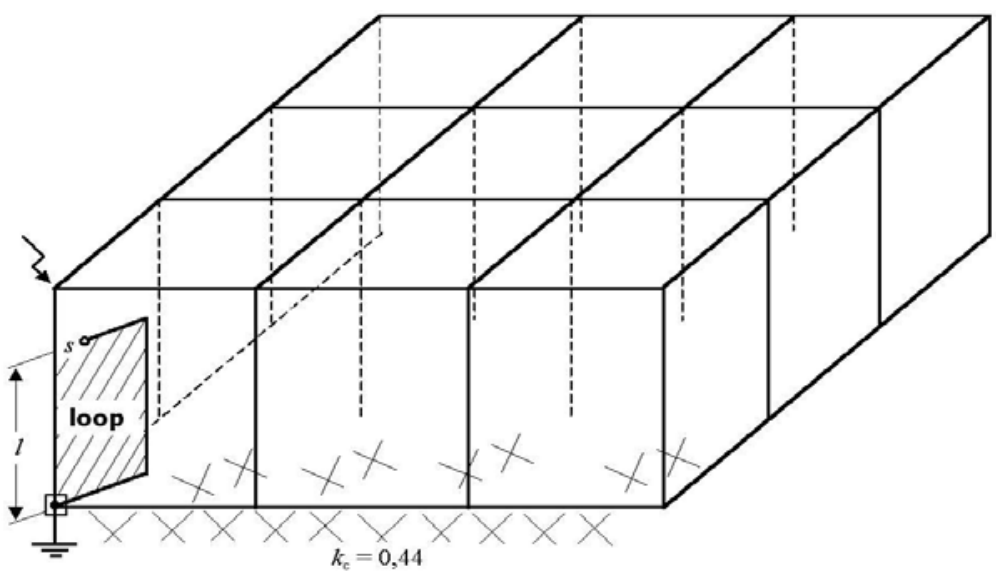

Figure F.4 The coefficient $k_{c}=0.44$ in a three-dimensional configuration 
When the space between down conductors is not in the order of $20 \mathrm{~m}, \mathrm{k}_{\mathrm{c}}$ calculation in IEC 1024 is given as below:

Table F.3 The $\mathbf{k}_{\mathrm{c}}$ coefficient

\begin{tabular}{|c|c|c|}
$\begin{array}{r}\text { Down } \\
\text { Conductors }\end{array}$ & $\begin{array}{r}\text { No Bonding } \\
\text { at ground level }\end{array}$ & $\begin{array}{c}\text { Bonding } \\
\text { at ground level } \\
\text { System Type }\end{array}$ \\
\hline One rod & 1 & 1 \\
\hline Conductor & 1 & Given in Figure F.5 \\
\hline Mesh & 1 & Given in Figure F.6 \\
\hline
\end{tabular}

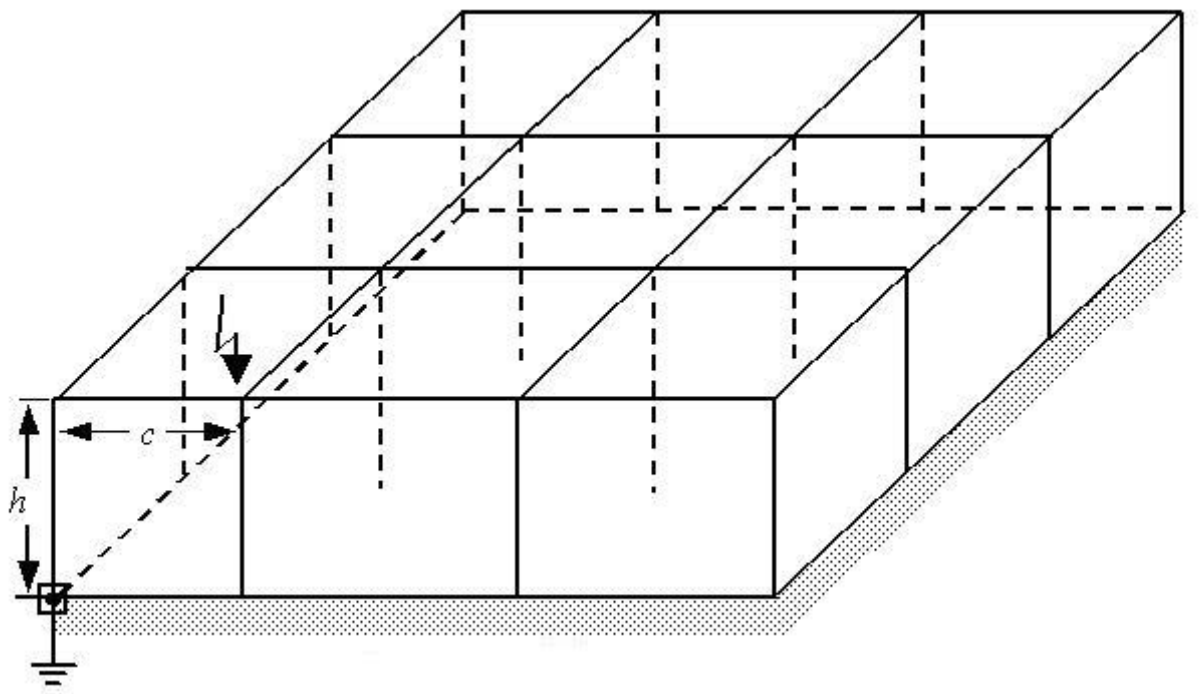

Figure F.5 Calculation of $k_{c}$ coefficient

$\mathrm{k}_{\mathrm{c}}$, the coefficient due to the current distribution among down conductors is dependent on the place of down conductors and mesh conductors and also the type of ATS and earthing system as indicated and shown in Table F.3, Figure F.5. $k_{c}$ for the case shown in Figure F.5 is calculated from the following formula: 
$k_{c}=1 /(2 n)+0,1+0,2 *(c / h)^{1 / 3}$

where,

$\mathrm{n}$ : total number of down conductors

c: distance from the nearest down conductor

$\mathrm{h}$ : space between the mesh conductors

For detailed calculation of $k_{c}$, Figures F. 6 and F.7 should be examined:

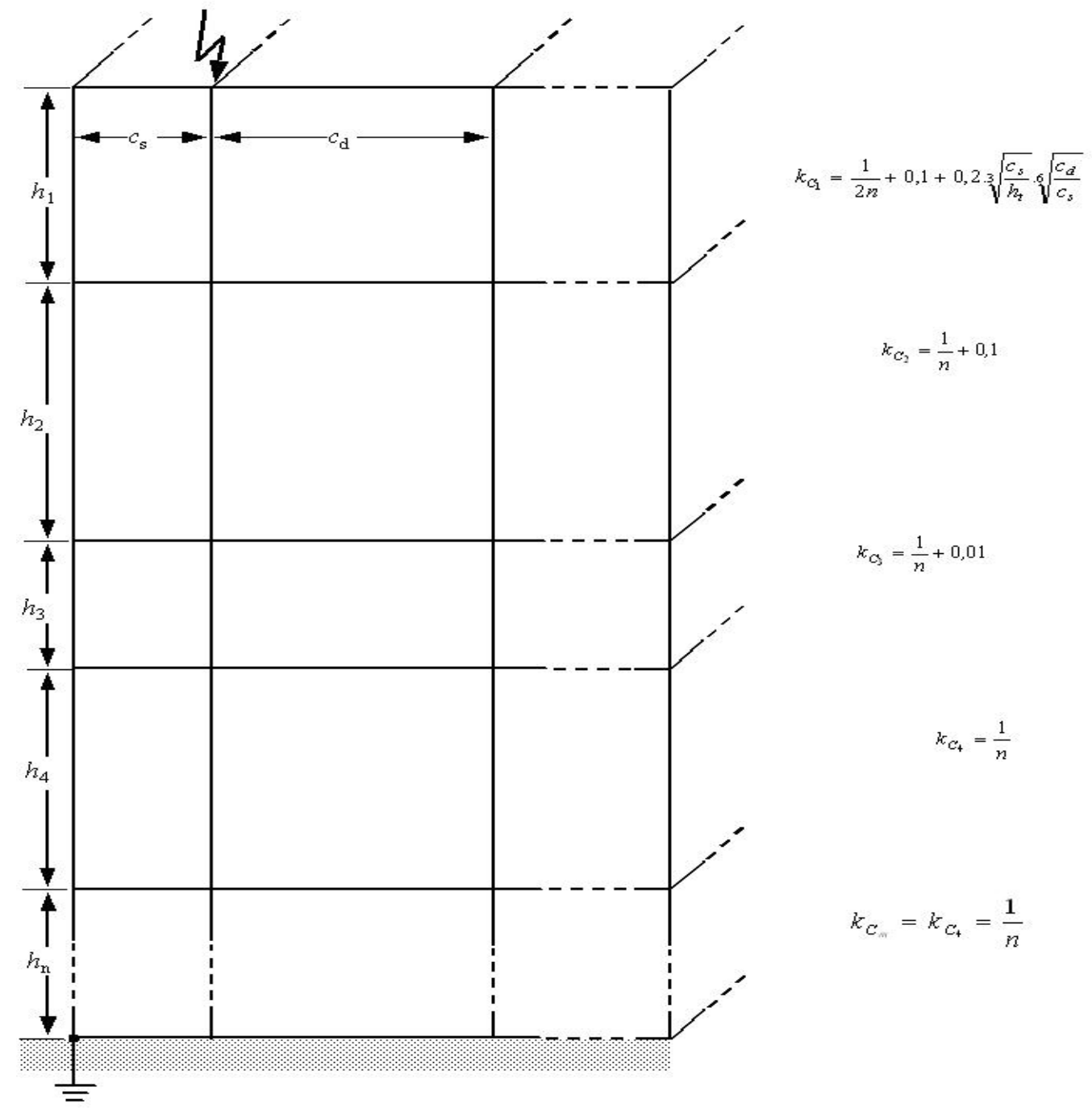

Figure F.6 Detailed calculation of $k_{c}$ 


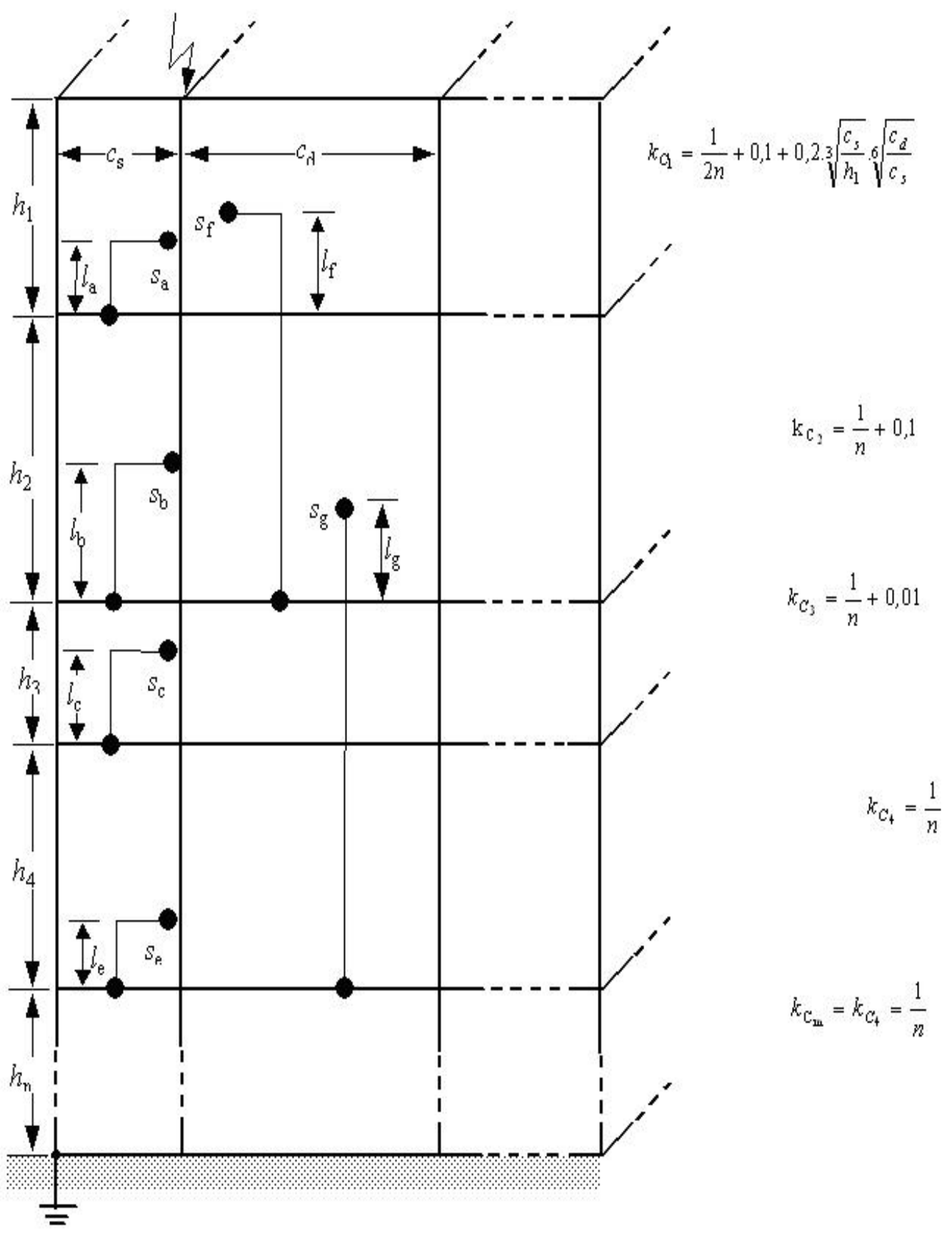

Figure F.7 Detailed calculation of safety distance, $d$

where
d: safety distance
s: separation distance

The safety distances are calculated as follows:

$s_{a} \geq d_{a}=\left(k_{i} / k_{m}\right) * k_{c 1} * I_{a}$ 
$s_{b} \geq d_{b}=\left(k_{i} / k_{m}\right) * k_{c 2} * I_{b}$

$s_{c} \geq d_{c}=\left(k_{i} / k_{m}\right) * k_{c 3} * I_{c}$

$s_{e} \geq d_{e}=\left(k_{i} / k_{m}\right) * k_{c 4} * I_{e}$

$s_{\mathrm{f}} \geq d_{\mathrm{f}}=\left(\mathbf{k}_{\mathrm{i}} / \mathbf{k}_{\mathrm{m}}\right){ }^{*}\left(\mathbf{k}_{\mathrm{c} 1}{ }^{*} \mathbf{k}_{\mathrm{c} 2}\right){ }^{*} \mathbf{h}_{2}$

$s_{g} \geq d_{g}=\left(k_{i} / k_{m}\right) *\left[\left(k_{c 2}{ }^{*} k_{c 3}\right){ }^{*} h_{3}+k_{c 4}{ }^{*} h_{4}\right]$

It could be interpreted that the safety distance is directly proportional to $k_{c}$ coefficient. If Eq. F.2 is analysed, the safety distance is decreased when the number of down conductors and the space between the mesh conductors are increased.

This is an expected result. Because the lightning current is decreased with the increasing number of down conductors and $\mathrm{h}$ value. The current value on the top of the structure is maximum after the stroke. While flowing downwards, its effect decreases due to dividing current by multiple current paths. Therefore, the risk due to the lightning stroke current value becomes smaller.

When the safety distance $s \geq d$ is not satisfied, i.e., $s<d$; the connection must be done at the farest point shown in Figure F.8. In the way that the conducting parts of the structure like concrete anchors are being used as natural down conductors, the connection point to these natural down conductors must be taken as a reference point.

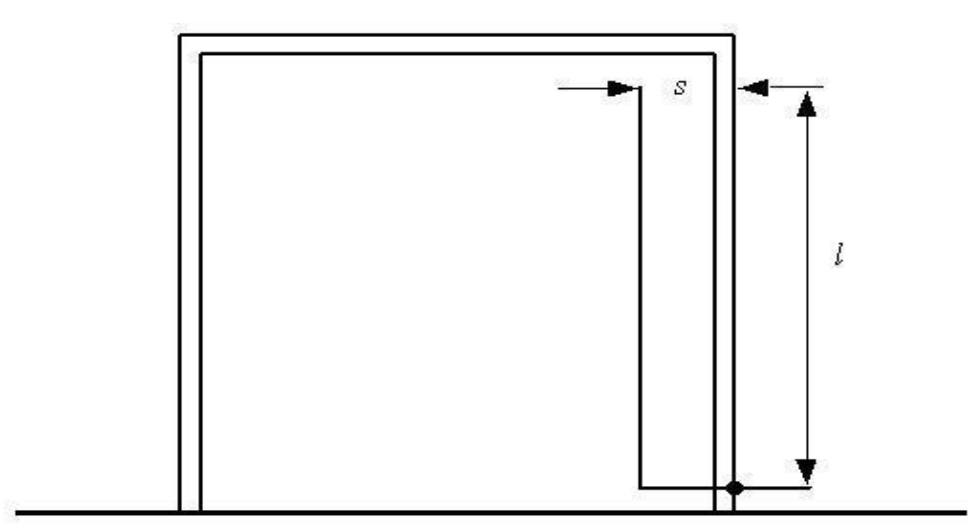

$s \geqslant d$

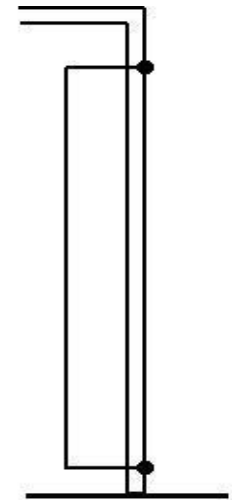

$s<d$

Figure F.8 Safety distance between protection system and the structures 


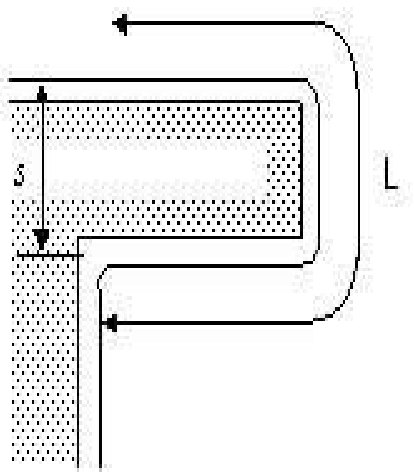

a

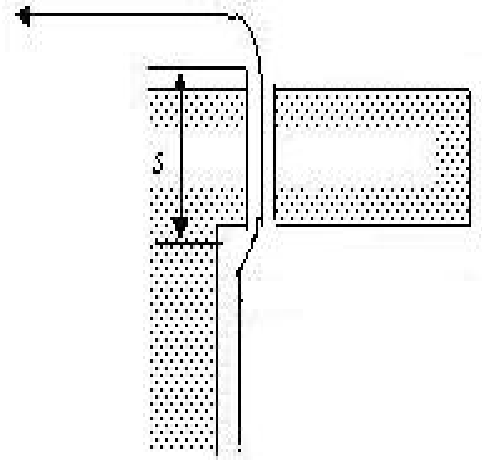

b

Figure F.9 Conductor forming a loop

When external routing is impractical, down conductors may be routed internally inside a nonmetallic and non-combustible duct, pipe etc with provided air space. When large re-entrant loops cannot be avoided, a hole can be provided through which the conductor can pass freely as shown in Figure F.9.b.

BS 6651:1999 states that the length (L) of the conductor forming the loop must not exceed the width (s) of the open side of the loop by multiple of eight as given in Figure F.9.a.

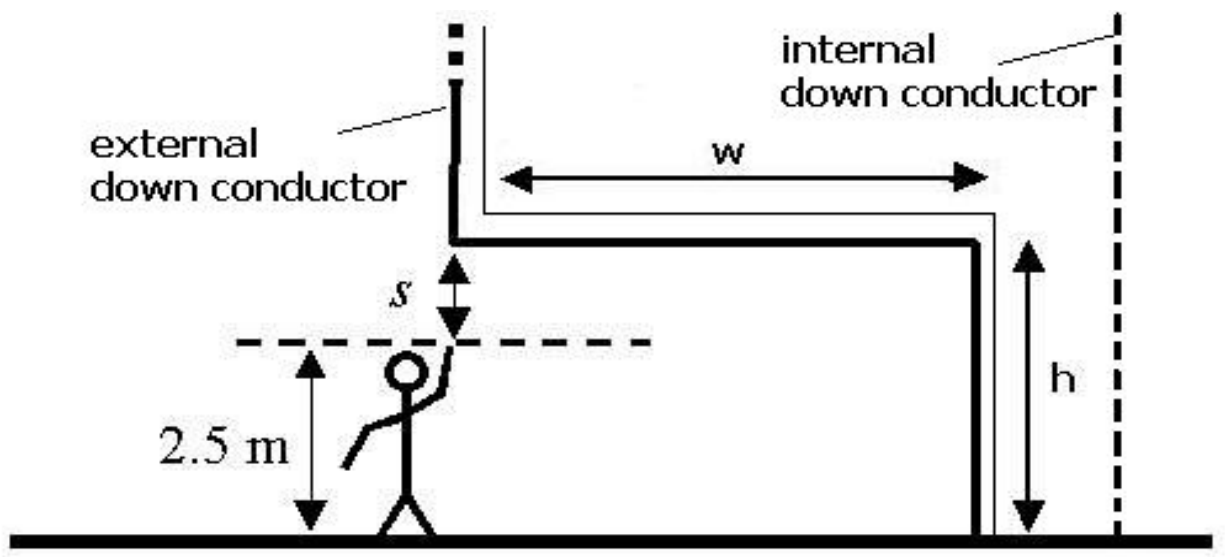

Figure F.10 Routes for down conductors in a building with centilevered upper floors 
In buildings with cantilevered upper floors, the risks of side flashing-from external down conductors (in Figure F.10, it should be assumed that the down conductors are mounted on the outer surface of the walls) to persons standing under the overhang should be considered.

The risk to persons is unacceptable if the height $(\mathrm{h})$ of the overhang is less than 3 meters. For overhangs equal or greater than $3 \mathrm{~m}$, the width $(\mathrm{w})$ of the overhang should be calculated as below if down conductors are to be routed externally.

$W \leq 15(0,9 * h-2,5)$

(Eq. F.9)

The above formula has been derived from IEC 61024-1:1990, part 3.2 and IEC 61024-1-2 Guide B, assuming protection level 1, down conductor spacing of $20 \mathrm{~m}$. 


\section{APPENDIX G}

\section{MATERIALS AND SIZES TO BE USED FOR A LPS}

The materials to be used in a lightning protection system must withstand the lightning current characteristics such that the materials should not be damaged or lost their performance after a lightning stroke.

The material size is selected according to the protection level. Therefore, the determining factor is the lightning current. The cross-sections of the conductors can be selected more accurate when the current is calculated.

Table G.1 According to the self-resistance, $\rho$ of soil, the Equivalent Earthing Resistance $Z$ and $Z_{1}$ values

\begin{tabular}{|c|c|c|c|c|}
\hline \multirow{2}{*}{$\begin{array}{c}\rho \\
{[\Omega \cdot \mathrm{m}]}\end{array}$} & \multirow{2}{*}{$\begin{array}{c}Z_{1} \\
{[\Omega]}\end{array}$} & \multicolumn{3}{|c|}{$\begin{array}{l}\text { Equivalent Earthing Resistance } Z[\Omega] \\
\text { corresponds to Protection Levels }\end{array}$} \\
\hline & & $I$ & II & III-IV \\
\hline 100 & 8 & 4 & 4 & 4 \\
\hline 200 & 13 & 6 & 6 & 6 \\
\hline 500 & 16 & 10 & 10 & 10 \\
\hline 1000 & 22 & 10 & 15 & 20 \\
\hline 2000 & 28 & 10 & 15 & 40 \\
\hline 3000 & 35 & 10 & 15 & 60 \\
\hline
\end{tabular}

The current flowing outside is the substantial part of the lightning current and it is dependent on the number of conductors, the equivalent earthing resistance of these conductors and the equivalent earthing resistance of the whole earthing system. If it is assumed that the current 
flowing through each conductor of the external LPS outside the structure is $\mathrm{I}_{\mathrm{f}}$, it is obtained by using the formula given below:

$I_{f}=(Z * I) /\left(n_{1} * Z+Z_{1}\right)$

where

$Z$ : the equivalent earthing resistance of the whole earthing system

$Z_{1}$ : the equivalent earthing resistance of the conductors of external LPS

$\mathrm{n}_{1}$ : the number of conductors

I: lightning current corresponds to the protection level

The $Z$ and $Z 1$ values are selected from Table G.1.

The conductor characteristics can be examined while selecting the appropriate size of conductors. The cross-section calculation of conductors is given in standards. There is no need to handle that subject here. It is an ordinary engineering problem and the rest is material selection and installation techniques.

The minimum cross-sections of the materials to be used for air termination systems, down conductors and earthing system are given in Table G.2. It should be noted that the crosssections of the materials to be used are the same for all the protection levels from I to IV.

Table G.2 Minimum cross-sections of the materials to be used in LPS

\begin{tabular}{|c|c|c|c|c|}
\hline $\begin{array}{c}\text { Protection } \\
\text { level }\end{array}$ & Material & $\begin{array}{c}\text { Air Termination } \\
\text { System } \\
\left(\mathrm{mm}^{2}\right)\end{array}$ & $\begin{array}{c}\text { Down } \\
\text { Conductor } \\
\left(\mathrm{mm}^{2}\right)\end{array}$ & $\begin{array}{c}\text { Earthing } \\
\text { Termination }\left(\mathrm{mm}^{2}\right)\end{array}$ \\
\hline \multirow{3}{*}{ I, II, III, IV } & $\mathrm{Cu}$ & 35 & 16 & 50 \\
\hline & $\mathrm{Al}$ & 70 & 25 & - \\
\hline & $\mathrm{Fe}$ & 50 & 50 & 80 \\
\hline
\end{tabular}

To prevent the heat effect of the lightning current, the minimum thickness of the metal sheets and metal pipes used in the ATS are given in Table G.3. 
Table G.3 Minimum thickness of the metal sheets and metal pipes used in the ATS

\begin{tabular}{|c|c|c|}
\hline Protection level & Material & $\begin{array}{c}\text { Thickness } \\
\text { [mm] }\end{array}$ \\
\hline \multirow{3}{*}{ I, II, III, IV } & $\mathrm{Fe}$ & 4 \\
\cline { 2 - 3 } & $\mathrm{Cu}$ & 5 \\
\cline { 2 - 3 } & $\mathrm{Al}$ & 7 \\
\hline
\end{tabular}

The bonding conductors must have capacity to carry the lightning current without any damage or break down. The minimum cross-sections of the conductors to be used for bonding are given below to withstand the given percent of the lightning current flow:

Table G.4 Minimum cross-sections of the bonding conductors

\begin{tabular}{|c|c|c|c|}
\hline \multirow{2}{*}{$\begin{array}{c}\text { Protection } \\
\text { level }\end{array}$} & \multirow{2}{*}{ Material } & \multicolumn{2}{|c|}{ Cross-section $\mathbf{( m m}^{\mathbf{2}}$ ) } \\
\cline { 3 - 4 } & & $\begin{array}{c}\text { If substantial part of } \\
\text { current flows (>25\%) }\end{array}$ & $\begin{array}{c}\text { If small part of } \\
\text { current flows (<25\%) }\end{array}$ \\
\hline \multirow{3}{*}{ I, II, III, IV } & $\mathrm{Cu}$ & 16 & 6 \\
\cline { 2 - 4 } & $\mathrm{Al}$ & 25 & 10 \\
\cline { 2 - 4 } & $\mathrm{Fe}$ & 50 & 16 \\
\hline
\end{tabular}




\section{APPENDIX H}

\section{CORRESPONDENCE WITH MARTIN A. UMAN}

The correspondence with Martin A. Uman, who is now Distinguished Professor in Department of Electrical and Computer Engineering, University of Florida, is given below:

\section{E-mail 1 of Ufuk Candar Foya and answer of Martin A. Uman:}

On 16 Jun 2004 at 20:07, Ufuk Candar FOYA wrote:

Dear Mr. Uman;

I am glad to find your e-mail and writing you. I am a M.Sc. student in Middle East Technical University, Ankara, Turkey. My thesis topic is "protection of structures against lightning". I have been working on this topic for 4 months. At last, I examined the French, Spanish, IEC, and British Standards on lightning protection.

I know your great workings on this topic for years and let me show my respect to you. I want to ask you a question. In French standard, a formula $D(m)=10^{*} 1^{2 / 3}$ where $D(m)$ is the Initiation Distance (rolling ball radius) of a lightning having peak current of $\mathrm{I}$. Is there any proof of this formula or is it derived from observations?

For example, according to the paper: "Determining the Probability of Lightning Striking a Facility by R.T. Hasbrouck, PE, National Lightning Safety Institute"67; there is a table given below which verifies this formula.

I would be pleased if you return me back about this question.

Best regards

Ufuk Foya

M.Sc. Student 
Table H.1. Cumulative Probability of Strike to facility

\begin{tabular}{|c|c|c|c|c|c|c|c|}
\hline $\begin{array}{c}\text { Decile } \\
\#\end{array}$ & $\begin{array}{c}\mathbf{I}_{\mathbf{p k}} \\
\mathbf{( k A )}\end{array}$ & $\begin{array}{c}\mathbf{D}_{\mathbf{s}} \\
\mathbf{( m )}\end{array}$ & $\begin{array}{c}\mathbf{r} \\
\mathbf{( m )}\end{array}$ & $\begin{array}{c}\mathbf{A}_{\mathbf{a}} \\
\left(\mathbf{m}^{2}\right)\end{array}$ & $\mathbf{P}_{\mathrm{o}}$ & $\mathbf{P}_{\mathbf{c}}$ & $\mathbf{R}(\mathbf{y r} / \mathbf{f l})$ \\
\hline 1 & 6 & 33 & 33 & 76,764 & $3.8^{*} 10^{-3}$ & & \\
\hline 2 & 13 & 53 & 48 & 93,489 & $4.7^{*} 10^{-3}$ & & \\
\hline 3 & 18 & 65 & 56 & 101,496 & $5.1^{*} 10^{-3}$ & & \\
\hline 4 & 23 & 76 & 62 & 108,624 & $5.4^{\star} 10^{-3}$ & & \\
\hline 5 & 28 & 88 & 68 & 115,399 & $5.8^{*} 10^{-3}$ & & \\
\hline 6 & 35 & 101 & 74 & 122,391 & $6.1^{*} 10^{-3}$ & & \\
\hline 7 & 45 & 118 & 81 & 130,658 & $6.5^{*} 10^{-3}$ & & \\
\hline 8 & 57 & 138 & 89 & 140,196 & $7.0^{\star} 10^{-3}$ & & \\
\hline 9 & 77 & 168 & 99 & 153,061 & $7.6^{*} 10^{-3}$ & & \\
\hline 10 & 112 & 215 & 113 & 171,380 & $8.6^{*} 10^{-3}$ & $6^{*} 10^{-2}$ & 17 \\
\hline
\end{tabular}

where;

Area enclosed by light poles: I = $312 \mathrm{~m}, \mathrm{w}=144 \mathrm{~m}\left(\mathrm{I}^{*} \mathrm{w}=44,928\right)-\mathrm{m}^{2}$

$\mathrm{h}=$ height of poles above ground level $=32-\mathrm{m}$

$\mathrm{I}_{\mathrm{pk}}=$ average peak return-stroke current per decile $-\mathrm{kA}$

$D_{s}=$ lightning striking distance $=10 * I_{p k}^{0.65}-m$

$r=$ radius of light pole's attractive area $=\left(2 * D_{s}{ }^{*} h-h^{2}\right)^{0.5}-m$

$A_{a}=$ attractive area/decile $=(I+2 r) *(w+2 r)-10 *[(4-p) / 4] * r^{2}-m^{2}$

$F_{g}=$ ground flash density $=0.5$ \{using GAl flash density analysis $\}-\mathrm{fl} / \mathrm{km}^{2} / \mathrm{yr}$

$P_{0}=$ strike probability $/$ decile $=A_{a} *\left(0.1 * F_{g}\right) * 10^{-6}$

$\mathrm{P}_{\mathrm{c}}=$ cumulative probability $=\mathrm{SP}_{\mathrm{o}}$

$R=$ mean return period (i.e., average strike frequency) $=1 / P_{c}-$ years $/$ flash

On 16 Jun 2004 at 21:30, Martin A. Uman wrote:

The data and methods (assumptions) by which striking distance has been estimated from return stroke peak current are reviewed best in Lightning Physics and Effects, Rakov and Uman, Cambridge U Press, 2003. There is also some discussion in my book The Lightning Discharge, which is available in inexpensive Dover paperback. I do not think that the currentstriking distance relation is accurate to better than a factor of 2, and there is little experimental evidence from actual protection systems one-way or the other.

Martin A. Uman 


\section{E-mail 2 of Ufuk Candar Foya and answer of Martin A. Uman:}

On 16 Jun 2004 at 20:13, Ufuk Candar FOYA wrote:

Dear Mr. Uman,

This is my second e-mail and I want to ask one more question?

The table below is in IEC 1024-1 (Table-1). I have been working on this numbers since my start of thesis especially. For 4 months, I have not developed any relationship between these numbers and the rolling ball method.

I would be pleased if you support me. I need a reference book or any paper to understand the table below. Now, I think these numbers given in the table are meaningless and no scientific base. I hope not.

Best regards

Yours faithfully

Ufuk Foya

Table H.2 Placing Interception Device and Down Conductors according to Protection Levels

\begin{tabular}{|c|c|c|c|c|c|c|c|}
\hline \multirow{2}{*}{$\begin{array}{l}\text { Protection } \\
\text { level }\end{array}$} & $h(m)$ & 20 & 30 & 45 & 60 & \multirow{2}{*}{$\begin{array}{c}\text { Mesh } \\
\text { size } \\
(\mathrm{m})\end{array}$} & \multirow{2}{*}{$\begin{array}{c}\text { Space } \\
\text { between } \\
\text { down } \\
\text { conductors } \\
\text { (m) }\end{array}$} \\
\hline & $R(m)$ & $\alpha^{(0)}$ & $\alpha^{(0)}$ & $\alpha^{(0)}$ & $\alpha^{(0)}$ & & \\
\hline I & 20 & 25 & * & * & * & 5 & 10 \\
\hline II & 30 & 35 & 25 & * & * & 10 & 15 \\
\hline III & 45 & 45 & 35 & 25 & * & 15 & 20 \\
\hline IV & 60 & 55 & 45 & 35 & 25 & 20 & 25 \\
\hline
\end{tabular}


On 16 Jun 2004 at 21:34, Martin A. Uman wrote:

I do not think there is a relation between the mesh size and the rolling sphere theory. If the mesh is laid on the roof, the rolling sphere will touch the roof between the mesh. I think the mesh size is a committee's best guess with little if any experimental validation.

Why not email someone on the IEC Committee and ask these questions.

M Uman

It should be noted here that the same question is asked to IEC centre via e-mail. However, no answer has been received yet since then.

\section{E-mail 3 of Ufuk Candar Foya and answer of Martin A. Uman:}

On 25 Jun 2004 at 10:04, Ufuk Candar FOYA wrote:

Dear Mr Uman,

I hope you are well since our last contact. I'd like ask you a question? The Spanish Standard (UNE 21-186:1996) gives "ESE lightning conductor test procedure" in Appendix C. Is there any scientific base of this method? If not, how do Spain and France Autoroties permit the use of ESE air terminals? In France, many important structures are being protected by these type of lightning protection systems.

I'd be pleased if you share you opinions with me.

Best regards

Ufuk FOYA

On 16 Jun 2004 at 17:08, Martin A. Uman wrote:

Politics driven by money. All scientific evedence is that ESE's do not work as advertised. U.S. authorities had a law suit which they won in order to keep the mention of ESE's out of the U.S. Standard NFPA 780.

M.Uman 
$\longrightarrow$ 